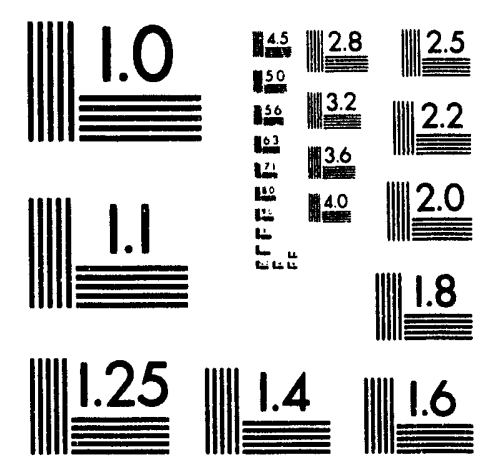



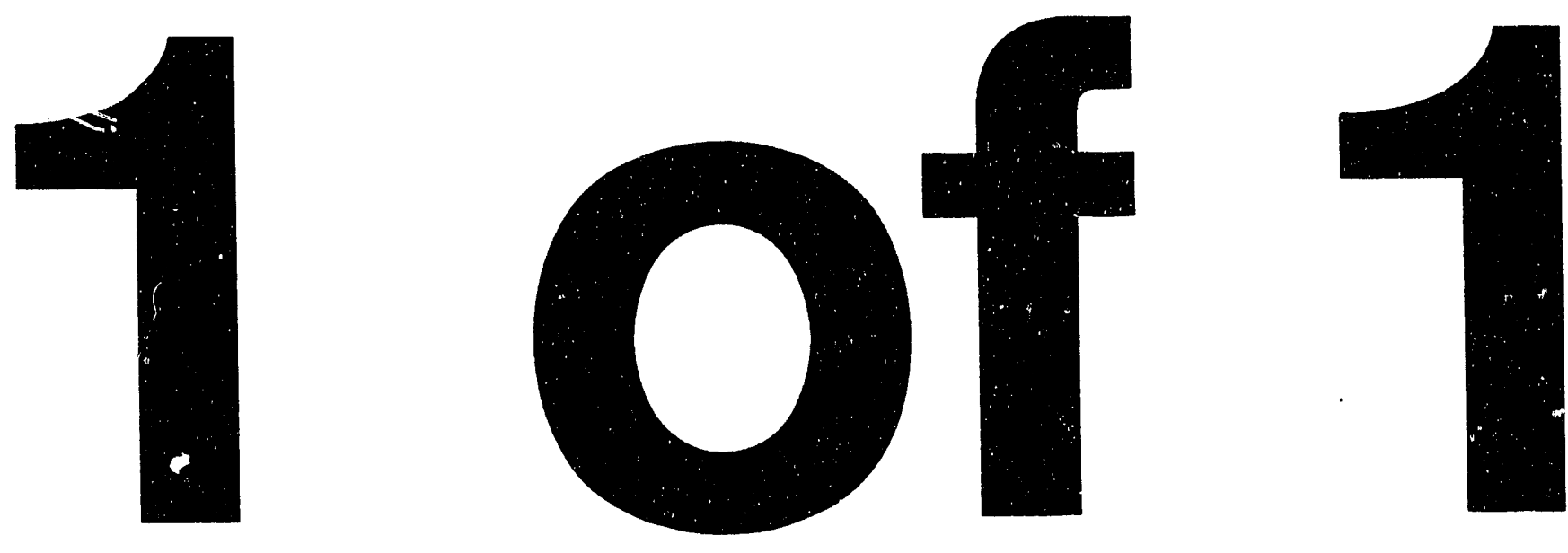


\title{
Metallurgical Evaluation of SRAM II/SRAM A Programmer Base Plates
}

\author{
Brian K. Damkroger \\ Michael C. Maguire \\ Charles V. Robino
}

\begin{abstract}
Ten MC4073/4369 programmer base plates were analyzed at the request of Jim Anastasio, Department 2314 and Ed Cull, Department 8154. This component, a programmer base plate for the SRAM II (and later the SRAM A), is specified as a Grade C quality casting made of aluminum Alloy A356, heat treated to the T6 condition. A concern was expressed regarding the choice of an A356 casting for this application, given the complexity and severity of the loading environment. In particular, concern was directed toward potential problems in highly stressed regions such as the base of the mounting feet. Preliminary tests and analyses suggested that the design was adequate, but noted the uncertainty involved in a number of their underlying assumptions. The uncertainty was compounded by the discovery that the casting used in the original series of mechanical tests did, in fact fail. In this investigation, several production castings were examined and found to be of a quality superior to that required under current specifications. Their defect content and microstructure were studied and compared with published data to establish a mechanical property data base. The data base was supplemented with a series of Xdirection static tests, which characterized the loading environment and measured the overall casting performance. It was found that the mechanical properties of the supplied "premium quality" castings were adequate for the anticipated X-direction loading environment, but the component is not over-designed. The established data base further indicates that a reduction in casting quality to the allowable level could result in failure of the component. Recommendations were made including (1) change the component specification to require higher casting quality in highly stressed areas, (2) supplement the inspection procedures to ensure adequate quality in critical regions, (3) alter the component design to reduce the stress levels in the mounting feet, (4) substitute a "modified" A356 alloy to increase the mechanical properties and their consistency, and (5) more thoroughly establish a data base regarding the mechanical property consequences of various levels and configurations of casting defects. The study was suspended in July/August 1992 following the decision to not include this component in PRESS A.
\end{abstract}




\section{Table of Contents}

ABSTRACT Title Page

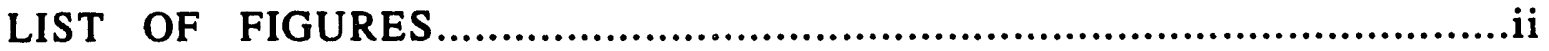

LIST OF TABLES........................................................................

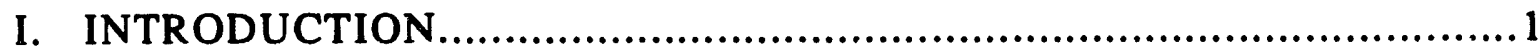

II. TASK DESCRIPTIONS AND PROCEDURES..........................................

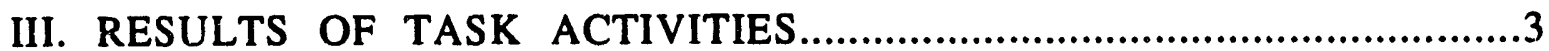

TASK 1: Verify the Validity of the Supplied Castings for Evaluation...................3

TASK 2: Non-Destructively Evaluate the Supplied Castings..............................3

Subtask A: Radiography........................................................3

Subtasl: B: Fluorescent penetrant Testing........................................3

TASK 3: Microstructural Evaluation of the Supplied Castings.............................3

TASK 4: Compilation/Evaluation of Available Mechanical Property Data............4

Subtask A: Static and Fracture Properties..........................................4

Subtask B: Fatigue Properties...................................................9

TASK 5: Initial Determination of the Loading Environment.............................10

Subtask A: Shock and Static Loading Conditions ...............................10

Subtask B: Fatigue Loading.................................................13

TASK 6: Subsequent Static Loading Tests to Determine Casting Response........14

Test Setup \& Procedure..........................................................14

Test Results.....................................................17

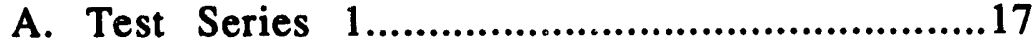

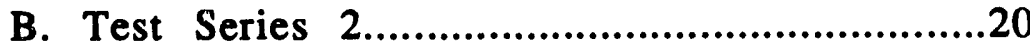

Loading Cycle 1.....................................................20

Loading Cycle 2.......................................................20

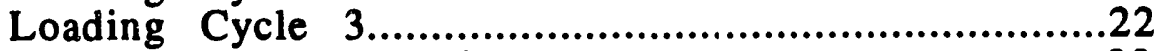

Summary and Discussion...........................................22

A. Loading Distribution...............................................24

B. Maximum Stress Calculation......................................24

Static Test Results - Conclusions........................................26

TASK 7 Evaluate the Suitability of Grade C A-356 Castings...........................26

Static Mechanical Properties.........................................26

General Fracture Toughness Considerations...........................26

Predicted Fracture Toughness Behavior of Supplied Castings.....27

Predicted Fracture Toughness Behavior of a Grade C Casting.....27

Fatigue Performance......................................................31

IV.SUMMARY, CONCLUSIONS, RECOMMENDATIONS................................31

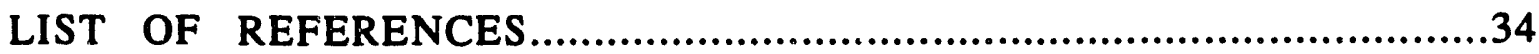




\section{List of Figures}

1. Photograph of a machined MC4073 programmer base plate............................2

2. Photomicrograph of base plate material..................................................2

3. Macrophotograph of base plate showing failed and undamaged mounting feet......6

4. Fractograph and micrograph showing detail of failed mounting foot...................7

5. Aluminum alloy mechanica! property data of Hahn and Rosenfiled (24).............9

6. Fatigue data of Wickberg (25)......................................................11

7. Fatigure data of Stephens, et al. (26)..................................................12

8. Macrophotographs showing crack in mounting foot 1 ..................................13

9. Photographs showing experimental setup of static tests..............................15

10. Photograph showing location of all strain gauges.........................................16

11. Output of strain gauges 1, 3, and 5 for Test Series 1, Load Cycle 2.................18

12. Output of strain gauges 2, 4, and 6 for Test Series 1, Load Cycle 2.................18

13. Output of displacement gauges for Test Series 1, Load Cycle 2......................1Y

14. Output of strain gauges 2, 4, and 6 for Test Series 2, Load Cycle 2.................19

15. Load vs displacement curves for Test Series 2, Load Cycle 2.........................21

16. Output of strain gauges 2, 4, and 6 for Test Series 2, Load Cycle 3.................21

17 Output of strain gauges 1, 3, and 5 for Test Series 2, Load Cycle 3.................23

18. Output of strain gauges 2, 4, and 6 for Test Series 2, Load Cycle 3................23

19. Schematic and calculation procedures for specific crack geometries (32).......28-30

20 Photomicrographs of unmodified and modified as-cast A356..........................32 


\section{List of Tables}

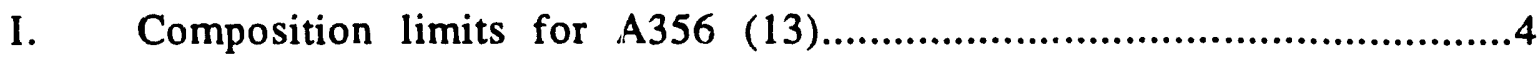

II. Mechanical Property Data of Scott, et al. (17)..............................................

III. Microstructure and Mechanical Property Data of Wickberg, et al. (25)................9

IV. Fatigue Strength Values for A356 T6 Premium Quality Castings (13)..............10

V. Threshold Values and Paris Equation Parameters for A356 T6 (26)..................12

VI. Location of Strain and Disp!acement Gauges..........................................14 


\section{Metallurgical Evaluation of SRAM IISRAM A Programmer Base Plates}

\section{INTRODUCTION}

This analysis was undertaken at the request of Jim Anastasio, Department 2314 and Ed Cull, Department 8154 . The component in question, a programmer base plate for the SRAM II (and later the SRAM A), is a casting made of aluminum Alloy A356, produced to Grade $C$ quality $(1,2)$. This alloy and specification had been wideiy used in similar applications in the past. A concern was expressed whether or not cast A356 aluminum was the appropriate material for development and ultimately production of programmer base plates considering the potential loading environment. In particular, concern was directed toward potential problems in highly stressed regions such as the base of the mounting feet. Eight castings were initially supplied for this analysis, and an additional two castings of a slightly modified geometry were supplied at a later date for mechanical testing. Figure 1 is a photograph of one of the original eight castings.

A preliminary structural analysis assessing the adequacy of the mounting feet was performed by J. Cherry, Department 8242 (3). This analysis was based on several assumptions regarding the loading environment and deformation pattern of the mounting foot. This analysis concluded the mounting feet were adequate. However, the validity of the assumptions in this analysis were acknowledged as uncertain, and a recommendation was made that the load conditions and mounting feet be examined more closely.

A series of X-direction static tests were conducted by P. Stirbis, Department 1522

(4) In these tests, a programmer base plate was loaded to approximately 5 times what was then believed to be the maximum required load, without macroscopic failure. However, three gauged locations on the base plate were displaced in a non-linear fashion.

Subsequent postmortem examination of the base plate confirmed that all three of the mounting feet had plastically deformed and revealed that one of the mounting feet had fractured.

Other uncertainties were associateci with the base plate as well. Further testing indicated that excessive vibration levels were present at certain locations within the programmer, and had resulted in failures of electronic components (5).

When this study began, a $720 \mathrm{hr}$ vibration test cycle had just been initiated on a programmer assembly, and concern existed regarding the fatigue performance of the mounting feet. The present investigation specifically addresses the concerns related to the performance and suitability of the base plate castings. The program was halted in July/August 1992 following the decision to not include this component in PRESS A.

\section{TASK DESCRIPTIONS AND PROCEDURES}

The castings were evaluated using non-destructive evaluation (NDE), light and electron microscopy, and mechanical testing to determine the suitability of a Grade C A356 casting for the base plate. The specific tasks which made up the test program included:

TASK 1 Verify the Validity of the Supplied Castings for Evaluation

TASK 2 Non-destructive Evaluation of the Supplied Castings

TASK 3 Microstructural Evaluation of the Supplied Castings

TASK 4 Compilation/Evaluation of Available Mechanical Property Data

TASK 5 Initial Determination of the Loading Environment

TASK 6 Subsequent Static Loading Tests to Determine Casting Response

TASK 7 Evaluate the Suitability of Premium vs. Grade C Castings

'The original tasks (TASKS 1-5 and 7) were supplemented with a mechanical test program (TASK 6) when it was decided that the loading conditions and component performance required further characterization. The original test plan was outlined in a memo 


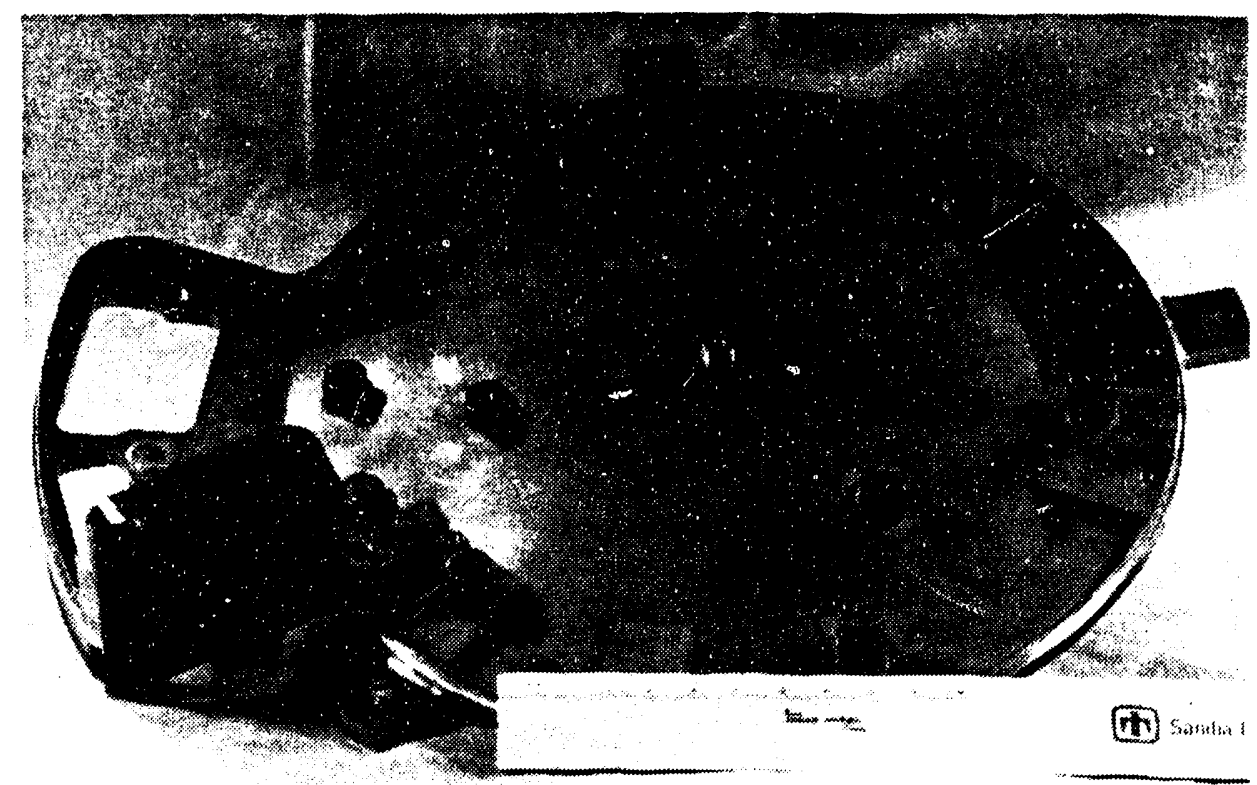

Figure 1. Photograph of a machined MC4073 Programmer Base Plate.

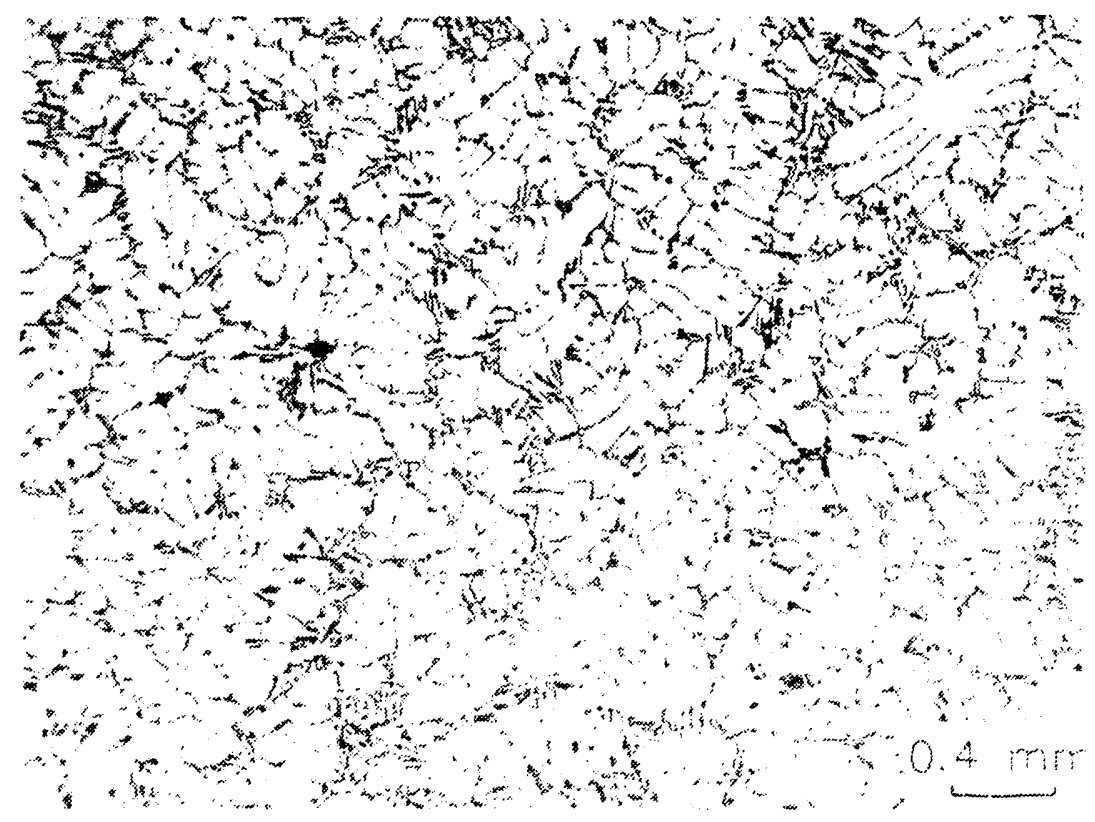

Figure 2. Photomicrograph of specimen removed from base plate mounting foot. Specimen anodized: $5 \mathrm{~g} \mathrm{HBF}_{4}$ in $100 \mathrm{ml} \mathrm{H}_{2} \mathrm{O}, 25 \mathrm{~V}$ for $-50 \mathrm{sec}$, ambient temperature. 
from B. Damkroger, 1833 to L. Tafoya, 2314 dated June 14, 1991 (6). Additional memos discussing the progress of the analysis are given in (7-9).

\section{RESULTS OF TASK ACTIVITIES}

\section{TASK 1: Verify the Validity of the Supplied Castings for Evaluation}

The eight (8) castings supplied by Department 2314 were described as "production castings", and were marked as such. Based on discussions with Bob Owens (AS/KCD), and Rich Blahowsky (Ceramet, Bethlehem, PA), it was determined that these castings were in fact "late production prototypes" $(6,7)$. The markings indicated that these castings had been inspected by the vendor and passed both their $x$-ray and fluorescent penetrant inspections. Because the castings were not actually delivered as production WR pieces, some deviation from final dimensional specifications was possible. However, the number of the print supplied by Division 2314 (8), which matched the castings, indicated that it was a current revision at the time (6). Further, the fact that the castings were machined, inspected, and supplied by the vendor suggests that any deviations from final dimensions were extremely minor (7). Because the bulk of the investigation was to involve metallurgical analyses and comparison with published property data, it was decided that any dimensional variation would nct affect the outcome of the analysis. It was concluded that the eight (7) supplied castings were found to be valid for further analyses.

\section{TASK 2: Non-Destructively Evaluate the Supplied Castings}

\section{Subtask A: Radiography}

The print (Drawing Number AY385268) specified that the castings were to be inspected per 9921013 , Grade C (1), which specifically refers to ASTM-E-155-79, Reference Radiographs, Inspection of Aluminum and Magnesium Castings Series 2 (2). ASTM-E-155 is a group of standard radiographs showing acceptable levels of specific casting defects, for example, internal porosity. For each type of defect, a numbered series of radiographs exist, each showing different amounts and sizes of that specific defect. The designation "Grade C" contained in the inspection requirements specifies the radiograph to be used for each type of defect. These radiographs, ASTM levels for each type of defect, are listed in Table 1 of 9921013 (1), which is included in Appendix A.

John Murray, 2752, radiographed seven of the supplied castings. His report is included in Appendix A. All seven castings were found to meet the required specification. It was further noted that the supplied castings were of a significantly higher quality level than the specification requires, more representative of Grade B or Grade A casting quality.

\section{Subtask B: Fluorescent penetrant Testing}

Fluorescent penetrant testing was performed by John Murray, 2752 on seven of the supplied castings. His report is included as Appendix A. No surface defects were defected on any of the castings.

The conclusion was reached that the supplied castings met the required specifications.

\section{TASK 3: Microstructural Evaluation of the Supplied Castings}

A356 is a variant of the general aluminum casting alloy 356. Compared to 356, A356 has slightly tighter compositional limits, leading to reduced impurity contents and "premium quality castings". While 356 is commonly used in sand castings, A356 is used 
primarily for investment and permanent mold castings and generally in the T6 or T61 heat treatments. The nominal composition of $\mathrm{A} 356 \mathrm{is} 7 \mathrm{Si}, 0.3 \mathrm{Mg}$. The compositional limits most often given in specifications are shown in Table $I$.

Table I - Compositional Limits for A356 (13)

\begin{tabular}{|c|c|c|}
\hline Element & Minimum & Maximum \\
\hline Copper & - & 0.20 \\
Magnesium & 0.20 & 0.40 \\
Manganese & - & 0.10 \\
Iron & - & 0.20 \\
Silicon & 6.5 & 7.5 \\
Zinc & - & 0.20 \\
Titanium & - & 0.20 \\
Others (each) & - & 0.05 \\
(total) & - & 0.15 \\
Aluminum & balance & balance \\
\hline
\end{tabular}

At cooling rates typical of castings, A356 solidifies as primary aluminum dendrites surrounded by an irregular eutectic constituent of silicon and an aluminum-rich matrix. The base-plate castings are supplied in the T6 condition. The specific heat treat sequence is called out in the casting specification (1), but a typical T6 heat treatment for A356 is $540^{\circ} \mathrm{C}$ for 8-24 hours, followed by a hot water quench and artificial aging for 1-5 hours at 150$250^{\circ} \mathrm{C}$. During solution treatment, some silicon and any magnesium present go into sclution and the interdendritic silicon becomes discontinuous and coarsens. The aging treatment causes precipitation of a relatively fine $\mathrm{Mg}_{2} \mathrm{Si}$ particles throughout the primary dendrites and eutectic matrix. Figure 2 shows micrographs of specimens removed from the mounting feet of one of the initial eight castings. The pertinent features in the micrograph are the primary aluminum dendrites, which were estimated to have a secondary dendrite arm spacing (DAS) of approximately 50-55 $\mu \mathrm{m}$, and the dark-etching regions, which are the eutectic silicon particles. The microstructures of the supplied castings are consistent with those expected for A356 investment castings, and have a DAS of $50-554 \mathrm{~m}$.

\section{TASK 4: Compilation/Evaluation of Available Mechanical Property Data}

* Note: All readily obtainable mechanical property daia refers to castings that are, as nearly as can be achieved, without defects. In most instances, investigators report that any test specimen which showed evidence of casting defects contributing to the failure was considered invalid. Similarly, researchers describing their starting material will state that "porosity was not detected" or "porosity was kept below 1\% throughout" (ASTM Plate 1). Defects can have a substantial effect on mechanical properties, particularly fracture and fatigue properties. It must be reiterated that unless otherwise specified. the properties given below are for essentially defect-free castings.

Subtask A: Static and Fracture Properties

Tensile property specifications and reported values vary slightly depending on source (13-15), but typically range from $150 \mathrm{MPa}(22 \mathrm{ksi}), 225 \mathrm{MPa}(33 \mathrm{ksi})$, and $2 \%$ for the yield strength, UTS, and elongation of cast test bars or specimens removed from any location in a casting, to $235 \mathrm{MPa}(34 \mathrm{ksi}), 310 \mathrm{MPa}$ (45 ksi), and $3 \%$ for the corresponding values from specified areas of a casting and procedures "negotiated with the 
foundry". In some instances, elongation values as high as $12 \%$ are quoted, at somewhat lower strength levels. Published mechanical property data suggests that reasonable values for A356 castings are (16-19):

yield strength (MPa)
ultimate strength (MPa)
elongation (\%)
Charpy V-Notch (N-m)
Poisson's Ratio
Young's Modulus (Gpa)

$185-225(27-33 \mathrm{ksi})$

$255-295(37-43 \mathrm{ksi})$

2-12

0.23-0.46 (2-4 in-lb) *at room temperature

0.33

$79.2\left(11.5 * 10^{6} \mathrm{psi}\right)$

Published values for the plane strain fracture toughness of A356 T6 castings per ASTM E 399 include:

$$
\begin{aligned}
& \text { 22-24 MPa } V_{m}(20 \text { - } 22 \mathrm{ksi} \text { in) } \\
& 14.2 \text { - 16.2 MPa } V_{m}(12.9-14.7 \mathrm{ksi} \sqrt{i n}) \\
& 20.7 \text { - 28.4 MPa } \mathrm{m}(18.8 \text { - } 25.8 \mathrm{ksi} \text { in) } \\
& { }^{* *} \mathrm{~K}_{\mathrm{Q}} \text { and Short Rod results }
\end{aligned}
$$

continuously cast billet (16**)

large sand castings (19)

directionally solidified castings (17)

In general, failure of these materials occurs in two steps, fracturing of the silicon particles followed by overload of the inter-particle ligaments. With the exception of Saigal's acoustic emission study (20), the fracture of the particles is considered to begin at relatively low strain levels. Although a detailed failure analysis study was not performed, the failure of the mounting foot which occurred in the initial static test conforms to this general failure model. Figure 3 shows macrophotographs of the failed foot, and Figure 4 shows a fractograph of the fracture surface and an optical micrograph of a section through the fracture surface. Figure 4a shows the mix of smooth facets and ductile dimples which correspond with the failed silicon particles and aluminum ligaments, respectively. Figure $4 \mathrm{~b}$ clearly shows that a number of the silicon particles near the failure surface are fractured.

Because of the typical failure mechanism for A356, microstructure/mechanical property studies (16-24) for cast aluminum usually relate the alloy ductility, toughness, and tensile strength to some combination of the size, aspect ratio, volume fraction and spacing of the silicon particles. Yield strength is less affected by the particles. Strength, ductility, and toughness are all affected by agin: of the primary aluminum dendrites and the aluminum-rich eutectic matrix. References 16 and 21 specifically discuss the microstructure/property relationships and the underlying failure mechanisms for A356 and A357, respectively.

For a given alloy composition, the factors affecting particle distribution will be the solidification rate and solution treatment, with solidification rate being the larger effect. As the solidification rate decreases, and microstructure becomes more coarse, the mechanical properties decrease and their variability increases $(16,22-23)$. A common means of making cooling rate comparisons is by examining secondary dendrite arm spacing. In this respect, the most directly applicable reference is Scott, et al. (17). His data for A356 is summarized in Table II. The material in the castings supplied for this investigation was found to have to a DAS of approximately $50-55 \mu \mathrm{m}$, roughly centering it between the two conditions tested by Scott, et al. (17). 


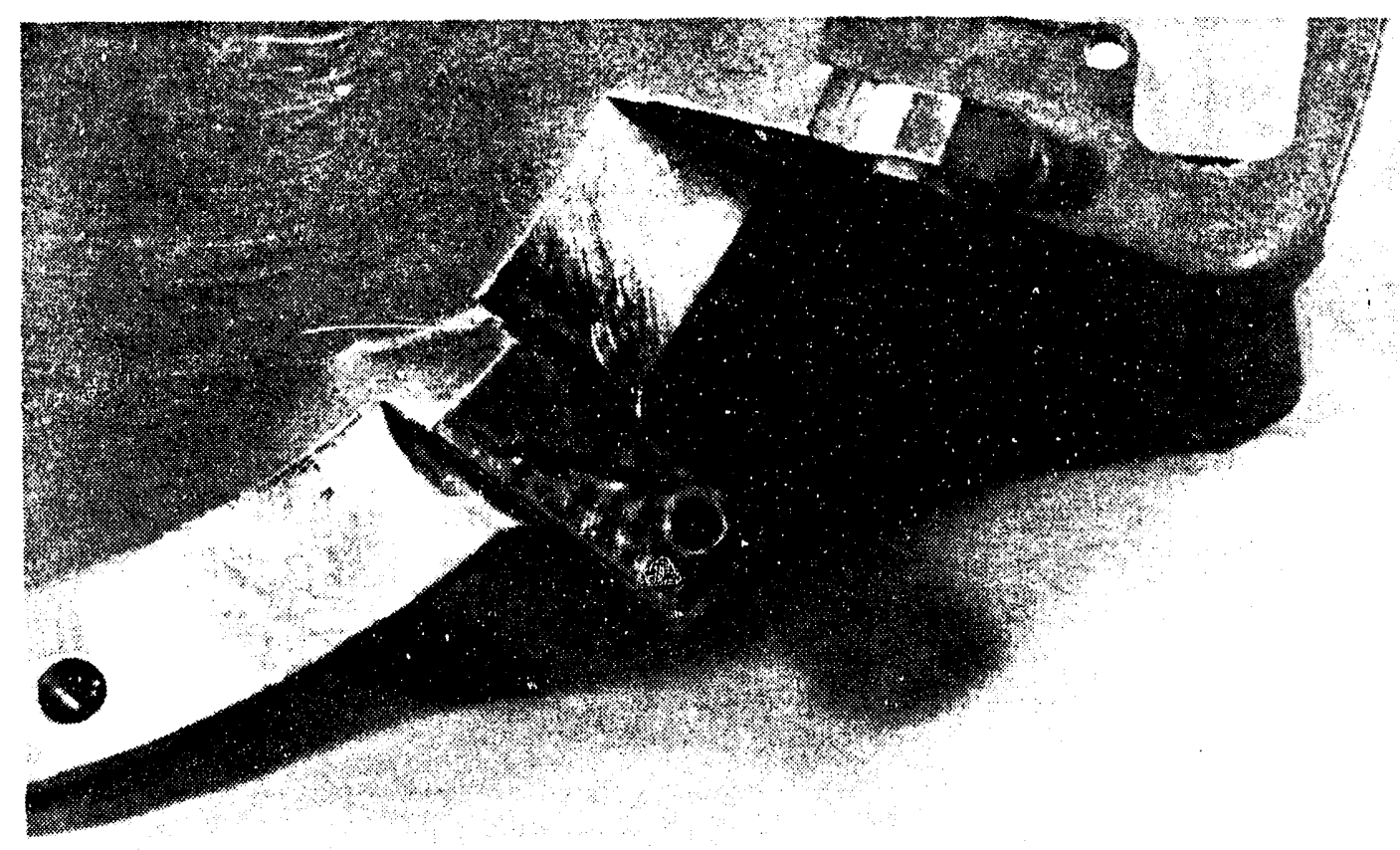

Figure 3a. Macrophotograph of the mounting foot which failed during the static tests performed by P. Stirbis, 1522 (4). Arrow indicaies fracture.

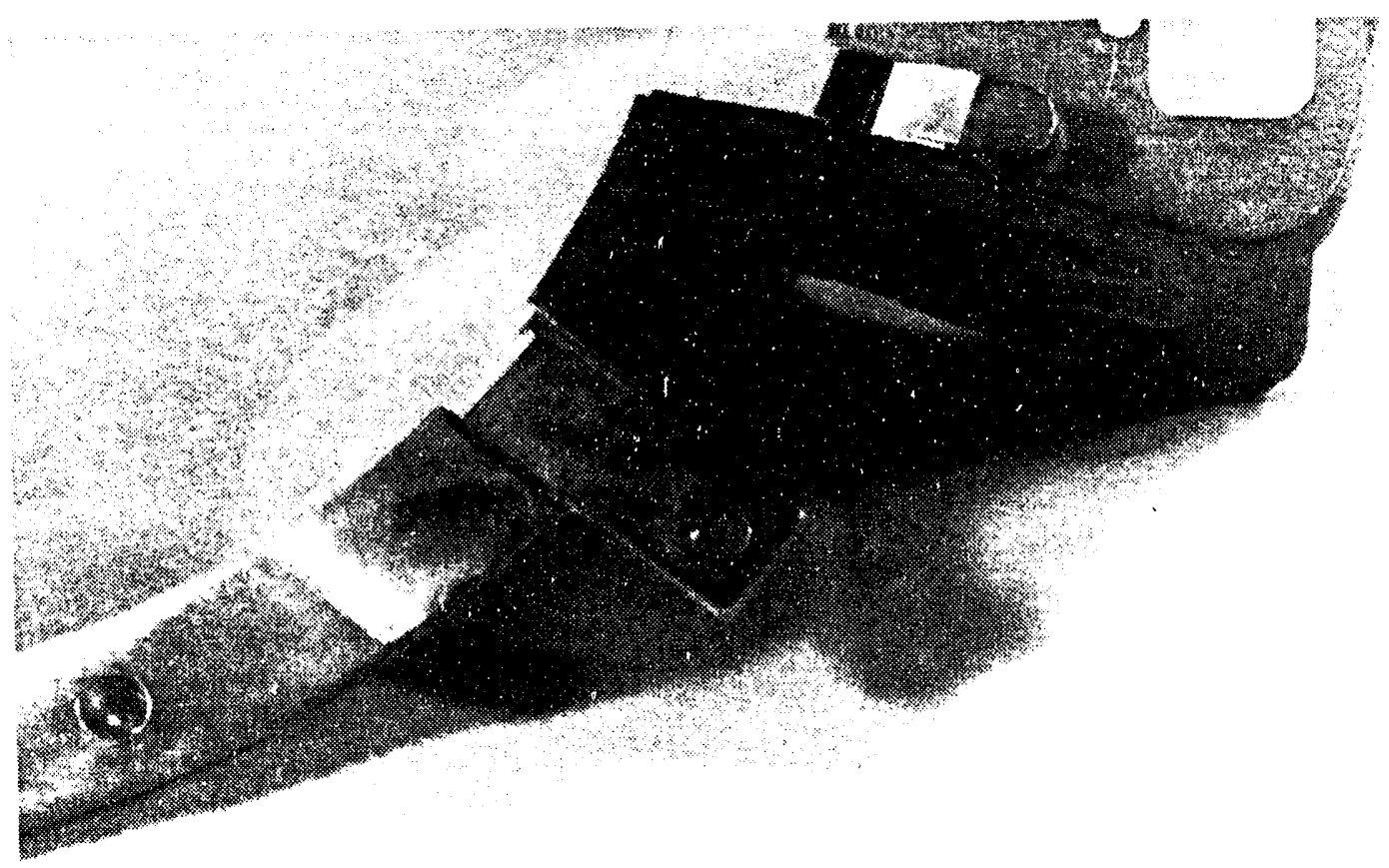

Figure 3b. Macrophotograph of mounting foot number 1 on a later base plate design. Note that the mounting hole is now centered in the foot. 

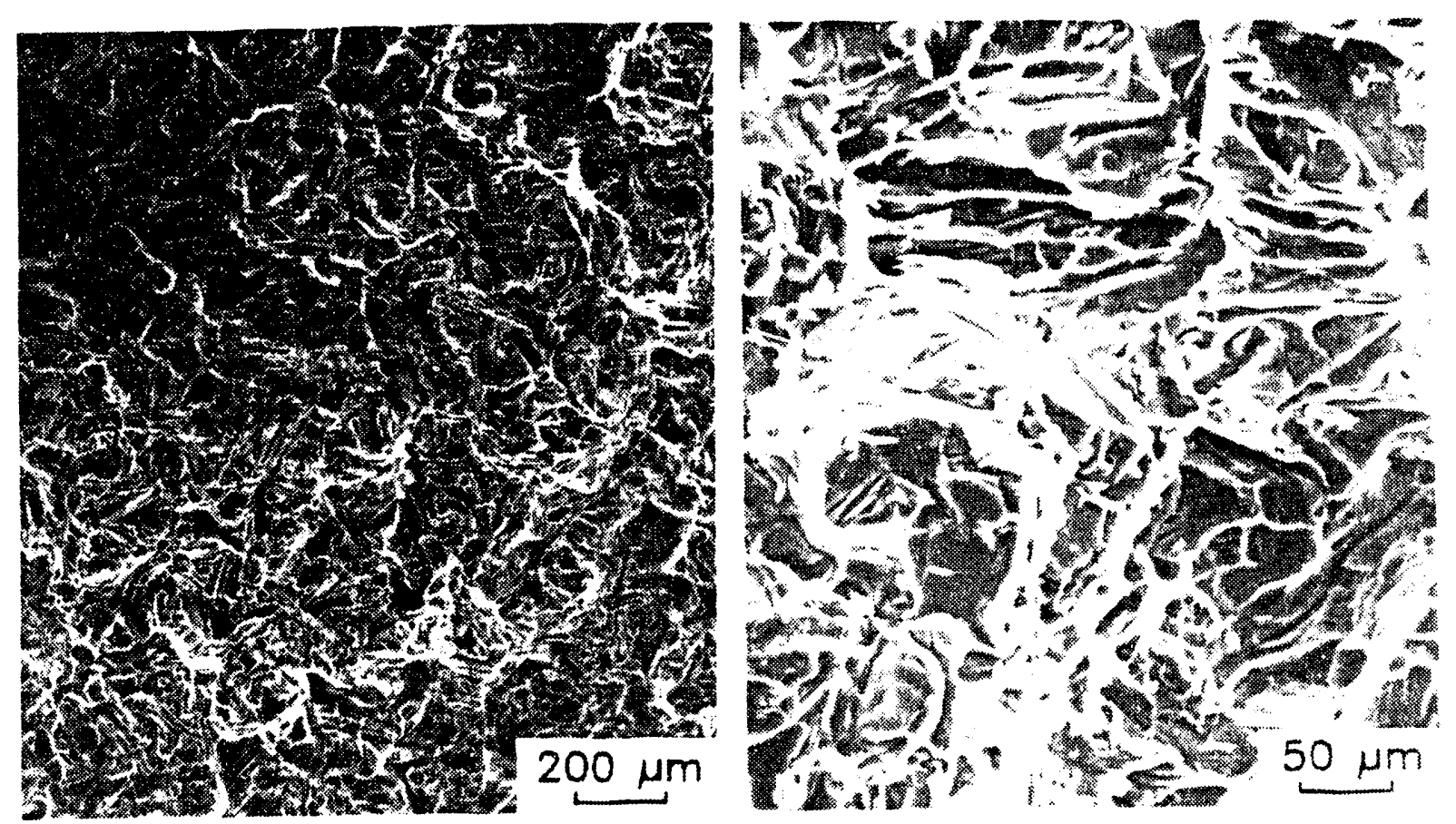

Figure 4a Scanning electron fractographs of the fracture surface shown in Figure 3. Note mix of smooth and dimpled surface, corresponding with failed silicon particles and aluminum ligamer.ts, respectively.

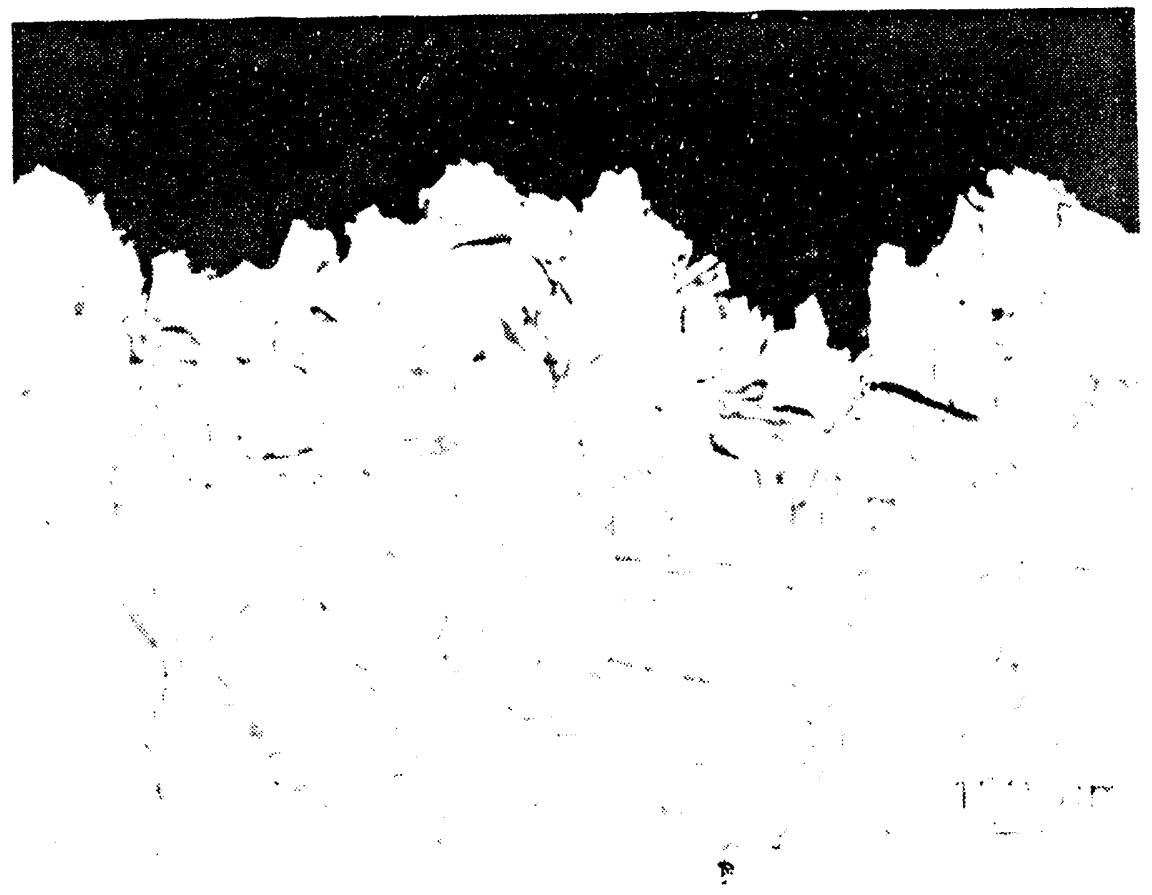

Figure 4h. (optical micrographs of section perpendicular to the fracture surface showre in Figure ta. Note that silicen partickes near the fracture surfice are fractured. 
Table II - Results of Scott, et al. (17)

\begin{tabular}{|c|c|c|c|c|c|c|}
\hline $\begin{array}{l}\text { DAS } \\
(\mu \mathrm{m})\end{array}$ & $\begin{array}{l}\text { Solid. Rate } \\
\left({ }^{\circ} \mathrm{C} / \mathrm{sec}\right)\end{array}$ & $\begin{array}{l}\text { Yield Str. } \\
(\mathrm{MPa})\end{array}$ & $\begin{array}{l}\text { UTS } \\
(\mathrm{MPa})\end{array}$ & $\begin{array}{c}\% \\
\text { elongation }\end{array}$ & $\begin{array}{c}\mathrm{K}_{\mathrm{g}} \\
\left(\mathrm{MPa} / \mathrm{J}_{\mathrm{m}}\right)\end{array}$ & $\begin{array}{l}\mathrm{K}_{\mathrm{IC}}(\mathrm{SR}) * \\
(\mathrm{MPa} \sqrt{\mathrm{m}})\end{array}$ \\
\hline $\begin{array}{l}33 \\
74\end{array}$ & 1.2 & $\begin{array}{c}195.8 \\
(28.4 \mathrm{ksi}) \\
195.8 \\
(28.4 \mathrm{ksi})\end{array}$ & $\begin{array}{c}273.0 \\
(39.6 \mathrm{ksi}) \\
244.8 \\
(35.5 \mathrm{ksi})\end{array}$ & 6.2 & $\begin{array}{c}27.4 \\
\left(24.9 \mathrm{ksi} V_{\mathrm{in}}\right) \\
20.7 \\
(18.8 \mathrm{ksi} \sqrt{\mathrm{in}})\end{array}$ & $\begin{array}{c}26.4 \\
(24.0 \mathrm{ksi} \sqrt{\mathrm{in}}) \\
22.5 \\
(20.4 \mathrm{ksi} \sqrt{\mathrm{in}})\end{array}$ \\
\hline
\end{tabular}

* $\mathrm{K}_{\mathrm{IC}}$ values were obtained using the short rod fracture toughness test.

Based on a the radiography results and the microstructural analysis of the supplied casting, comparison with published data suggests that the static and fracture properies are expected to be:

\begin{tabular}{|c|c|}
\hline $\begin{array}{l}\text { yield strength }(\mathrm{MPa}) \\
\text { ultimate strength (MPa) } \\
\text { elongation (\%) } \\
\text { Charpy V-Notch (ft-lb) } \\
\text { Poisson's Ratio }\end{array}$ & $\begin{array}{l}185-205(27-30 \mathrm{ksi}) \\
255-275(37-40 \mathrm{ksi}) \\
4-5 \\
2-4 \text { *at room temperature } \\
0.33\end{array}$ \\
\hline $\begin{array}{l}\text { ing's Modulus (Gpa) } \\
\text { ture toughness }\left(\mathrm{MPa} \sqrt{\mathrm{m}}_{\mathrm{m}}\right)\end{array}$ & $\begin{array}{cl}79.2 & \left(11.5 * 10^{6} \mathrm{psi}\right) \\
26-28 & \left(24-25 \mathrm{ksi}{ }^{\mathrm{in}}\right)\end{array}$ \\
\hline
\end{tabular}

A second major factor affecting the mechanical properties is the quality of the casting. In an analysis of a failed pressure vessel hatch cover, Kaplan et al. (19) found that the material showed "evidence of shrinkage porosity". Specimens removed from representative hatch covers were tested and found to have properties far inferior to those reported by Scott, et al. (17). The specimens in the Kaplan study were found to have yield strengths of $131 \mathrm{MPa}(19 \mathrm{ksi})$, ultimate strengths of $137.9-161.7 \mathrm{MPa}(20-23.3 \mathrm{ksi})$, and fracture toughness values of $11.9-16.2 \mathrm{MPa}$ in $(10.8-14.7 \mathrm{ksi}$ in). The Kaplan et al. study includes only a brief description of the microstructure of the material studied, but the supplied micrograph suggests that the DAS was approximately $50-75 \mu \mathrm{m}$. It is likely that the inferior mechanical properties are, at least in some degree, due to the casting defects. A second reference point for considering the effects of porosity on mechanical properties is shown in the data compiled by Hahn and Rosenfield (24), Figure 5 . This data shows the effect of volume \% second phase on true strain to failure and includes data where voids in powder metallurgy copper are considered to be the second phase. Although not directly comparable to casting porosity, this data shows a drastic reduction of failure strain due to the presence of small quantities of voids.

Wickberg et al. (25) measured the tensile and fatigue properties of material having a range of DAS values and levels of porosity. These data are listed in Table III. The relationship between cooling rate and DAS agrees well with that of Scott (17), but the degradation in mechanical properties with increasing DAS was far more severe. However, Wickberg found that the level of porosity increased dramatically with increasing DAS, reaching ASTM 6 at a DAS of $55 \mu \mathrm{m}$. The material in the castings supplied for this investigation also had a dendrite spacing of $50-55 \mu \mathrm{m}$, but showed no evidence of the porosity seen in the Wickberg material. It is significant to note that the allowable levels for gas and shrinkage porosity in a Grade C castings are ASTM 6-7, equivalent to that of the Wickberg material. The Wickberg data is not directly applicable to the castings supplied for this investigation. However this data does demonstrate the effects of casting defects on mechanical properties and provide insight regarding the ramifications of using a Grade $C$. casting. 


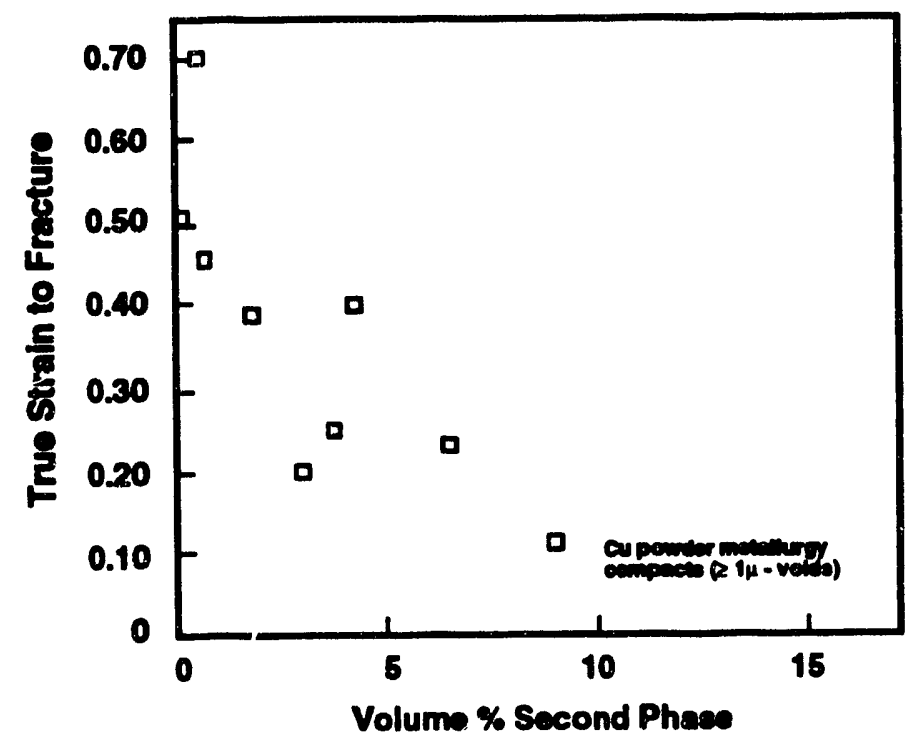

Figure 5. Mechanical property data for aluminum alloys compiled by Hahn and Rosenfield (24). Note that the presence of a small amount of porosity in (PM) copper drastically reduces the true strain to failure.

Table III - Microstructure and Mechanical Property Data of Wickberg, et al. (25)

\begin{tabular}{|c|c|c|c|c|c|c|}
\hline $\begin{array}{c}\text { Cooling Rate } \\
\left({ }^{\circ} \mathrm{C} / \mathrm{s}\right)\end{array}$ & $\begin{array}{c}\text { DAS } \\
(\mu \mathrm{m})\end{array}$ & $\begin{array}{c}\text { Vol\% } \\
\text { Porosity }\end{array}$ & $\begin{array}{c}\text { ASTM* } \\
\text { Rating }\end{array}$ & $\begin{array}{c}\text { Yield Str. } \\
(\mathrm{MPa})\end{array}$ & $\begin{array}{c}\text { UTS } \\
(\mathrm{MPa})\end{array}$ & $\begin{array}{c}\text { Elongation } \\
(\%)\end{array}$ \\
\hline 8.9 & 19 & $<0.5$ & - & $\begin{array}{c}205 \\
(29.7 \mathrm{ksi})\end{array}$ & $\begin{array}{c}270 \\
\left(\begin{array}{l}39.1 \mathrm{ksi}) \\
265\end{array}\right.\end{array}$ & 6.0 \\
4.5 & 25 & 0.7 & 1 & $\begin{array}{c}190 \\
(27.6 \mathrm{ksi})\end{array}$ & $\begin{array}{c}(38.4 \mathrm{ksi}) \\
215\end{array}$ & 3.4 \\
1.4 & 40 & 1.4 & 2 & $\begin{array}{r}175 \\
(25.4 \mathrm{ksi}) \\
160\end{array}$ & $\begin{array}{c}31.2 \mathrm{ksi}) \\
175\end{array}$ & 1.7 \\
0.6 & 55 & 4.0 & 6 & $\begin{array}{r}(23.2 \mathrm{ksi}) \\
(25.4 \mathrm{ksi})\end{array}$ & 1.0 \\
\hline
\end{tabular}

*ASTM-E-155-79(2)

Subtask B: High-Cycle Fatigue Properties

In engineering applications, high-cycle fatigue properties of materials are typically given in terms of a fatigue strength, or a plot of stress amplitude vs. cycles to failure. The fatigue strength values for A356 T6 permanent mold castings given in the Aerospace materials Handbook (13) are given in Table IV. These values are for smooth bar rotating beam tests, $\left(K_{t}=1, R=-1\right)$.

DAS, iron content, and defect content were all found by Wickberg, et al. to have a substantial effect on fatigue life (25). Figures 10-12 from the Wickberg et al. study are presented as Figure 6. These data show that castings with a gas porosity ASTM rating of 6 
(99021013, Grade B-C) had fatigue strengts values at 105, 106, and $10^{7}$ cycis's of approximately $120 \mathrm{Mpa}(17 \mathrm{ksi})$, $75 \mathrm{inipa}(11 \mathrm{ksi})$, and $50 \mathrm{MPa}(7 \mathrm{ksi})$, respectrvely.

Table IV - Reported Fatigue Strength Values for A356 T6 Castings (13)

\begin{tabular}{|ccc|}
\hline Stress Amplitude (DMPa) & Cycles to Failure & Reference \\
\hline $200(29 \mathrm{ksi})$ & $10^{5}$ & 14 \\
$160(23 \mathrm{ksi})$ & $10^{6}$ & 14 \\
$120(17 \mathrm{ksi})$ & $10^{7}$ & 14 \\
$96(14 \mathrm{ksi})$ & $10^{8}$ & 14 \\
$14(13 \mathrm{ksi})$ & $5 * 10^{8}$ & 14 \\
\hline
\end{tabular}

Wickberg et al. also found that increased DAS and defect content reduced the slope of the $\mathrm{SN}$ curve and shifted the knee of the curves to higher $\mathbf{N}$ values. This was interpreted as implying that the crack nucleatiol. phase was reduced and the fatigue life is determined more by crack propagation. This is consistent with the low cycle fatigue data of Stephens, shown in Figure 7. These results are for material having DAS values of $36-58 \mu \mathrm{m}$. A comparison of these results with those of Wickberg shows a significantly lesser effect of DAS. This comparison stiggests that the large effect noted by Wickberg is more likely due to differences in defect content. It is anticipated that the fatigue life performance of the supplied castings is most accurately represented by the Stephens et al, dat? Figure 7 (26).

A difficulty with the use of an overall design fatigue curve is that the data usually represents high cycle ( $>10^{4}$ cycles) data and is generated using smooth, unnotched specimens. In high cycle fatigue, crack initiation constitues a large component of overall life. In the case of castings however, some defect structure is usually present and the initiation component of the fatigue life is substantially reduced. In these instances, the situation is more typical of high cycle fatigue where the overall life is controlled by the crack growth rate. The fatigue performance is better expressed in terms of crack growth rate $(\mathrm{da} / \mathrm{dN})$ vs. applied concentrated stress amplitude $(\Delta \mathrm{K})$, usually fit to the equation $\mathrm{da} / \mathrm{dN}=\mathrm{A}(\Delta \mathrm{K})^{\mathrm{m}}$, and a threshold level for crack propagation $\left(\Delta \mathrm{K}_{\mathrm{th}}\right)$. Studies of the fatigue crack growth behavior of $A 356 \mathrm{~T} 6$ show that both $\Delta \mathrm{K}_{\text {th }}$ and da/dN vary with dendrite arm spacing and loading condition $(26,27)$. These data are presented in Table $V$. The DAS and low defect content of the material in the base plate castings places it in the first group of this data set. To date, no crack initiation data for A356 has been found.

\section{TASK 5: Initial Determination of the Loading Environment}

\section{Subtask A: Shock and Static Loading Conditions}

A preliminary analysis of the shock loading requirements were performed by Jeff Cherry (8482) and reported to Carl Pretzel (8154) in a memo dated April 10, 1990 (3). A copy of this memo is included in Appendix B. Based on this spectra, and an assumed resonant frequency of less than $400 \mathrm{~Hz}$ for the programmer, the peak shock response was determined to be less than or equal to $60 \mathrm{~g}$. This acceleration was then combined with a static acceleration of $15.6 \mathrm{~g}$, a programmer mass of $11 \mathrm{~kg}(5 \mathrm{lb})$ and the following assumptions (1) even distribution of the loads to the three mounting feet, (2) treatment of the mounting feet as cantilever beams, and (3) no stress concentrations present. Based on these assumptions, the maximum stress experienced by the mounting feet was estimated to be approximately $120 \mathrm{MPa}(17 \mathrm{ksi})$. 
The programmer base plate was statically tested by Division 1522 and an analysis of the results presented in a memo from P. Stirbis (1522) to M.R. Taylor (2314) dated July 11,1990 (4). A copy of this memo is attached in Appendix B. The test showed that a maximum axial load of greater than or equal to $8.9 \mathrm{kN}(2000 \mathrm{lb})$ could be supported by the programmer feet. The static testing also indicated that the secant stiffness of the programmer was $18,300 \mathrm{kN} / \mathrm{m}(162,000 \mathrm{lb} / \mathrm{in})$, suggesting an axial first mode of approximately $560 \mathrm{~Hz}$. These results were compared to both the estimaied shock loading requirements and a recommended dynamic test criteria (28) and suggested that the maximum shock response experienced by the programmer cover would be $130 \mathrm{~g}$.

Following Cherry's analysis, this leads to a maxi. um stress on the mounting foot of 225 $\mathrm{MPa}(32.5 \mathrm{ksi})$, essentially equal to the expected yield strength. However, the test reached loads approximately three times this value, so Stirbis concluded that for shock response, the programmer design incorporated an factor of safety of about 3 (4).

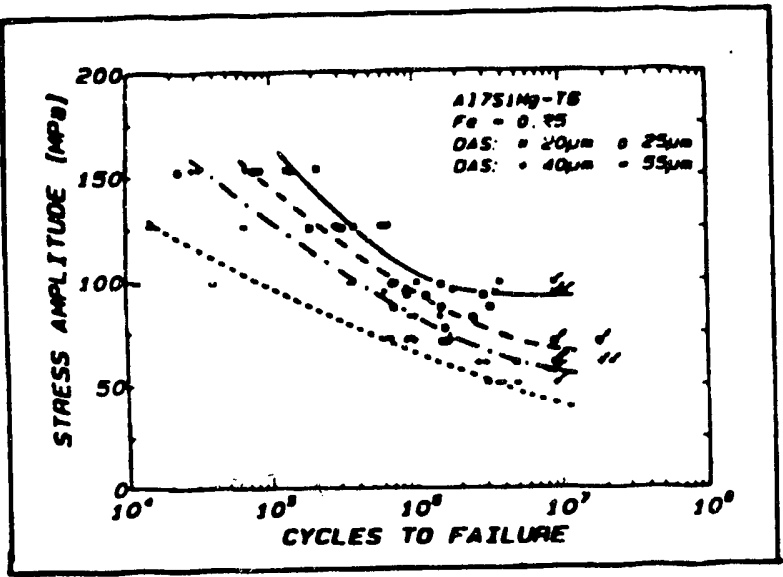

Fig 10. The influence of DAS on the fatigue strength.

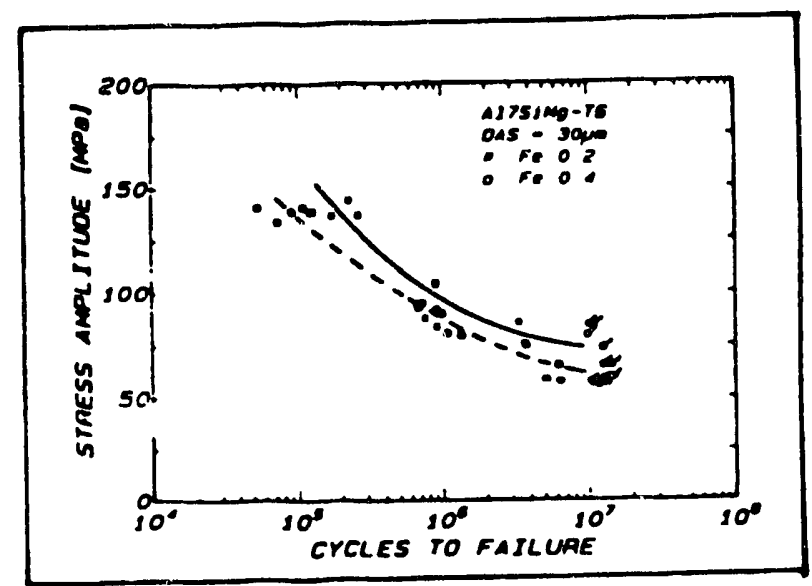

Fig 11. The influence of Fe-content on tha fatigue strength.

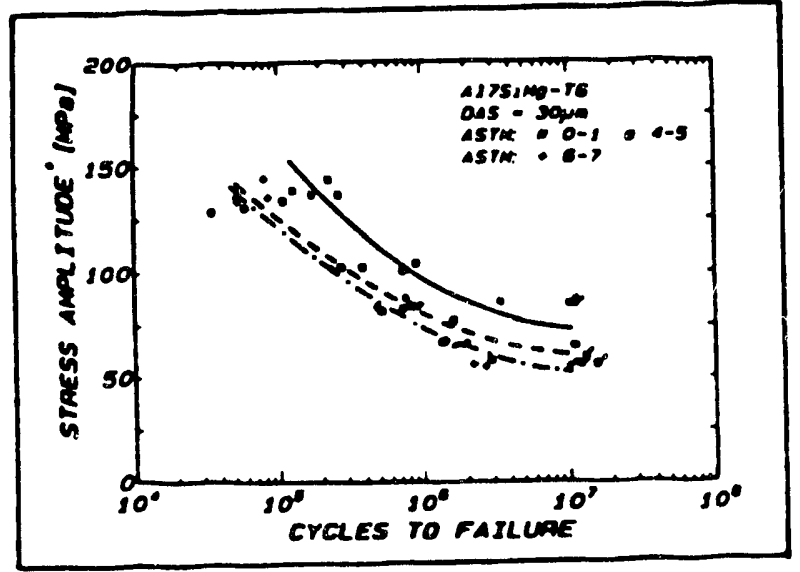

Fig 12. The influence of porosity on the fatigue strength.

Figure 6. Figures 10-12 from Wickberg (25). Stress-controlled high-cycle fatigue data showing reduction in fatigue life due to increases in DAS, iron content, and porosity, respectively. 


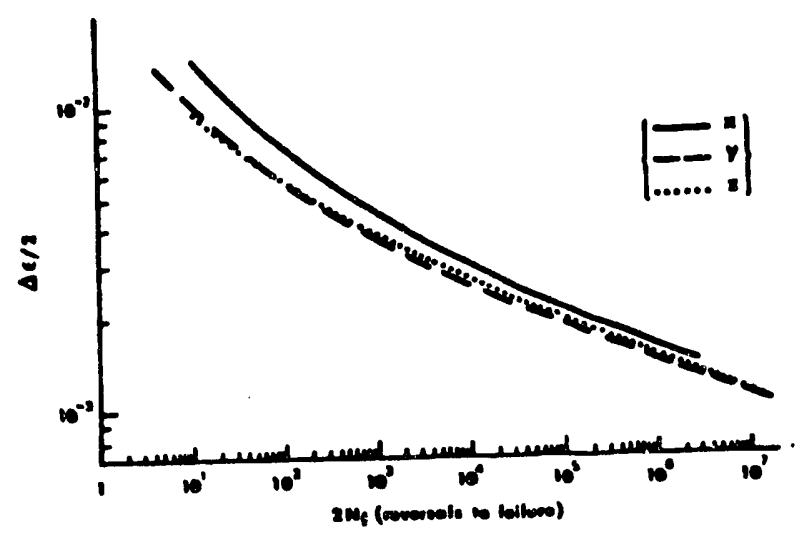

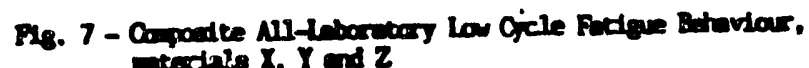

Figure 7. Strain-controlled low cycle fatigue data of Stephens, et il. (26), for A356 T6 having DAS values from 36 (material X) - $58 \mu \mathrm{m}$ (materials Y\&Z). Note that DAS has a smaller effect than shown by the Wickberg (25) data, Figure 6.

Table V - Threshold Values and Paris Equation Parameters for A356 T6 (26)

\begin{tabular}{|c|c|c|c|c|}
\hline $\begin{array}{l}\text { Dendrite Arm Spacing } \\
(\mu \mathrm{m})\end{array}$ & $\begin{array}{l}\text { Loading } \\
\text { Condition }\end{array}$ & $\begin{array}{c}\Delta \mathrm{Kth} \\
(\mathrm{MPa} \sqrt{\mathrm{m}})\end{array}$ & $\begin{array}{c}A \\
\left(10^{-21} \mathrm{~m} / \text { cycle }\right)\end{array}$ & $\mathbf{m}$ \\
\hline $\begin{array}{l}30-50 \\
30-50\end{array}$ & $\begin{array}{l}R=0.1 \\
R=0.5\end{array}$ & $\begin{array}{c}2.9 \\
\left.2.7 \text { (ksi } \sqrt{i n}_{\text {in }}\right) \\
3.2 \\
2.9\end{array}$ & $\begin{array}{c}7.5 \\
2.95 * 10^{-19}(\mathrm{in} / \text { cycle }) \\
8.7 \\
3.42 * 10^{-12}\end{array}$ & $\begin{array}{l}11.6 \\
6.4\end{array}$ \\
\hline $\begin{array}{l}80 \\
80\end{array}$ & $\begin{array}{l}R=0.1 \\
R=0.5\end{array}$ & $\begin{array}{l}3.7 \\
3.4 \\
4.2 \\
3.8\end{array}$ & $\begin{array}{c}14.9 \\
5.90 * 10^{-19} \\
22.0 \\
8.66 * 10^{-14}\end{array}$ & $\begin{array}{l}11.2 \\
8.4\end{array}$ \\
\hline $\begin{array}{l}90 \\
90\end{array}$ & $\begin{array}{l}\mathbf{R}=0.1 \\
\mathbf{R}=0.5\end{array}$ & $\begin{array}{l}3.0 \\
2.7 \\
3.6 \\
3.3\end{array}$ & 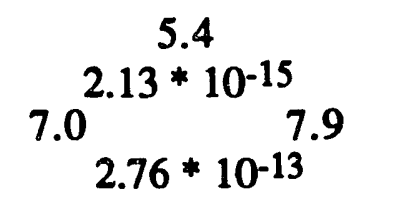 & 8.0 \\
\hline $\begin{array}{l}90 \\
90\end{array}$ & $\begin{array}{l}\mathbf{R}=0.1 \\
\mathbf{R}=0.5\end{array}$ & $\begin{array}{l}1.3 \\
1.2 \\
4.0 \\
3.6\end{array}$ & $\begin{array}{c}8.6 \\
3.38 * 10^{-15} \\
12.0 \\
4.72 * 10^{-11}\end{array}$ & 5.0 \\
\hline
\end{tabular}


A later examination of the programmer base plate that underwent static testing revealed that the mounting feet were, in fact, permanently deformed and that the most highly stressed foot had been fractured. Photographs of the fractured foot are shown in Figure 8, and the fracture surface was shown in more detail in Figure 2. Therefore, the factor of safety suggested by the static test must be questioned. In order to address the cuncerns associated with the base plate loading conditions and the material performance, the decision was made to perform a second set of static tests. These results and their implications are included in the discussion of TASK 6.
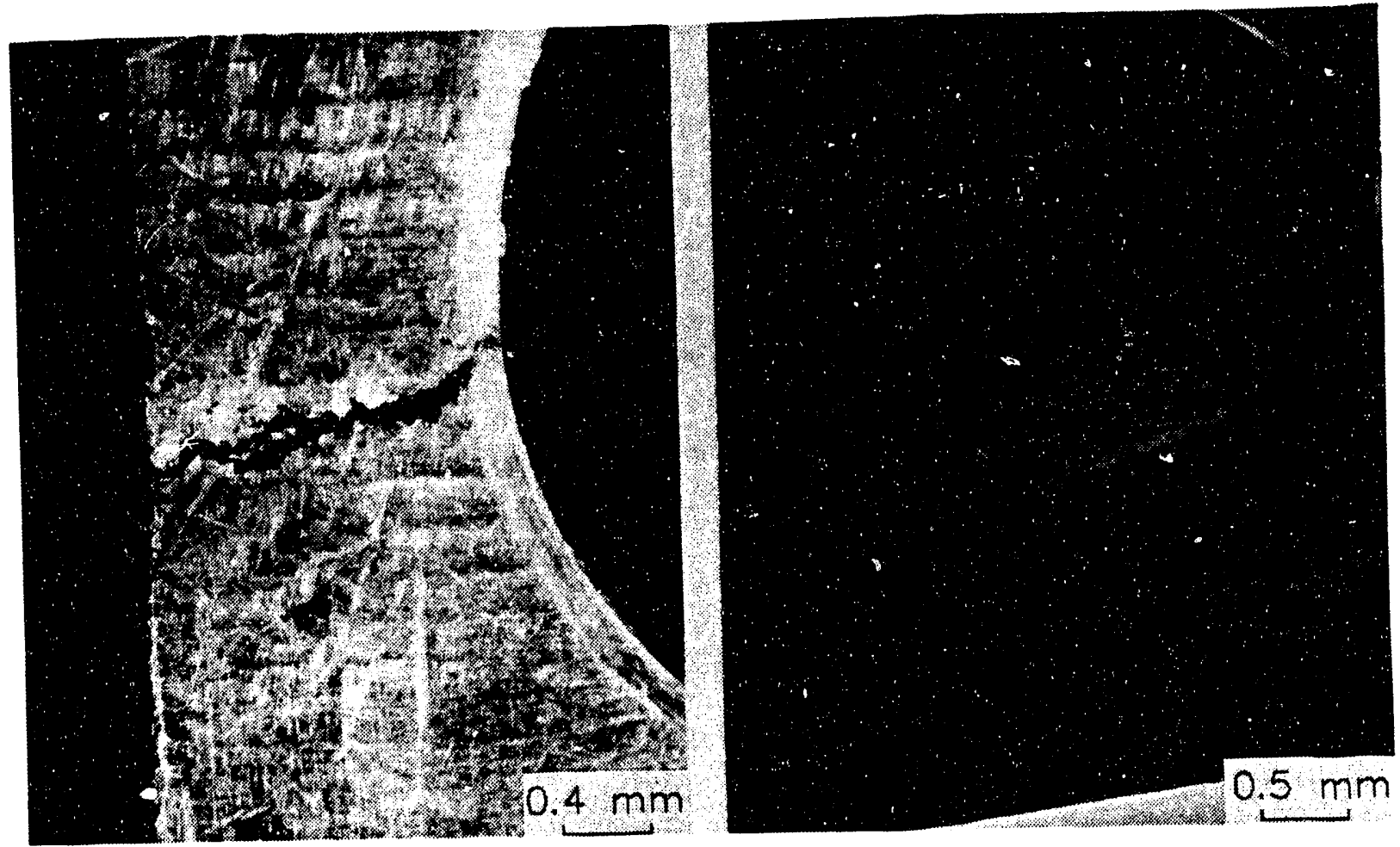

Figure 8. Macrophotographs of the mounting foot fractured during the static tests performed by P. Stirbis, 1522 (4).

Subtask B: Fatigue Loading

A 720 hour, random spectrum excitation vibration test was performed on a programmer assembly by Dept. 7542. Discussions were held with J. Anastasio and L Tafoya, 2314, and S. Klenke, 7542 regarding the results. The programmer assembly did not fail during the test sequence and a post-test inspection did not reveal any evidence of fatigue crack nucleation. In lieu of any further investigation of the potential fatigue loading environment for this component, the supplied castings are assumed to be adequate for the application. 


\section{TASK 6 Subsequent Static Loading Tests to Determine Casting Response}

Because of questions regarding the loading environment and material performance of the mounting feet, it was decided to perform additional static tests under more controlled conditions, using a fixture designed to simulate actual aft case mounting. The test plan for these tests is discussed in reference 9 and the results, in reference 10.

\section{Tesi Setup \& Procedure}

The castings were tested using a fixture designed by M. Markewicz (2361) to simulate the "worst case" scenario of the actual aft case mounting (29). The test apparatus design is attached as Appendix C. The load is applied via a plate attached to the casting at each of the bosses on the upper surface. The load is applied to the plate above the geometric center of the casting, rather than above the center of gravity (c.o.g.) and the plate is free to rotate. A system of diagnostics was developed by R. May and J. Kubas (2742) to thoroughly characterize the load-deflection behavior of the overall base plate and the mounting feet individually, and to examine the validity of the "cantilever beam" model for the mounting feet load environment. The diagnostic set up includes:

1) two uniaxial strain gauges on the underside (with respect to the direction of loading) of each mounting foot, one located at each end of the "cantilever beam" and with the measurement axis oriented parallel to the expected maximum strain axis

2) load cell

3) displacement gauge measuring hydraulic ram displacement

4) displacement gauge located on the top plate

5) one displacement gauge inboard of each mounting foot, to measure the relative displarement between the clamping fixture and the base of the mounting foot

The assembly of casting, mounting fixture, and loading plate is shown in Figure 9a. Figure $9 \mathrm{~b}$ shows the location of the four displacement gauges. Figure 10 shows the location of the strain gauges. With reference to these figures, the gauges were located as listed in Table VI. Prior to static testing, the mounting feet of the selected casting (\#385267-00-X0116) were radiographed and fluorescent penetrant tested by John Murray (2752). The quality of the casting was found to be consistent with those previously supplied and no surface defects were found.

Table VI - Location of Strain and Displacement Gauge

\begin{tabular}{|c|cc|c|l|}
\hline Location & \multicolumn{2}{|c|}{$\begin{array}{c}\text { Strain Gauge ID\# } \\
\text { (hole) }\end{array}$} & Displacement & \multicolumn{1}{c|}{ Comments } \\
\hline Foot 1 & 2 & 1 & 1 & $\# 2,4$, and 6 span \\
Foot 2 & 4 & 3 & 2 & hole centerline. \\
Foot 3 & 6 & 5 & 3 & $\# 1,3$, and 5 butt up to \\
Plate & - & - & 4 & end of cantilever beam. \\
\hline
\end{tabular}




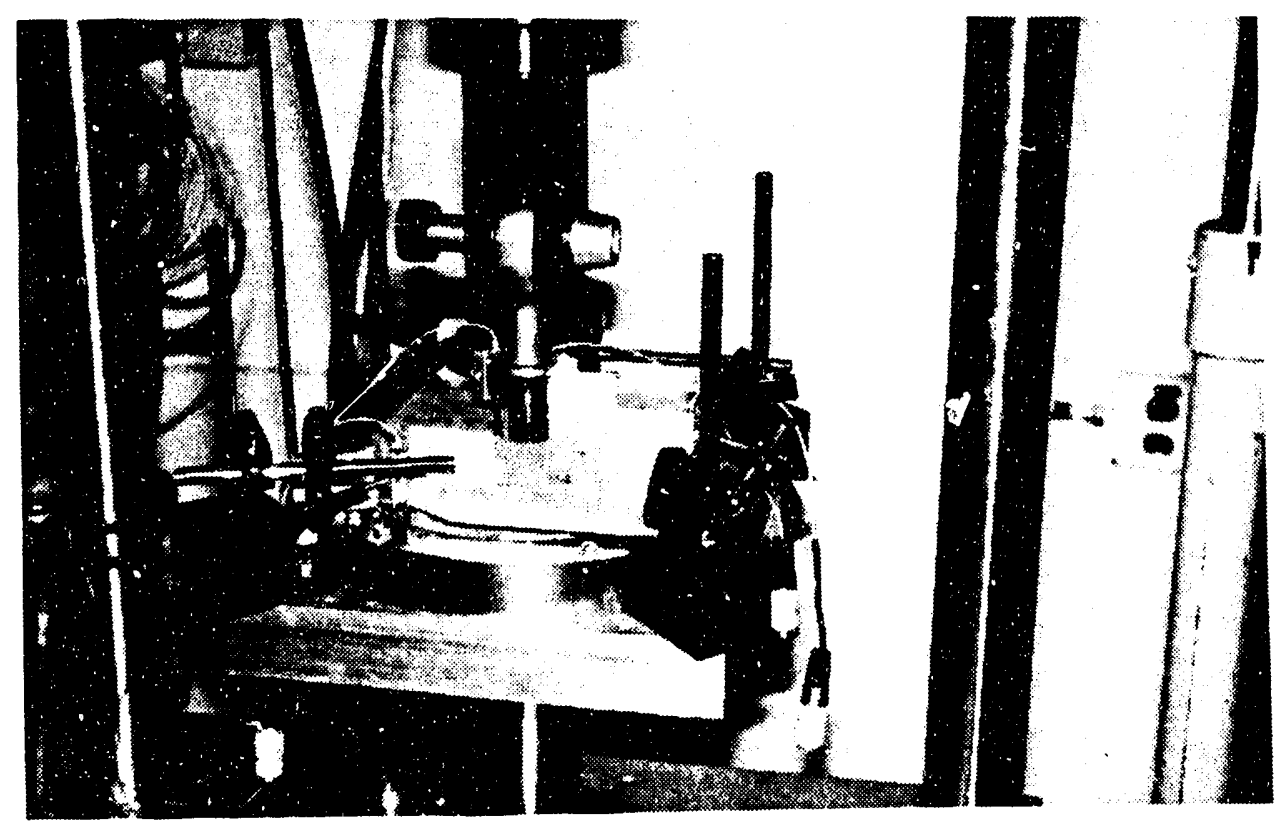

Figure 9a. Experimental setup showing base plate held between mounting fixture (below) and loading plate (above). Assembly sits on machine base plate (shown, drilled on 1" centers) and load is applied at the large central hole in loading plate. Direction of loading is upward.

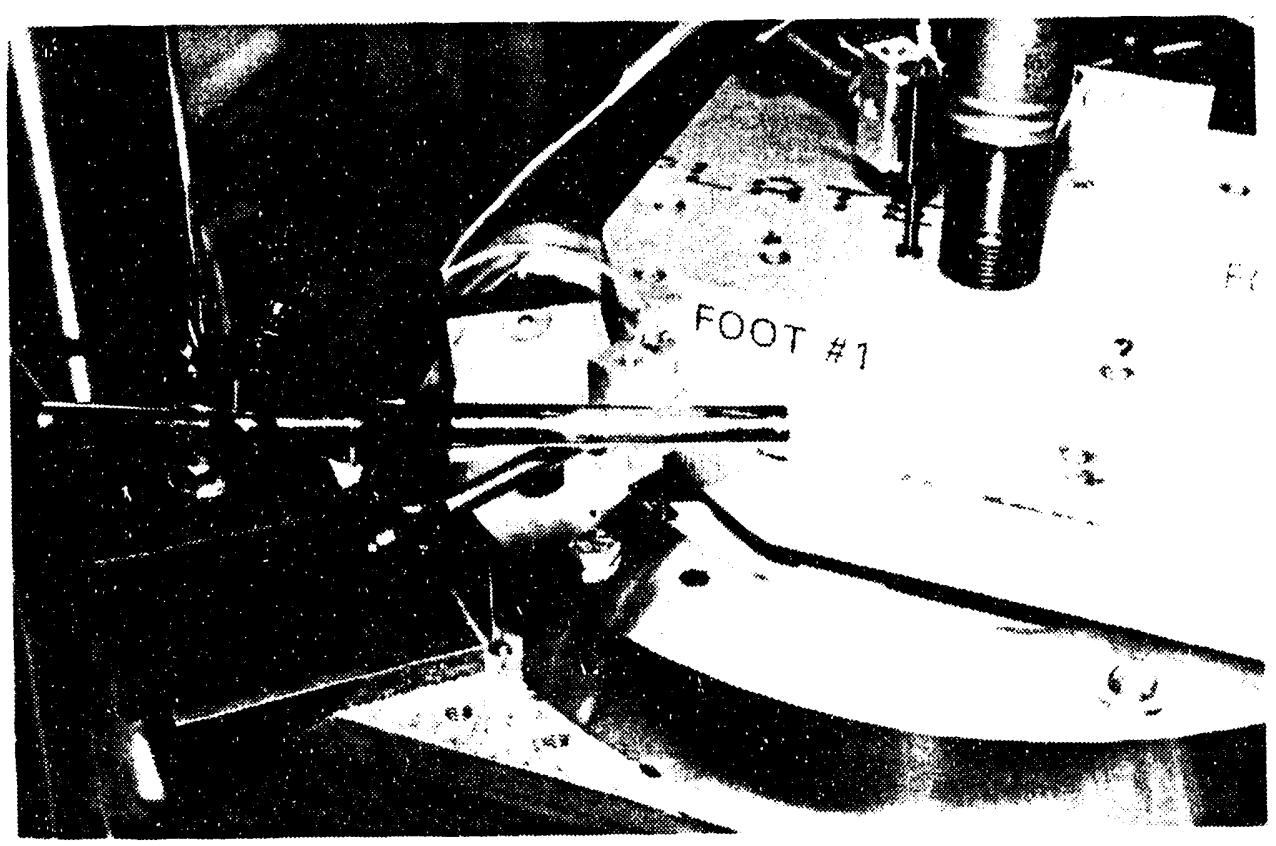

Figure 9b. Experimental setup showing location of displacement gauges and position of ram in center of loading plate. 


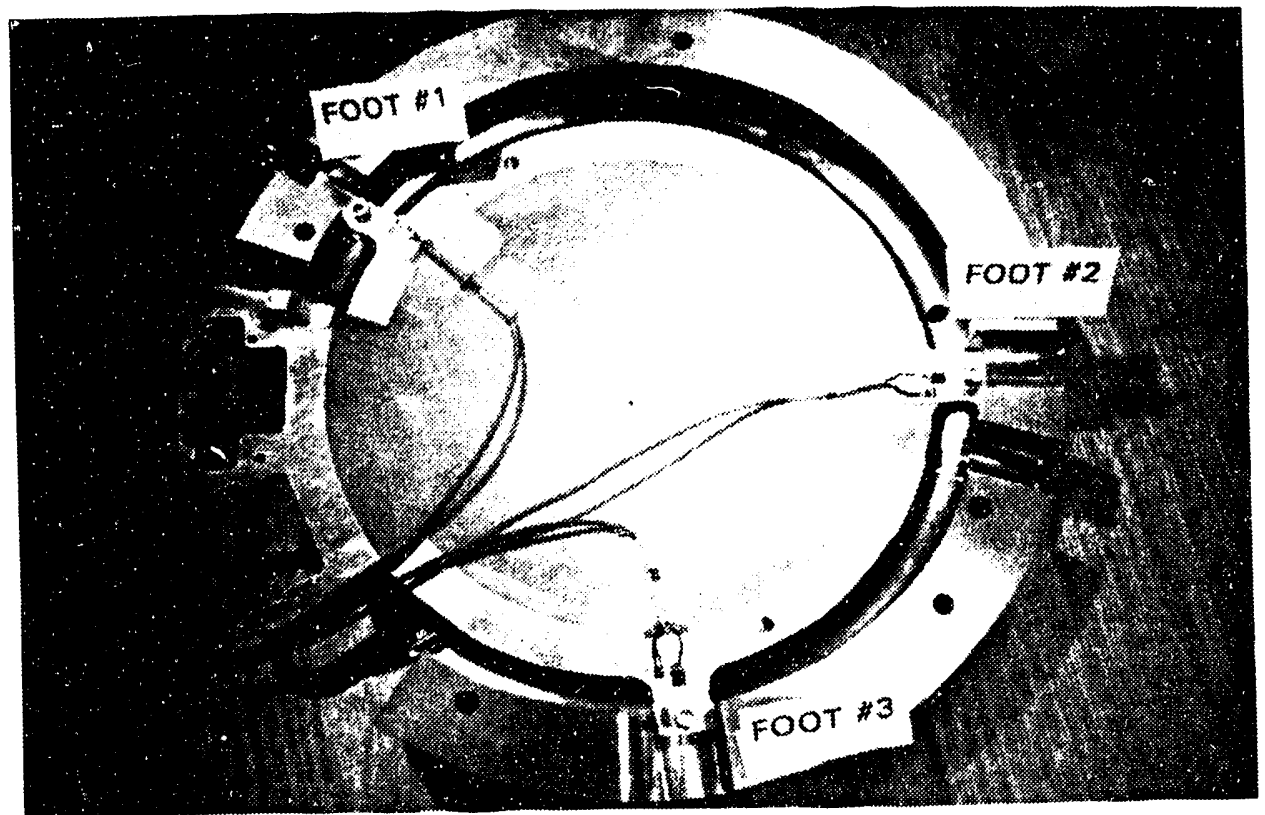

Figure 10a. Location of strain gauges on underside of mounting feet.

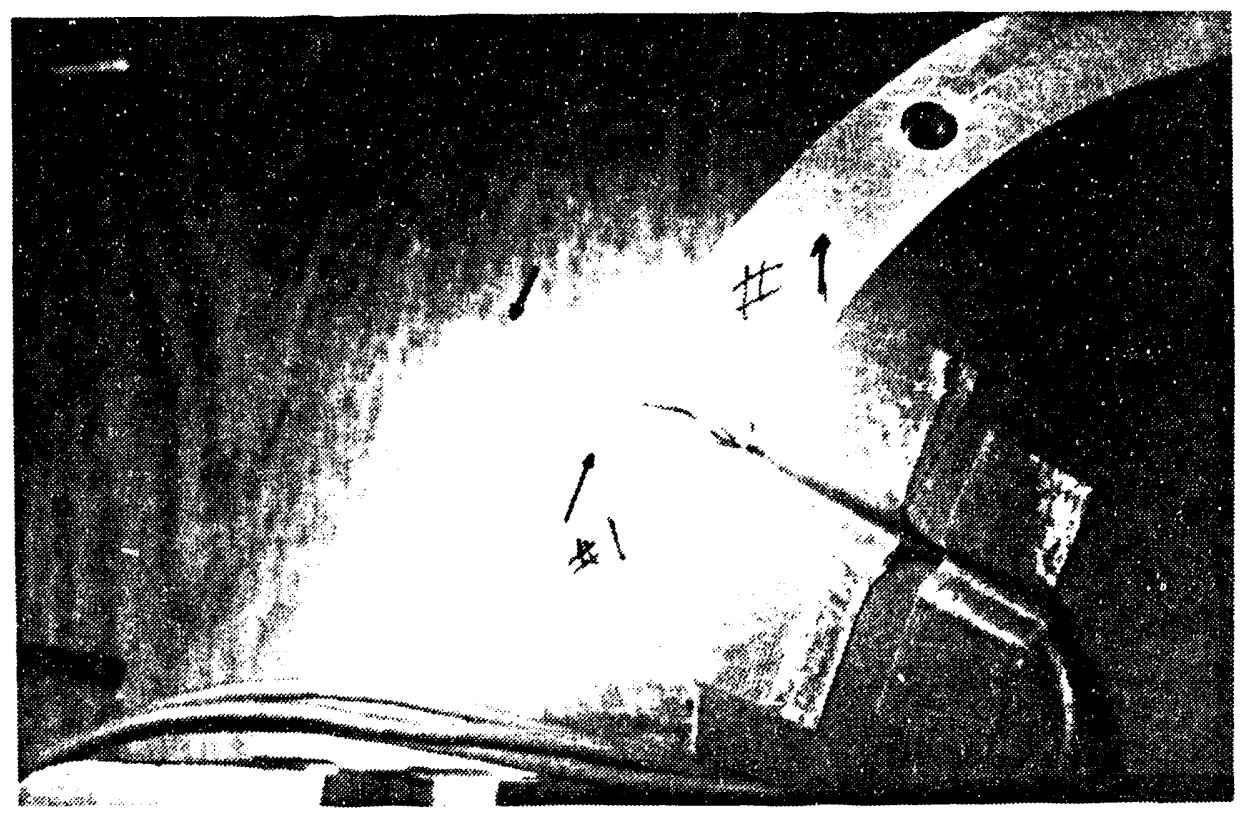

Figure 10b Detail of the underside of mounting foot \# 1 showing location of two strain gauges. Note that gauge at hole end spans the hole center line. Note also that gauge at base of foot butts up against the effective cantilever beam end, defined by the outside diameter of the base plate body. 


\section{Test Results}

\section{A. Test Series 1}

In the first series of static tests, the casting was loaded in the X-Direction in $220 \mathrm{~N}$ (50lb) increments to a maximum of $1.335 \mathrm{kN}(30 \mathrm{lb})$. This load is based on the most severe estimated shock response, and the results of the vibration tests which show a first natural frequency of $310 \mathrm{~Hz}$. Three individual loading cycles were conducted with similar results for each. Figure 11 shows strain vs lrad curves for strain gauges \#1, 3, and 5, generated in the second test, and Figure 12 shows the curves from $\# 2,4$, and 6 . Figure 13 shows load vs displacement curves for all four gauges, also from the second test. These figures show several things:

1) The output of gauges \#1,3, and 5 is negative, indicating a compressive load on the underside of the mounting foot at its base. The output of gauges \#2,4, and 6 is positive, indicating a tensile strain on the underside of the foot at the opposite end (at the mounting hole).

These results indicate that the "single cantilever bearn" assumption for the mounting foot is not accurate. The foot is deforming to assume a sigmoidal shape and thus would probably be better treated as two cantilever beams joined at an inflection point somewhere along the beam's length. This beam configuration would alter the loading and stress state, distributing the stress along the beam in a manner defined by the location of the inflection point. A first order assumption, locating the inflection point at the beam's center, would reduce the maximum stress developed in half, with both ends of the foot being stressed equally. The beam loading will be discussed in a later section.

2) As expected, the maximum strain is seen in gauge \#2, mounted at the hole end of foot 1 , the narrow foot. This strain is slightly greater than that occurring at the same location on the other feet.

3) The maximum compressive strain is seen at the base of foot 1 . The magnitude of the strain developed here is about $1 / 2$ of that developed at the hole end of this foot, and about 1.5 - $2 \mathrm{X}$ that developed at the base of the other two mounting feet.

4) The maximum displacement of the loading plate was found to typically be 0.038 $\mathrm{mm}\left(0.0015^{\prime \prime}\right)$. The displacemerit of the casting, just inside of foot 1 , was also about $0.038 \mathrm{~mm}\left(0.0015^{\prime)}\right.$. The displacement inboard of mounting foot 3 (see Fig $9 \mathrm{~b}$ ) was found to be slightly less, and inboard of foot 2, only about $0.005 \mathrm{~mm}$ (0.0002").

The displacement results verify that foot 1 is deforming to a greater degree than foot 3 , which in turn deforms more than foot 2 . These results indicate that the casting is twisting somewhat under these loading conditions.

5) None of the strain or displacement gauges indicate that permanent deformation has taken place.

Following Test Series 1, the mounting feet were fluorescent penetrant inspected. No surface defects were detected.

The compiled results from Test Series 1 show that the casting would not be expected to fail under the loading conditions based on the predicted shock response. These results also show the the single cantilever beam model for the mounting foot is overly conservative, and overestimates the maximum stress developed in the foot by a factor of perhaps two. 


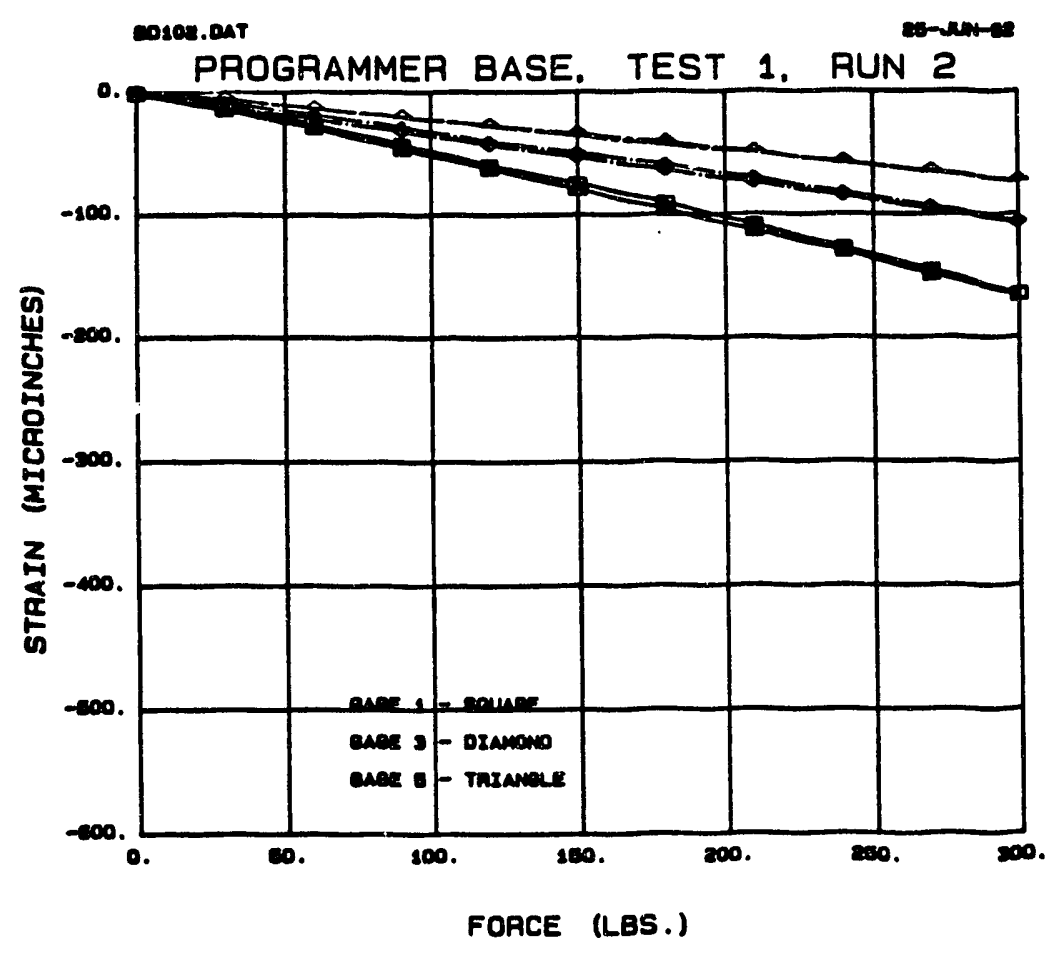

Figure 11. Output of strain gauges \#1, 3, and 5 for Test Series 1, Load Cycle 2. Note that output is negative, showing that strain is compressive

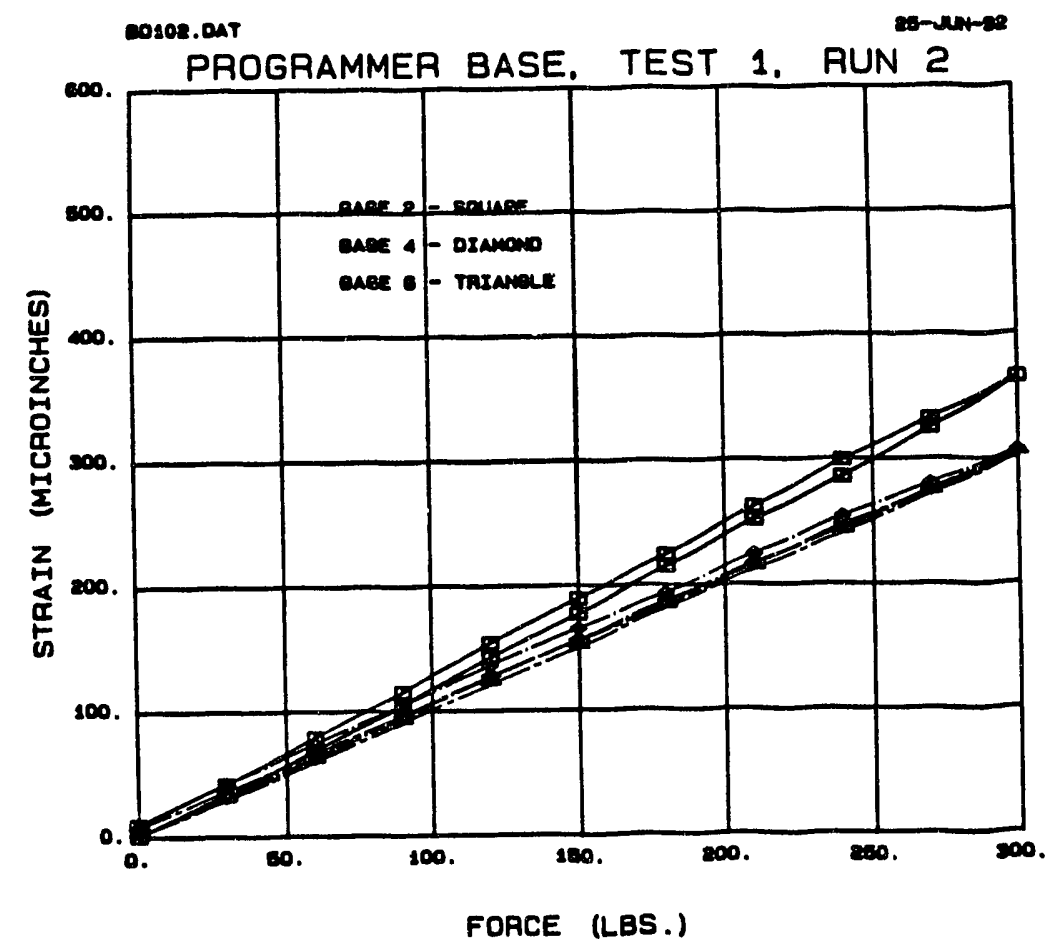

Figure 12. Output of strain gauges $\# 2,4$, and 6 . Note that all strains are tensile and that the strain is greatest for gauge $\# 2$ (mounting foot 1 ). 


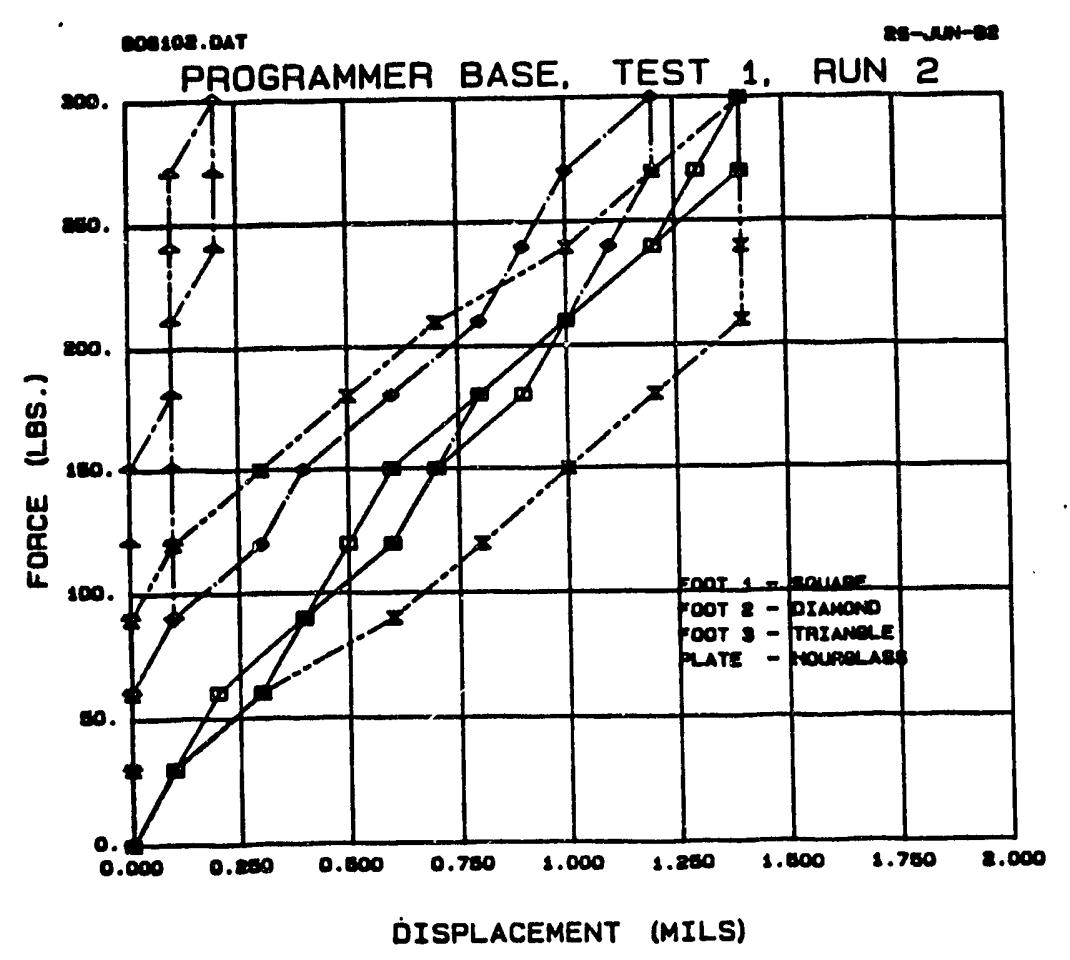

Figure 13. Output of displacement gauges for Test Series 1, Load Cycle 2. Note that displacement is greatest at location 1 (mounting foot 1 ) and least at location 2 (mounting foot 2). This indicates that the casting is twisting under the centrally applied load. Note also that all displacement gauges return to essentially zero.

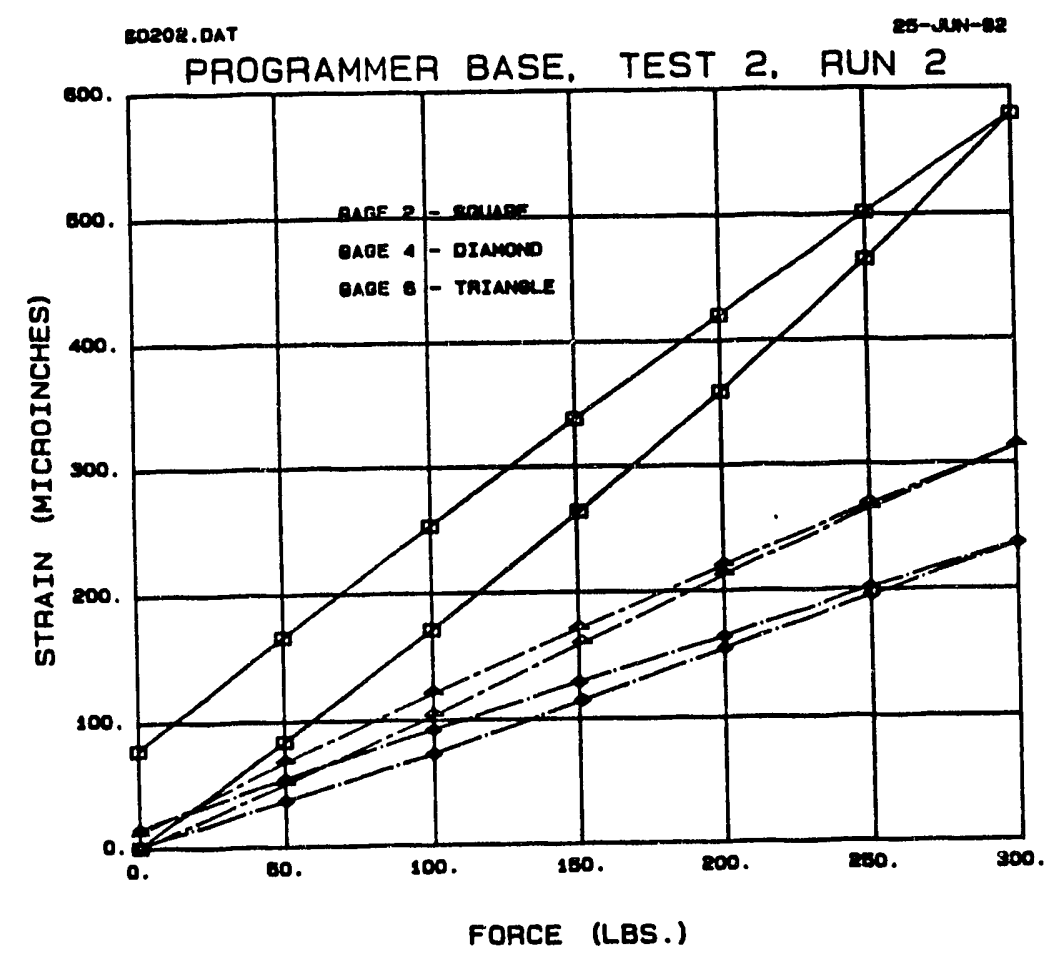

Figure 14. Output of strain gauges \#2, 4, and 6 for Test Series 2, Load Cycle 2. Note that a minor non-linearity appears to occur between 100 and $150 \mathrm{lbs}$. 


\section{B. Test Series 2}

The second test series was intended to load the casting in the X-direction, in $220 \mathrm{~N}$ (50lb) increments, to $3.56 \mathrm{kN}(800 \mathrm{lb})$. As discussed in an earlier memo (1), this load corresponds with the maximum load seen in the application of a $130 \mathrm{~g}, 10 \mathrm{msec}$ haversine shock, assuming a $1^{\text {st }}$ natural frequency of $310 \mathrm{~Hz}(28,30)$.

It must be noted that this particular shock load was selected to encompass the load developed by any combination of the predicted shock response and $1^{\text {st }}$ natural frequency for the component (based on vibration test results). At any particular $1^{\text {st }}$ natural frequency, the $130 \mathrm{~g} 10 \mathrm{msec}$ shock load may result in a significantly larger load than the predicted shock response. This is the case here. Because the vibration testing indicated a I st riatural frequency of $310 \mathrm{~Hz}$, the load associated with the predicted shock response is $60 \mathrm{~g}$, but the haversine recommended for shock testing results in a load of $160 \mathrm{~g}$ for a component with this $1^{\text {st }}$ natural frequency.

In Test Series 2, the first two loading cycles took the casting to a maximum load of $1.335 \mathrm{kN}(300 \mathrm{lb})$, and the third loading cycle to a maximum of $2.00 \mathrm{kN}$ (450lb). Because of the onset of non-linear behavior, the originally intended maximum load of $3.56 \mathrm{kN}(800$ lb)s was not reached.

\section{Loadirig Cycle 1}

The results from Test Series 2, Loading Cycle 1 were very similar to those seen in Test Series 1. Slightly higher strain values were seen on foot $1(500-600 \mu \mathrm{m} / \mathrm{m})$ than were seen in Test Series $1(350-400 \mu \mathrm{m} / \mathrm{m})$. The values produced in feet 2 and 3 were very similar to those seen in Test Series $1(-300 \mu \mathrm{m} / \mathrm{m})$. Similarly, the maximum displacements of the loading plate and the casting inboard of mounting foot 1 were slightly larger than was the case in Test Series $1,0.043-0.050 \mathrm{~mm}(0.0017-0.0020 ")$ vs $0.038 \mathrm{~mm}\left(0.0015^{\prime \prime}\right)$. The minimum displacement, $-0.005 \mathrm{~mm}\left(0.0002^{\prime \prime}\right)$, inboard of mounting foot 2 , was similar to that seen in Test Series 1, but the displacement inboard of mounting foot 3 was lower than in Test Series 1.

In total, the differences in values between Test Series 1 and the first load cycle of Test Series 2 are very minor. It is most likely that the differences in the results are due to minor differences in gauge location as opposed to actual changes in the deformation of the casting.

As was the case with Test Series 1, no permanent deformation was detected in any of the strain or displacement gauges.

\section{Loading Cycle 2}

Test Series 2, Loading Cycle 2 was carried out in a manner identical to that used in Loading Cycle 1. Figures 14 and 15 show the output of strain gauges $\# 2,4$, and 6 , and the four displacement gauges, respectively, for Loading Cycle 2. The maximum strain and displacement levels reached in Loading Cycles 1 and 2 were similar, but the specific strain and displacement behavior was found to differ slightly. In Loading Cycle 1, all strains and displacements increased smoothly to a maximum, then smoothly returned to zero. In Loading Cycle 2 , the strain seen at gauge \#2 (foot 1 ), shows a minor non-linearity at 445 $667 \mathrm{~N}$ (100-150 lbs), and indicates a residual strain of about $15 \%$ of the maximum level. Figure 15 shows that the displacement inboard of foot 1 increases to its maximum, then smoothly decreases as the load is removed. However, the displacement inboard of feet 2 and 3 reaches a maximum, then remains constant while the load is initially lowered. Gauges 2 and 3 also show a residual (unloaded) displacement of approximately half the maximum value. 


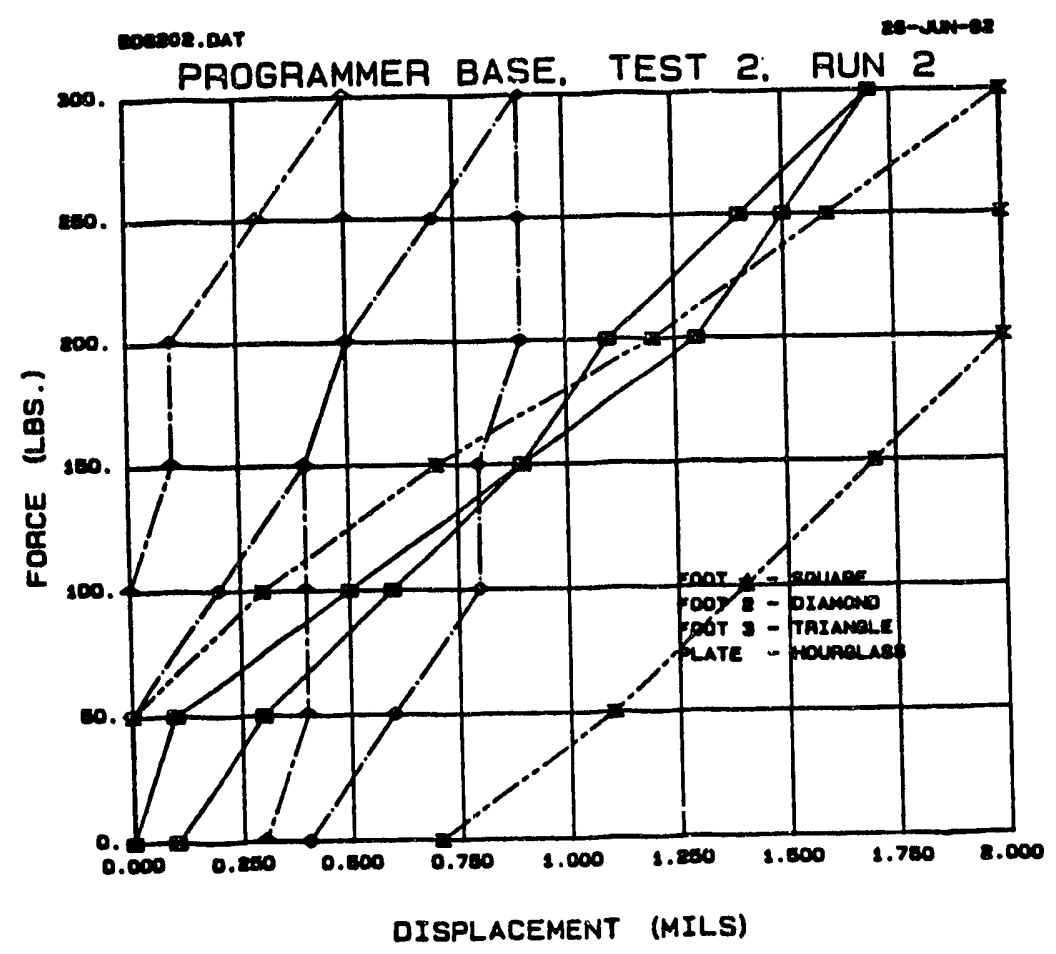

Figure 15. Load vs displacement curves for Test Series 2, Load Cycle 2. Note that the displacement at location 1 is greatest. Note also that the displacements at locations 2 and 3 remain at the maximum value as load is initially decreased, and only return approximately half way to zero.

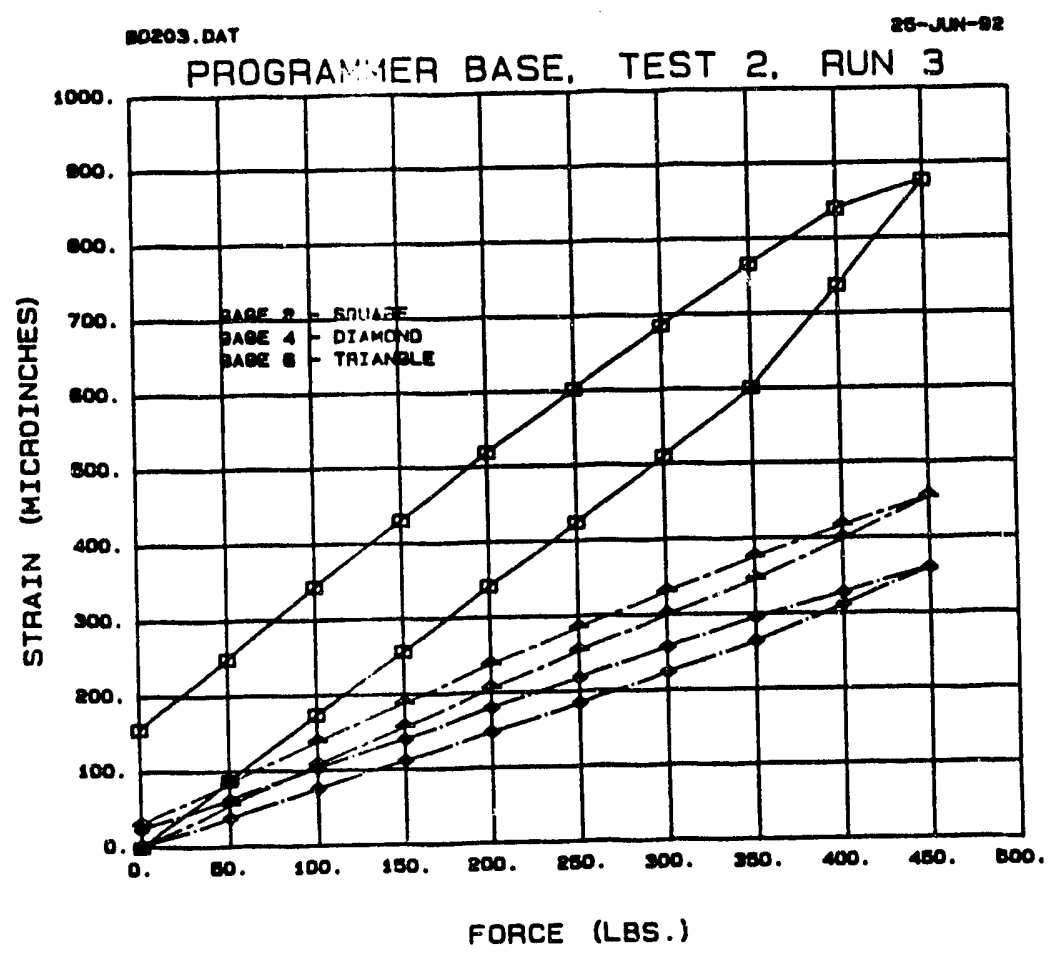

Figure 16. Output of strain gauges $\# 2,4$, and 6 for Test Series 2, Load Cycle 3. Note that plastic deformation appears to begin between 350 and $400 \mathrm{lbs}$. 
It is possible that some permanent deformation occurred during Loading Cycle 2. However, the low levels of residual strain and distortion, and the low load at which the apparent non-linearity occurred suggest that some movement, or "settling" of the gauges is also a likely cause.

\section{Loadin: Cycle 3}

The results of Test Series 2, Loading Cycle 3 are shown in Figures 16-18 These results show that up to $1.335 \mathrm{kN}(300 \mathrm{lb})$, the casting defo.med in a manner identical to that observed previously. However, the casting began deforming in a non-linear manner between 1.56 and $1.79 \mathrm{kN}$ (350 and $400 \mathrm{lbs}$ ), which agrees reasonably well with the data of Stirbis (4).

The specific results from Loading Cycle 3 are:

1) The maximum strain (gauge *2) was found to be $876 \mu \mathrm{m} / \mathrm{m}$, with the maximum strains on gauges $\# 4$, and 6 lower by factors of $\sim 2$ and 2.5 , respectively.

2) A strain of $156 \mu \mathrm{m} / \mathrm{m}$ was retained in gauge $\# 2$ after unloading.

3) The largest negative strain, $-510 \mu \mathrm{m} / \mathrm{m}$, was produced in gauge \#1. The strains in gauges \#3 and 5 were lower by a factor of $\sim 3$. No residual strain was shown, indicating that the area at the base of foot 1 did not deform plastically.

4) The results of the displacement gauges, Figure 18, show a pattem similar to that seen in Loading Cycle 2. The displacement inboard of foot 1 is the largest, $0.069 \mathrm{~mm}\left(0.0027^{\prime}\right) \max$, and increases and decreases smoothly with load. The displacement inboard of feet 2 and 3 increase to a (lower) niaximum, then initially remain constant as the load is removed.

Unlike Loading Cycle 2 however, no residual displacement was detected at any of the displacement gauges. Strain gauge \#2, Figure 16, clearly indicates a deviation from linear tehavior between 1.56 and $1.78 \mathrm{kN}$ (350 and $400 \mathrm{lbs}$ ). However, the lack of any residual displacement suggests that the yielding occurring in the region of strain gauge \#2 was a local phenomenon and not sufficient to cause significant overall deformation of the casting.

\section{Summary and Discussion}

The results of these tests indicate that the mounting feet will not fail or plastically deform at loads approximating those associated with the predicted shock response. The results also show that the most highly strained location is adjacent to the mounting hole on the narrow foot (foot 1). This location begins deforming plastically when the overall applied load is between 1.56 and $1.78 \mathrm{kN}$ (350 and $400 \mathrm{lbs})$. This load is greater than that associated with the predicted shock response, but potentially lower than loads reached in the proposed shock loading test, namely $2.00 \mathrm{kN}$ (450lbs). Locations inboard of the three mounting feet are not permanently displaced as a result of this load. This indicates that the yielding of foot 1 is very local, and does not affect the configuration or location of the base plate as a whole. These results agree reasonably well with those of Stirbis (4). In his test, Stirtis loaded the base plate to $8.90 \mathrm{kN}(2,000 \mathrm{lbs})$ with relatively minor overall permanent deformation, but the failure of foot 1 .

The original loading analysis (3) of the mounting feet assumied that they behaved as a simple cantilever beam but noted that another assumption, that the beam was fixed on both ends, would lower the marimum stress by a factor of 2 . The original analyses also assumed that any load applied 


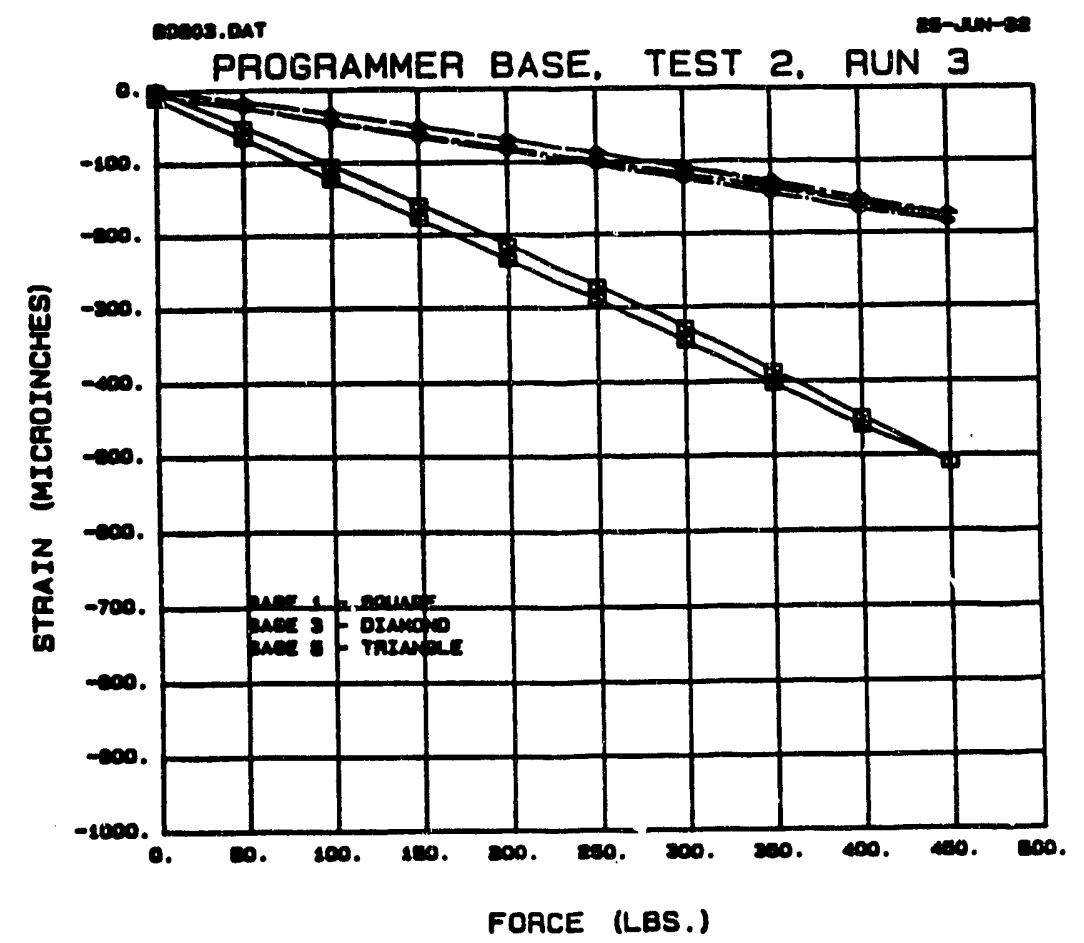

Figure 17. Output of strain gauges \#1,3, and 5 for Test Series 2, Load Cycle 3. Note that no no plastic strain was detected.

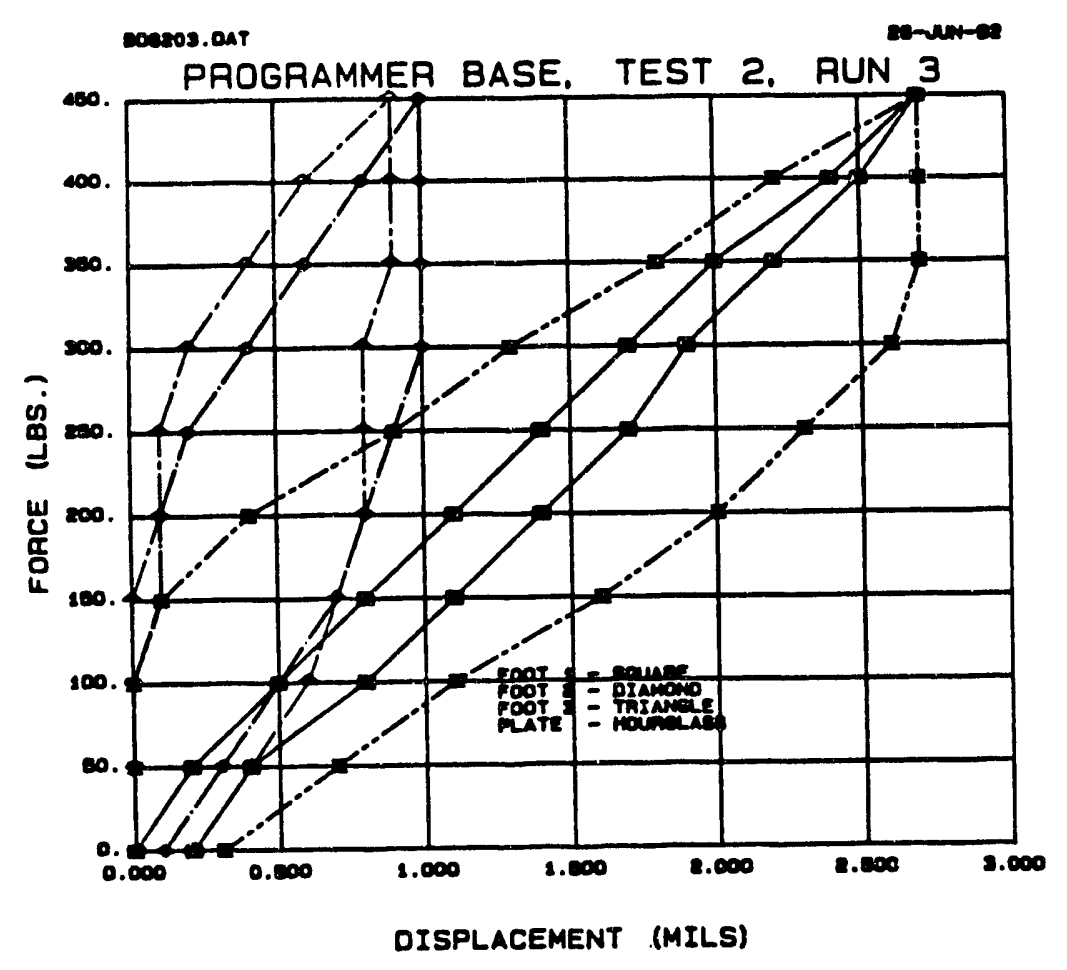

Figure 18. Load vs displacement curves for Test Series 2, Load Cycle 3. Note that no permanent deformation occurs. 
to the casting in the $\mathrm{X}$-direction would be evenly split between the three feet, but noted that this was likely a non-conservative assumption. One goal of this testing and analysis was to evaluate these assumptions.

\section{A. Loadine Distribution}

Assuming that the use of the loading plate approximates a load distributed uniformly around the $X$-axis, a load applied on the $X$-axis can be resolved onto the three mounting feet based on their approximate location in the $\mathrm{Y}-\mathrm{Z}$ plane.

$$
\begin{aligned}
& F_{1}=0.431 F_{T} \\
& F_{2}=0.323 F_{T} \\
& F_{3}=0.246 F_{T}
\end{aligned}
$$

If instead the location of the mounting feet in the $\mathrm{Y}-\mathrm{Z}$ plane is referenced to the actual center of gravity, as would be case for an acceleration load, the resolution of forces is:

$$
\begin{aligned}
& F_{1}=0.485 F_{T} \\
& F_{2}=0.176 F_{T} \\
& F_{3}=0.340 F_{T}
\end{aligned}
$$

It is most significant to note that for an actual $\mathrm{X}$-direction acceleration, approximately $1 / 2$ of the load is borne by foot 1 , rather than $1 / 3$, as assumed previously (3). Using these values, the point where local yielding in foot 1 has certainly begun corresponds with:

$$
1.78 \mathrm{kN}(400 \mathrm{lbs}) * 0.431=765 \mathrm{~N}(172 \mathrm{lbs}) \text { on foot } 1
$$

Back-calculating, this load corresponds with an actual acceleration load, applied at the c.o.g. of:

$$
765 \mathrm{~N} *(1 / 0.485)=1.58 \mathrm{kN} \text { (355 lbs) of acceleration load (at c.o.g.) }
$$

Similarly, the load associated with the shock response spectra and the vibration test results, $60 \mathrm{~g}$, plus $15.6 \mathrm{~g}$ static acceleration load, both applied at the c.0.g., may be resolved onto foot 1:

$$
1.70 \mathrm{kN}(382.5 \mathrm{lbs}) * 0.485=824 \mathrm{~N}(185 \mathrm{lbs})
$$

which corresponds with the following load applied at the casting center point (i.e. loading as in the static tests):

$$
824 \mathrm{~N} * 1 / 0.431=1.91 \mathrm{kN} \text { (430 lbs) }
$$

It is significant to note that using these assumptions, the SB requirement translates to a centrally applied load very nearly identical with the point where mounting foot begins deforming plastically.

\section{B. Maximum Stress Calculation}

The static test results may be interpreted with respect to comparisons of the maximum stress developed in mounting foot 1 during the static testing and the expected material properties. The strain gauge results show that the feet are deforming to assume a sigmoidal shape. This corresponds with the alternate deformation pattern mentioned by Cherry (3), and may be approximated by two cantilever beams, joined at an inflection point. Given this deformation pattern, the maximum stress in the mounting foot may be estimated according to several simplified models, to bracket the actual stress levels reached.

The simplest model is to assume that the mounting foot is comprised of two equal length cantilever beams, joined at an inflection point. In this case, the beams are each 6.86 $\mathrm{mm}\left(0.27^{\prime \prime}\right)$ in length. (The overall foot is $13.7 \mathrm{~mm}\left(0.54^{\prime \prime}\right)$ from base to center line of 
mounting hole.) Based on this, the maximum stress associated with the $1.78 \mathrm{kN}$ (400 lb) load, or $765 \mathrm{~N}$ (172 lbs) on foot 1 may be calculated as follows:

$$
\begin{aligned}
& M_{\max }=0.00686 m * 765 \mathrm{~N}=5.25 \mathrm{~N}-\mathrm{m}(46.4 \mathrm{in}-\mathrm{lbs}) \\
& I=\mathrm{BH}^{3} / 12=\left[(0.0127 \mathrm{~m})(0.0056 \mathrm{~m})^{3} \mathrm{~V} / 12=1.85 * 10^{-10} \mathrm{~m}^{4}\left(4.44 * 10^{-4} \mathrm{in}^{4}\right)\right. \\
& S=M c / I=(5.25 \mathrm{~N})(0.0028 \mathrm{~m}) / 1.85 * 10^{-10} \mathrm{~m}^{4}=7.95 * 10^{7} \mathrm{~N} / \mathrm{m}^{2} \\
& 79.5 \mathrm{MPa}(11.5 \mathrm{ksi})
\end{aligned}
$$

This ssumes that the beam cross-section is $0.0127 \mathrm{~m} * 0.0056 \mathrm{~m}(0.5 \mathrm{in} * 0.22)$. However, if the beam cross section is reduced to account for the mounting hole, I and $\mathrm{S}$ become:

$$
\begin{aligned}
& I=1.15 * 10^{-10} \mathrm{~m}^{4}\left(2.77 * 10^{-4} \mathrm{in}^{4}\right) \\
& S=127.5 \mathrm{MPa}(18.5 \mathrm{ksi})
\end{aligned}
$$

A slightly more realistic assumption might be to assume that the beam ends are identically constrained, so that if the deformation is linear, the ratio of their effective lengths will be equal to the ratio of the actual strains measured at the beam ends. Using the 1.335 $\mathrm{kN}(300 \mathrm{lb})$ strain values of $510 \mu \mathrm{m} / \mathrm{m}$ and $-327 \mu \mathrm{m} / \mathrm{m}$, the ratio of beam lengths would be $1.56 / 1$, resulting in beam lengths of 8.36 and $5.36 \mathrm{~mm}\left(0.329^{\prime \prime}\right.$ and $\left.0.211^{\prime \prime}\right)$. A calculation similar to those above now results in a maximum stress at the hole end of foot 1 equal to:

$$
\mathrm{S}=96.5 \mathrm{MPa}(14.0 \mathrm{ksi})
$$

And again, if the beam cross section is reduced to account for the mounting hole:

$$
\mathrm{S}=155 \mathrm{MPa}(22.5 \mathrm{ksi})
$$

Further, the strain gauges at the hole ends of the mounting feet approximately span the hole center line. Because this center line is assumed to be the end of the cantilever beam, only half of the gauge would be sensing deformation. An upper bound on this effect would be to double the measured strain value. If this assumption is made, the $1.335 \mathrm{kN}$ $(300 \mathrm{lb})$ strain values become $1020 \mu \mathrm{m} / \mathrm{m}$ and $-327 \mu \mathrm{m} / \mathrm{m}$, and the beam lengths become 10.4 and $3.33 \mathrm{~mm}\left(0.409^{\prime \prime}\right.$ and $\left.0.131^{\prime \prime}\right)$, and the maximum stress becomes

$$
\mathrm{S}=120 \mathrm{MPa}(17.4 \mathrm{ksi})
$$

And if the beam cross section is reduced to account for the mounting hole:

$$
\text { S = } 193 \text { MPa (28 ksi) }
$$

These calculated maximum stress levels, based on the yield loads measured in the static test series and several models for beam configuration, range from 80 to $190 \mathrm{MPa}$. These levels range from about $1 / 2$ the material's expected yield strength to about the expected yield strength. As a comparison, a different approach, $i$ ised on measured local strain levels, may also be taken to estimate the stress levels reachec: during the static tests. This approach is to use the measured yield strain and the material's elastic modulus to calculate the yield stress. In the static tests, the strain level at $1.78 \mathrm{~N}(400 \mathrm{lbs})$ was found to be $737 \mu \mathrm{m} / \mathrm{m}$. If this strain value is doubled (to account for the gauge spanning the mounting hole, as above) and multiplied by the elastic modulus for this material, the calculated stress is:

$$
\left(1.474 * 10^{-3} \mu \mathrm{m} / \mu \mathrm{m}\right) *(72.4 \mathrm{GPa})=107 \mathrm{MPa}(15.5 \mathrm{ksi})
$$

This stress level falls within the range resulting from the beam calculations, from approximately $1 / 2$ of the expected yield strength to the yield strength. Given that the stress concentration due to the mounting hole may be as large as 2 , and that the stress state is more complex than these simple treatments, it seems reasonable to conclude that the area near the hole on mounting foot 1 is plastically deforming during the static test. Test Series 2, Loading Cycle 3. 


\section{Static Test Results - Conclusions}

Unfortunately, the results of these tests suggest that the supplied base plate castings are neither inadequate nor robustly designed. The lack of permanent displacement at any of the gauges in the sample loaded to $2.00 \mathrm{kN}$ (450lbs) suggests that the the yielding is a very local phenomenon, and should not be interpreted as failure of the component. Therefore, with respect to the $\mathrm{X}$-direction and under loading conditions given by the predicted shock response and vibration test results, the component may be viewed as adequate. However, these test results suggest that the hole region of mounting foot 1 is the "weak link" in the system. These results also raise concerns regarding the $Y$ and $Z$ axis loading scenarios which, with the cancellation of the W89 program, remain unaddressed.

\section{TASK 7: Evaluate the Suitability of Premium vs. Grade C Castings}

As noted, the material property and testing showed that premium quality castings (Spec 9921013 Grade A, ASTM-B-618 or MIL-C-6021 Grade A or B), are adequate for this application, but not over-designed. The eight originally supplied castings and the two later castings are of this quality and therefore, not anticipated to present any problems.

However, the specification calls for Grade C castings as per 9921013. As discussed by John Murray in his report, Appendix A, the allowable defect structure in a (irade C casting is considerable and must be addressed in a discussion of projected material performance.

\section{Static Mechanical Properties}

In terms of static mechanical properties, there are three consequences of using a casting produced to the minimum Grade $C$ standards. The first is the reduction of load bearing area due to the presence of defects. The second is the intensification of stress in local areas. The third consequence is the reduction of mechanical properties, illustrated in the data of Wickberg (25). Given that the static mechanical properties of premium castings are marginal, the acceptance and use of Grade $C$ castings is not recommended.

\section{General Eracture Toughness Considerations}

A major concern of attempting to use material with a significant pre-existing defect structure is the effect on fracture behavior. The application of linear elastic fracture mechanics to the mounting feet is not strictly correct and will result in a very conservative treatment. The minimum specimen dimensions for linear elastic behavior may be calculated based on the materials yield strength and fracture toughness according to the formula;

$$
A \geq 2.5\left(\mathrm{~K}_{\mathrm{IC}} / \sigma_{\mathrm{y}}\right)^{2}
$$

$$
\begin{gathered}
\text { where : } \text { specimen width }=A \\
\text { specimen depth }=2 A \\
\text { crack length }=A
\end{gathered}
$$

Using values for $\mathrm{K}_{\mathrm{IC}}$ and $\sigma_{\mathrm{y}}$ of 16.5-22.0 MPa $V_{\mathrm{m}}(15-20 \mathrm{ksi} / \mathrm{in})$ and $185-230 \mathrm{MPa}(27-$ $33 \mathrm{ksi}$ ), respectively, the required specimen thickness and depth are approximately 12.7 $15.2 \mathrm{~mm}(0.5-0.6 \mathrm{in})$ and $25-33 \mathrm{~mm}$ (1.0-1.3 in), respectively (31). Still, the application of linear elastic analyses may be used as a "worst case" scenario. The application of elastic/plastic fracture mechanics is extremely complicated and not recommended, given the rudimentary understanding of the local loading environment. 


\section{Predicted Eracture Toughness Behavior of Supplied Castings}

The supplied castings were examined using radiography and fluorescent penetrant techniques and only minor porosity, $\mathrm{d} \leq 0.5 \mathrm{~m}(0.020 \mathrm{in})$ diameter, was detected. Using this flaw size as a base, worst case scenarios ere calculated for various flaw orientations, Figure 19 (32). Using a $225 \mathrm{MPa}$ ( $32.5 \mathrm{ksi}$ ) to: the applied stress, $\mathrm{K}_{\mathrm{I}}$ values were calculated as follows:

A) Crack(s) Emanating from a Pore (Figure 19a)

$$
\begin{array}{lll}
\text { pore diameter } & =0.5 \mathrm{~mm}(0.020 \mathrm{in}) \\
\text { initial crack length } & = & 0.25 \mathrm{~mm}(0.010 \mathrm{in}) \\
\text { maximum } \mathrm{K}_{\mathrm{I}} & =9.5 \mathrm{MPa} V_{\mathrm{m}}\left(8.6 \mathrm{ksi} V_{\text {in }}\right)
\end{array}
$$

B) Crack in the Specimen Surface (Figure 19b)

$$
\begin{array}{lll}
\begin{array}{l}
\text { pore diameter } \\
\text { maximum } K_{I}
\end{array} & =\quad \text { initial crack length }=0.5 \mathrm{~mm}(0.020) \text { in } \\
& =5.9 \mathrm{MPa} J \mathrm{~m}(5.3 \mathrm{ksi} \text { in })
\end{array}
$$

C) Crack on Specimen Edge (Figure 19c)

$$
\begin{array}{lll}
\text { pore diameter } & =\quad \text { initial crack length }=0.5 \mathrm{~mm}(0.020 \mathrm{in}) \\
\text { maximum } \mathrm{K}_{\mathrm{I}} & = & 5.7 \mathrm{MPa} \sqrt{\mathrm{m}}(5.2 \mathrm{ksi} \sqrt{\mathrm{in}})
\end{array}
$$

All of the calculated $K_{I}$ values are well below the range of $K_{I C}$ values expected for $A 356$ T6, 16.5-22.0 MPa ${ }_{\mathrm{m}}\left(15-20 \mathrm{ksi}{ }_{\mathrm{in}}\right)$. Therefore, it is unlikely that the supplied castings will fracture under the projected loading.

\section{Bredicted Fracture Toughness Behavior of a Grade C Casting}

Repeating the above calculations using the maximum flaw size allowed in a Grade $C$ casting yields $K_{I}$ values of $11.9,7.4$, and $7.0 \mathrm{MPa} / \mathrm{m},(10.9,6.7$, and $6.4 \mathrm{ksi} V$ in). These values are still well below the $\mathrm{K}_{\text {IC }}$ for A356. However, as was noted earlier, the $\mathrm{K}_{\mathrm{IC}}$ values are for much higher quality material than a Grade C casting contains. Data applicable to Grade $C$ castings is not currently available, but the fracture toughness would be expected to be much lower. Also, the non-homogeneous nature of Grade C castings suggests that their fracture behavior will be unpredictable, and quite conceivably poor to the point where fracture would become a problem.

The supplied castings clearly show that the vendor is capable of producing and supplying 9921013, Grade A castings. If the specification were changed to require ASTMB-618 (or ML-C-6021) Grade B casting quality in the critical regions (mounting feet, etc.), it is anticipated that potential fracture problems could be avoided. A program to characterize the fracture toughness and variability for materials associated with the various casting grades would be extremely useful, given the DOE Complex's increasing application of castings. Such a program could emulate commonly used casting alloys and utilize the short-rod test technique. The short rod technique is far simpler and less expensive than ASTM-E-399 CT specimens and the results have been shown to correlate well with ASTME-399 tests. 


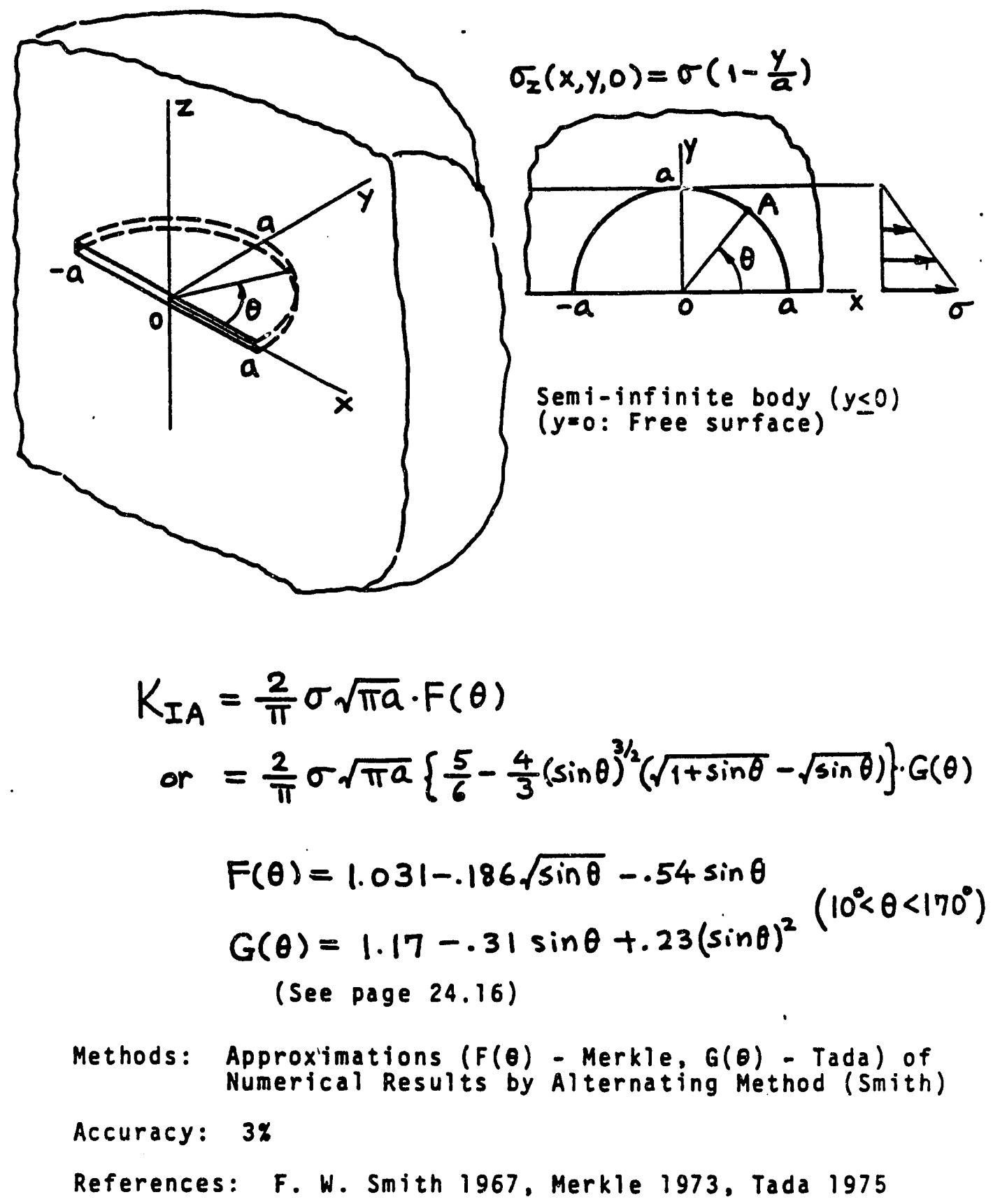

Figure 19a Schematic and calculation procedure for stress concentration factor for a crack emanating from an internal pore (33). 


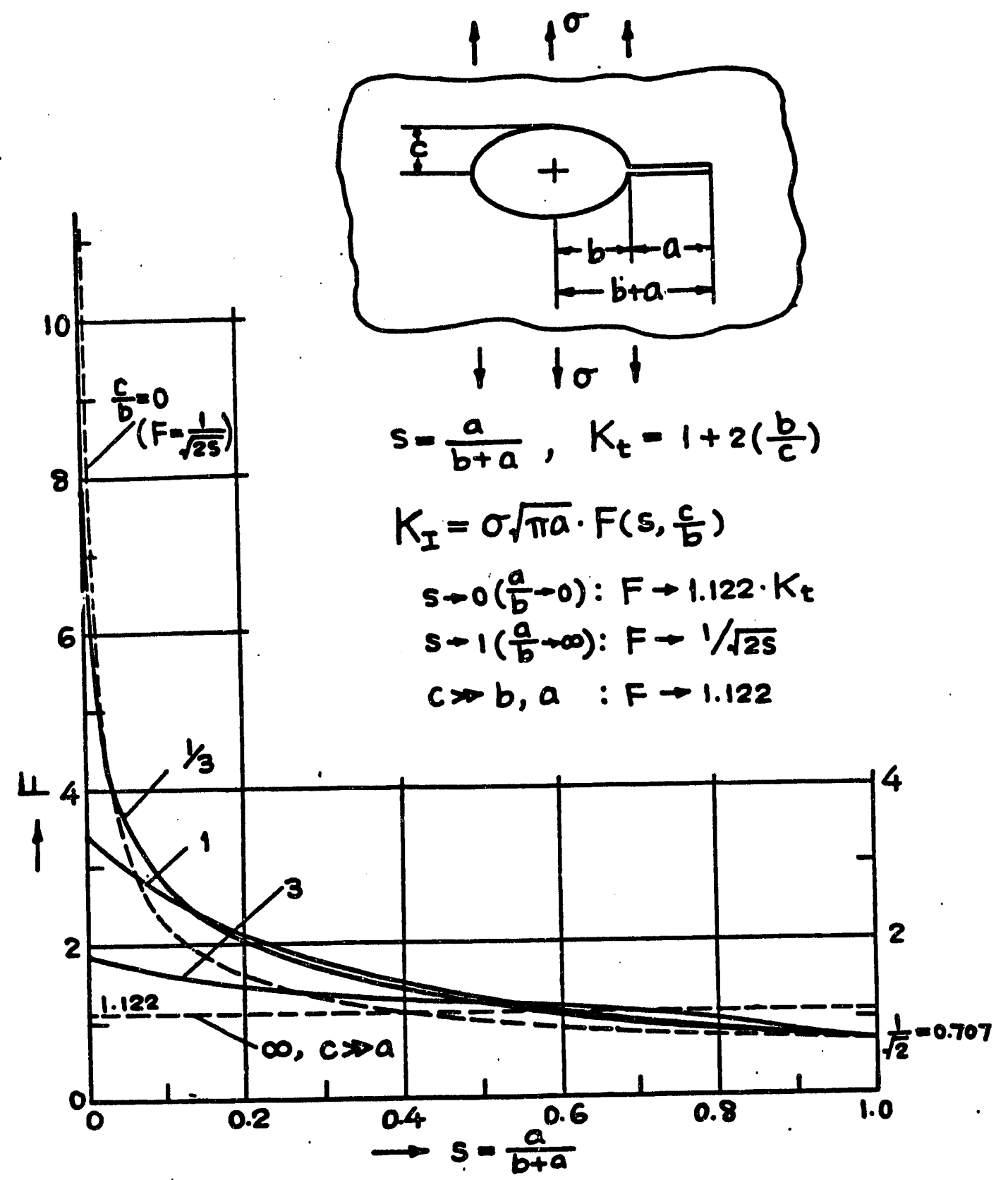

Method: Integral Equation

Accuracy: $3 \%$

Reference: Brezhnitskif 1966

Figure 19b Schematic and calculation procedure for stress concentration factor for a surface crack (33). 


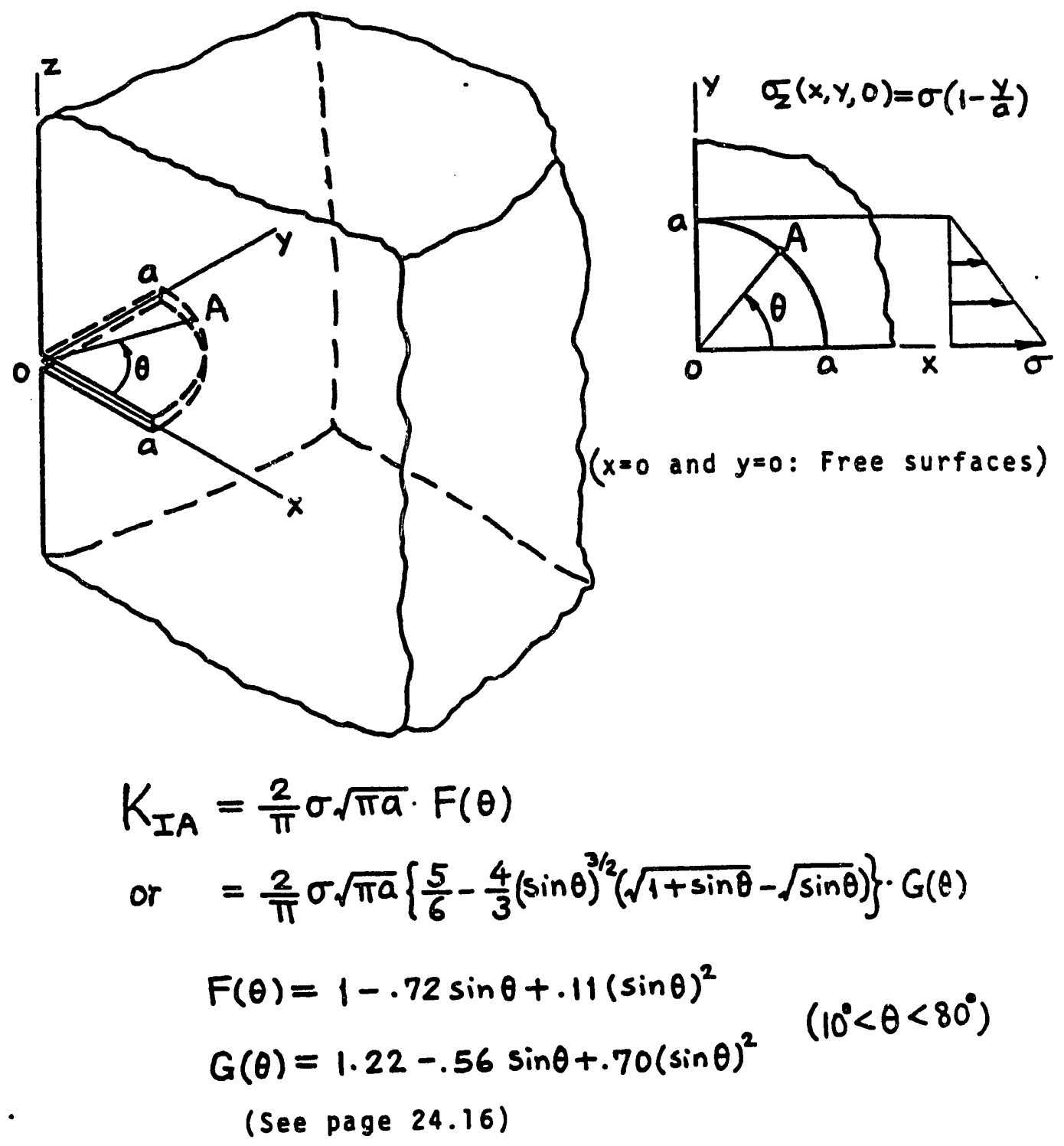

Method: Approximation of Numerical Results by Alternating Method (Kobayashi)

Accuarcy: $3 \%$

References: Kobayashi 1976, Tada 1975

Figure $19 \mathrm{c}$ Schematic and calculation procedure for stress concentration factor for an edge (X33). 


\section{Eatigue Performance}

No fatigue failures have were detected in programmer X222, which underwent an extensive sequence of high amplitude/short time tests, or in X226, the programmer subjected to the $720 \mathrm{hr}$ test. However, these castings were from the same batch characterized in this report, i.e., premium quality castings. Published data shows significant reduction in fatigue properties in the presence of defects. For example, gas porosity corresponding with ASTM Plate 6, or Specification 9921013 Grade B-C, was shown to the degrade the fatigue strength of $\mathrm{A} 356 \mathrm{~T} 6$ by approximately $1 / 3$. Without a more detailed knowledge of the fatigue environment, it is impossible to predict the performance of Grade C castings, but this would be a concern should this component be resurrected in the future.

\section{SUMMARY, CONCLUSIONS, RECOMMENDATIONS}

Several production A356-T6 aluminum castings were evaluated in this study. The castings were evaluated to determine whether they met specifications and to establish a baseline for the structure of castings which were to be supplied. The castings were evaluated using non-destructive techniques, metallographic analysis, and mechanical testing. A casting which had failed in a prior test was evaluated to determine the cause of failure and to characterize the failure mechanism of this material. Once a baseline for the quality and structure of the supplied castings was established, the material properties and component design were evaluated with respect to the application requirements and anticipated loading conditions.

The supplied castings were found to meet or exceed the specified quality level, being more representative of a Grade B or Grade A castings. The microstructure of the castings was found to be typical of this material. Based on these findings, the mechanical properties have been estimated based on published data. It is anticipated that A356-T6 castings of a quality level equal to that of the supplied and characterized castings will meet all requirements. However, the best estimate of mechanical properties and loading environment suggest that this material/production/design combination does not provide a great deal of excess capability. The cancellation of the program prevented the completion of a full series of static tests which would have thoroughly characterized the material and component performance and supported the establishment of a realistic failure criteria. Very little data is available regarding the mecahnical properties of material containing a defect structure of the type permitted in Grade C castings. What data does exist, however, suggests that the properties of the material will be severely degraded by the presence of the allowable defects. Because of this potential property degredation, it is possible that Grade $C$ castings may not perform adequately under all anticipated conditions.

Two general recommendations may be made for using aluminum castings in a potentially highly stressed structural application, particular in the presence of impact or fatigue loading. The first is to specify a higher grade of casting, at least in critical areas. In this case, an appropriate level would be ASTM-B-618 (or MII-C-6021) Grade B. A second general recommendation is to replace the standard A356 alloy with a modified alloy. Figure 20 compares the microstructures of unmodified A356 with sodium modified material. Note the microstructural refinement and reduced aspect ratio of the silicon particles in the modified material. Given the role that the silicon particles and their distribution play in the failure of this type of alloy, the modified alloys would be expected to have far superior ductility, tensile strength, and fracture toughness. 


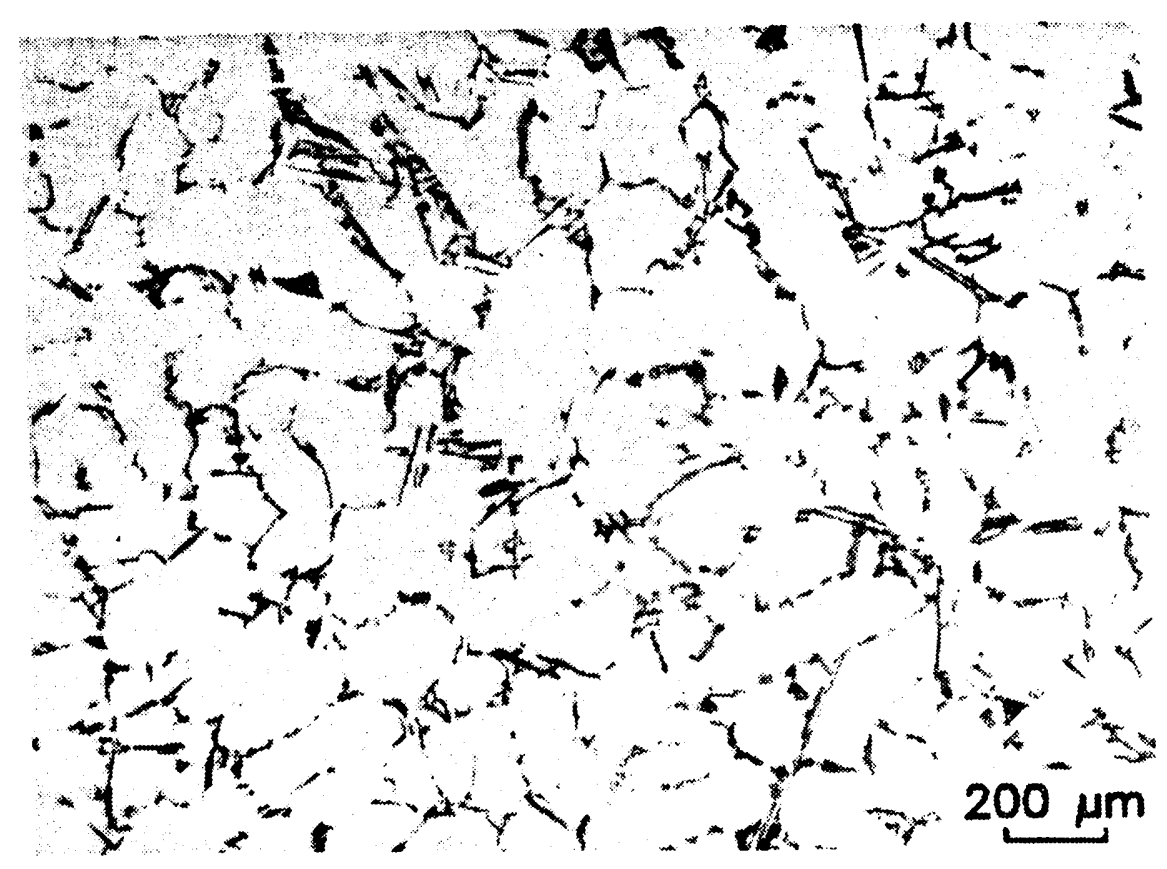

Figure 20a Micrograph of unmodified, as-cast A356. Specimen anodized: $5 \mathrm{~g} \mathrm{HBF}_{4}$ in $100 \mathrm{ml} \mathrm{H}_{2} \mathrm{O}$, $25 \mathrm{~V}$ for $-50 \mathrm{sec}$, ambient temperature.

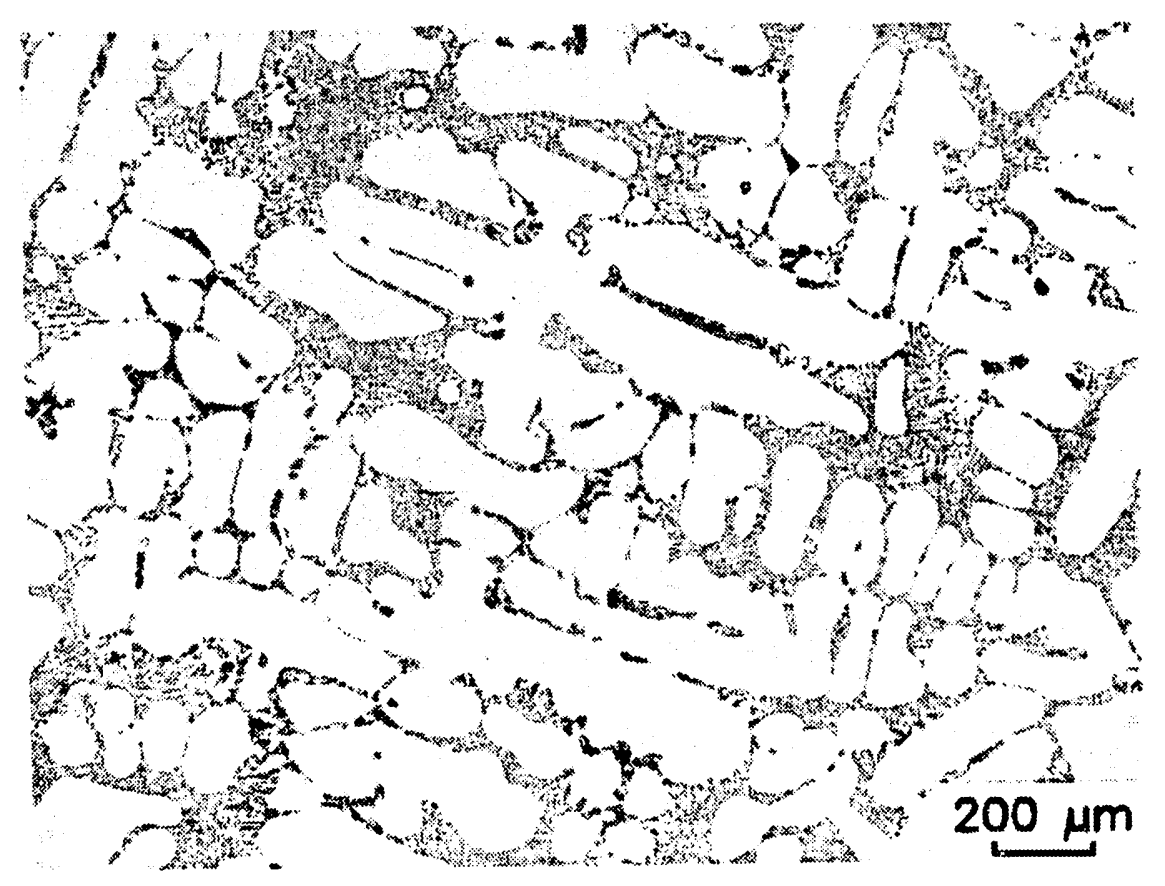

Figure 20b Micrograph of sodium-modified A356, as-cast. Nominal addition, $0.3 \mathrm{wt} \%$. Specimen anodized: $5 \mathrm{~g} \mathrm{HBF}_{4}$ in $100 \mathrm{ml} \mathrm{H}_{2} \mathrm{O}, 25 \mathrm{~V}$ for $-50 \mathrm{sec}$, ambient temperature. Note refinement of microstructure. 
With respect to the programmer base plate, should this component or a similar one be required in the future, the following additional specific recommendations would be made:

1) Complete the test program to address the $Y$ and $Z$ axis response and to identify the point of component fracture, or characterize the component deformation to develop an appropriate deformation-based criteria for failure.

2) Increase the thickness of the mounting feet from the current value of 0.22 ". This geometric change will lower the maximum stress on the feet significantly due to the change in moment of inertia (I).

3) Add a fourth mounting foot. This will have the effect of reducing the load on the feet and will damp the amplification observed in the vibration testing.

4) Institute $100 \%$ NDT of the mounting feet to insure that these locations are of a quality equivalent to ASTM-B-618 (or MIL-C-6021) Grade B. 


\section{List of References}

1) Inspection Specification 9921013 "Casting, Graded Quality"

2) ASTM Specification ASTM-E-155-79 "Reference Rafiographs, Inspection of Aluminum and Magnesium Castings Series 2"

3) "Adequacy of Programmer Feet During Shock Loading," memo from J. Cherry, 8242, to C. Pretzel, 8154, April 10, 1990.

4) "SRAM II MC4073 Programmer Static Test Results", memo from P. Sturbis, 1522, to M. Taylor, 2314, July 11, 1990.

5) J. Anastasio, Department 2314, Sandia National Laboratory, Albuquerque, NM. Private communication, June 1991.

6) "Test Plan for SRAM II Castings," memo from B. Damkroger, 1833, to L. Tafoya, 2314, June 14, 1991.

7) "Preliminary Summary of SRAM II Programmer Base Plate Analysis" memo from B. Damkroger, 1833 to J. Anastasio, 2314, August 9, 1991.

8) "Update on SRAM AJSRAM II Programmer Base Plate Analysis" memo from B. Damkroger, 1833 to J. Anastasio, 2314, March 19, 1992.

9) "Summary of SRAM A/SRAM II Programmer Bass: Plate Static Tests", memo from B. Damkroger, 1833 to J. Anastasio, 2314, September 11, 1992.

10) R. Owens, Allied Signal - Kansas City Division, Kansas City, MO. Private communication, June 1991.

11) R. Blahowsky, Ceramet Corp., Bethlehem, PA. Private communication, June 1991.

12) "Casting, Baseplate", Drawing Number AY385268, Issue B, released 3-13-90.

13) Sessler, John G. 1969. "356, A356" Aerospace Structural Metals Handbook, 1990 Revision, Code 3105. Cindas-Purdue University, West Lafayette, Indiana.

14) "Properties and Selection: Nonferrous Alloys and Special-Purpose Material". Metals Handbook 10th Edition, Volume 2. ASM International, Metal Park, Ohio, pp 164167.

15) Structural Alloys Handbook 1975 Edition. Cindas-Purdue University, West Lafayette, Indiana, pp 70-85. (Formerly Metals and Ceramics Information Center, Battelle Columbus Laboratory, Columbus, Ohio.)

16) Saudners, D.S., Parker, B.A., and Griffiths, J.R. 1975. "The Fracture Toughness of an Aluminum Casting Alloy", Inl Australian Inst of Metals (Metallurgical Eorum), 20 (1), pp 33-38. 
17) Scott, G.D., Cheney, B.A., and Granger, D.A., 1988. "Fracture Toughness and Tensile Properties of Directionally Solidified Aluminum Foundry Alloys", Technology for Premium Quality Castings, Conf. Proc., E. Dunn and D.R. Durham, Eds. TMS/AIME, Warrendale, PA., pp 123-149.

18) Northrop Aircraft Division Report NOR-75-40, February 12, 1975.

19) Kaplan, M.P., Willis, T., and Barnett, R.L. 1985. "A Pressure Vessel Hatch Cover Failure: A Design Analysis". Case Histories Involving Fatigue and Fracture Mechanics, Proc. of a Symposium sponsored by ASTM Committee E-24 on Fracture Testing, C.M. Hudson and T.P. Rich, eds. ASTM, Philadelphia, PA, pp 46-64.

20) Saigal, A., 1987. "Study of Aluminum Alloy Deformation Behavior Using Acoustic Emissions", AES Transactions, v. 40, pp 47-50.

21) Meyers, C.W., Saigal, A., and Benry, J.T., 1983. "Fracture Related Properties of Aluminum A357-T6 Cast Alloy and their Inerrelation With Microstrcture". AES Transactions, v. 35, pp. 281-288.

22) Haagen, C.W., and Berry, J.T., 1977. "Charting the Fracture Toughness Characteristics of Castings Using the Double Trosion Method". Advances in Research on the Strength and Fracture of Materials Vol. 3B - Applications and NonMetals Conf. Proc., D.M.R. Taplin, Ed. Pergamon, New York, NY, pp. 565-572.

23) Murphy, M.C., Kumble, R.G., Bery, J.T., and Outwater, J.O., 1973. "Fracture Toughness Determination in Cast Metals". AFSTransactions, v.30, pp 158-162.

24) Hahn, G.T. and Rosenfield, A.R., 1975. "Metallurgical Factors Affecting Fracture Toughness of Aluminum Alloys". Met. Trans. 6A, pp. 653-668.

25) Wickberg, A., Gustafsson, G., and Larsson, L-E. 1985. "Microstructural Effects on the Fatigue Properties of a Cast Al-7Si-Mg Alloy". SAE Transactions, Section 1Volume 93 (Report No. 840121). SAE, Warrendale, PA, pp 1.728-1.735.

26) Stephens, R.I. 1989. "The SAE Round-Robin Fatigue Program with A356-T6 (AL7Si-Mg) Cast Aluminum Alloy". Advances in Fatigue Science and Technology Conf. Proc., G. Rosa, ed. Kluwer Academic Publishers, Dordrecht, Netherlands, pp 491-510.

27) Stephens, R.I. 1987. "The Influence of Microstructure on the Fatigue Behavior of A356-T6 Cast Aluminum Alloy". Basic Mechanisms in Fatigue of Metals, Conf. Proc., P. Lukas and J Polak, eds. Elsevier, New York, NY, pp 185-195.

28) "Recommended Dynamic Test Criteria for the MC4073 Programmer and Contained Components," memo from W. Sieger, 1522, to J. Curtis, 2314 and M. Robertson, 2431, may 24, 1989.

29) "Programmer Base Plate Pulling Fixture", memo from Michael Markewicz, 2361 to B. Damkroger, 1833, January 29, 1992.

30) "SRAM II MC4073 Programmer Environmental Development Test Plan", M. Taylor, 2314, May 15, 1990. 
31) Rolfe, S.T. and Fiarsom, J.M. 1977. Fracture and Fatigue Control in Structures. Prentice-Hall, inc., Englewood Cliffs, NJ, pp 208-291.

32) Tada, H. and Paris, P. 1985. The Stress Analysis of Cracks Handbook, Second Edition. Paris Productions and Del Resarch Corporation, St. Lous, MO, pp 19.819.9 and 28.1-28.4. 


\section{APPENDIX A}

Table 1. Radiographic Film Standards, from 9921013 (1)

NDE Inspection Report on original seven (7) supplied castings 

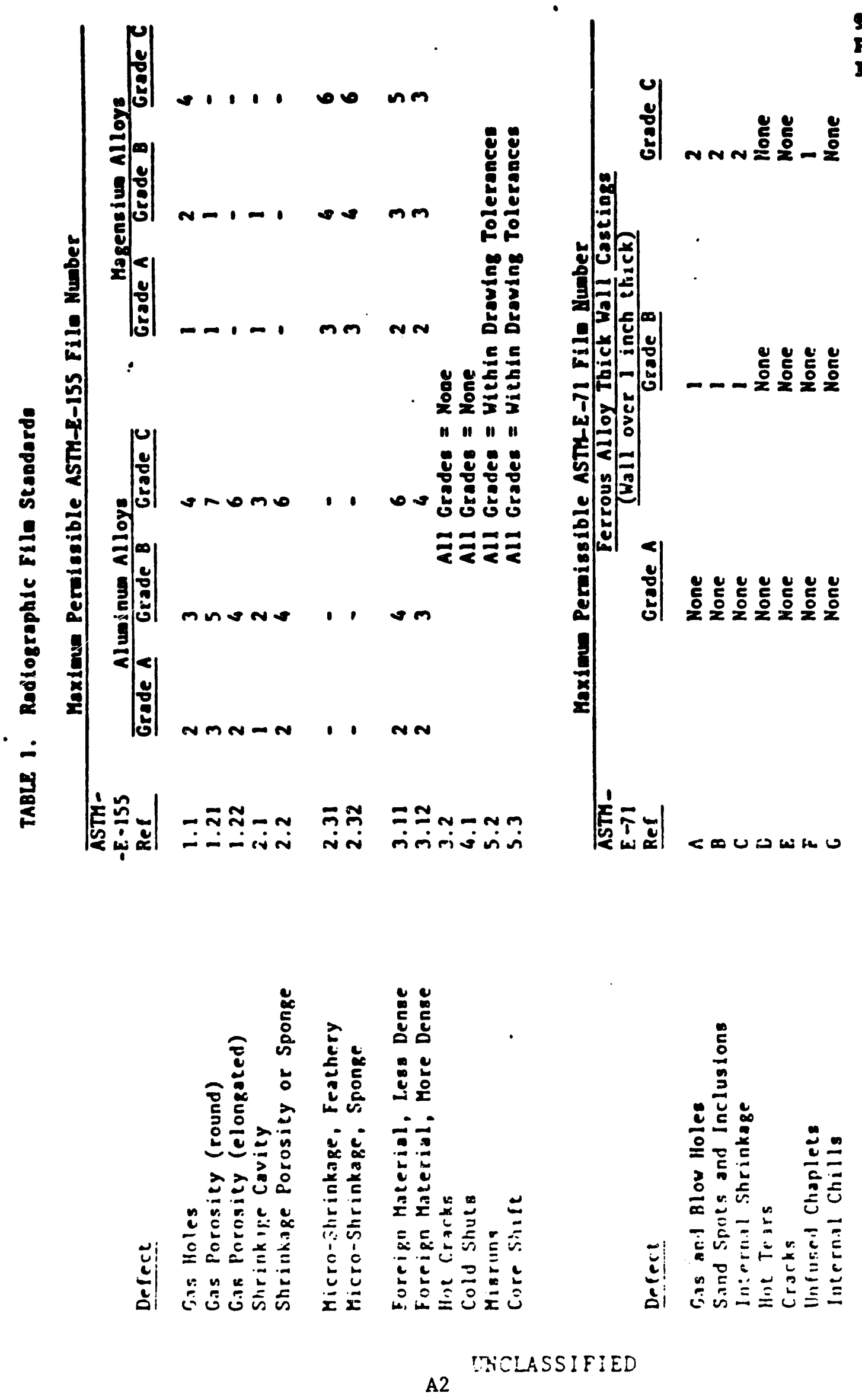
Date: $8 / 4 / 91$

To: Brian Damkroger, 1833

Fron: J.D. Murray, 2752

Subject: Nondestructive Inspection Report

Nondestructive inspection as described herein was performed on the following itens: 7 each, SCRAM II Programmer covers, Nos. $82,83,88,89,91,92$, and 93 .

Areas inspected: $100 \%$ inspection

Date(s) of Inspection: July 13, 1991

Method(s) of inspection: _X_ Dye penetrant(PT) Magnetic particle(MP)

_. Radiographic testing(RT)

visual inspection Other (specify) :

Applicable code(s)/specification(s):

Sandia Dwg. 9921013, Casting, Graded Quality. Mil-I-6866B, Inspection, Penetrant.

Mil-std-454B, Inspection, Radiographic.

ASTM-1B-155-79, Reference Radiograph, Inspection of Aluminum and Magnesium Castings, Series 2.

Applicable Sandia nondestructive inspection procedure(s):

Iiquid Penetrant Inspection Procedure, Fluorescent, water Washable, High Sensitivity (Non-Nuclear).

Radiographic technique-

Thick sections: Medium sections Thin sections:

(Approx. .35") (.80-.125") (Approx. $\left.05-.80^{\prime \prime}\right)$ $110 \mathrm{kv}, 3 \mathrm{~mA}, 1 \mathrm{~min}, 90 \mathrm{Kv}, 3 \mathrm{~mA}, 1 \mathrm{~min} 70 \mathrm{Kv}, 3 \mathrm{~mA}, 1 \mathrm{~min}$. Kodak M Ready Pack' Kodak M Rea!ly Pack Kodak M Ready Pack

All exposures made in a Faxitron :i-ray machine with a source to film distance of $24 "$.

Radiographic sensitivity: $2-2 T$ 
Inspection Report: All of the 7 each, SCRAM II Programmer covers, which were subjected to radiographic and dye penetrant inspection, meet or exceed the Grade C, "Above Average Quality Castings", as required.

Inspector's Comments: Brian, per your request, here is a more detailed interpretation of the Sandia Dwg. 9921013, Casting, Graded Quality and the quality grade of the specimen castings that I inspected. This is written in a question and answer format so that your customer hopefully you won't have to read through a detailed, esoteric report.

"What quality level does a Grade c casting provide ?".

The Grade $c$ casting is described as having minimum levels of specified internal and surface quality (applicable with minimum limitation of producibility).

Examples of the maximum permissible radiographically imaged discontinuities, per my interpretation of the ASTM-E-155 standard films, would be:

1. Gas Holes - Approximately.125" diameter. Any larger diameter gas holes or additional gas holes of .125" diameter are not acceptable.

2. Gas Porosity(round) -Approximately.020" diameter, separated by .030"-.040" between pores, scattered uniformly throughout part or all of the casting.

3. Gas Porosity (elongated) - Approximately .005"-.010" diameter $x .040 "-.050 "$ in length, separated by $.040 "$ - .050", scattered uniformly throughout part or all of the casting.

4. Shrinkage Cavity - Approximately .020" width $x .4 "$ length area of severe shrinkage. (Note this is not a crack or cold shut, but is an irregular internal tearing.)

5. Shrinkage Porosity or Sponge - Approximately .25" width $x .75^{\prime \prime}$ length area of localized moderate shrinkage.

6. Foreign Material, Less DE:sse - Approximately .030" width $x .150 "$ length.

7. Foreign Material, More Disse - Approximately .125" diameter.

8. Hot Cracks - None. (A discontinuity would typically require a dimension of.$i^{\prime} .0^{\prime \prime}$ and $a$ width/length ratio of $1 / 3$ or greater b. fore it would even be considered as a crack.)

9. Cold Shuts - None. (A discontinuity would typically require a dimension of . $30 "$ and a width/length 
ratio of $1 / 3$ or greater before it would even be considered as a cold shut.)

Examples of the maximum permissible dye penetrant imaged discontinuities, per my interpretation of Sandia Dwg. 9921013 would be:

1. Surface voids and pits - .12" diameter, which includes small, closely spaced pores which when grouped together exceed that size.

2. Cracks - None (See crack criteria above).

3. Cold Shuts - None (See cold shut criteria above).

In the worst case, the casting could contain voids up to approximately. $125^{\prime \prime}$ in diameter and still meet the Grade $c$ acceptance criteria.

"What is the highest casting grade that these 6 sample SCRAM II Programmer covers would meet? ".

In my opinion, these $/$ sample castings would meet the Grade A requirements of Sandia Dwg. 99221013.

"Other comments ?".

Since I am not certain of the end use requirements for these castings, I do have some concern that the Grade $C$ requirements may not be stringent enough. Specifically, would the maximum allowable discontinuity levels for Grade $C$ be acceptable for mechanical and/or liquid containment ? The Grade C requirements would allow for a .125" diameter void in areas where the wall thickness is .050 , i.e. a through hole. Would this become a problem if nuclear safeguard's exclusion regions are under the programmer cover ?

An unwitting (or unscrupulous) manufacturer might be able to deliver a large (and expensive) quantity of castings which meet the specified quality requirements for a Grade $C$ casting, but which would ngt be acceptable for WR production.

Inspector's signature:

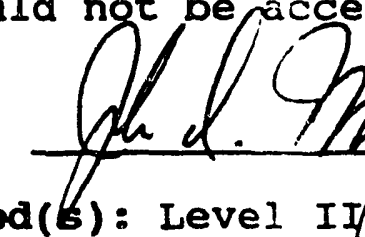

NDT level(s) and method(s): Level III/ Radiography and Liquid Penetrant.

Certificate number and expiration: date: ASNT LM-967, 11/95. Radiographs attached.

Copy to: พ.ศ. Shurtleff, 2752 (w/o attachments)

B. D. Hansche, 2752 ( $w / 0$ attachments)

J. D. Murray, 2752 ( $w / 0$ attachments) 


\section{APPENDIX B}

Memo: J. Cherry to C. Pretzel, 4-10-90

Memo: P. Stirbis to M. Taylor, 7-11-90 
date: Aprị 10, 1990?

to: Carl Pretzel, 8154

from: Jeff Cherry, 8242

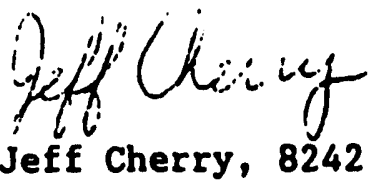

subject: Adequacy of Programmer Feet During Shock Loading

Reference: 'W89 (SRAM II) Component Environmental

Requirements', SB210447-000 Issue B.

The 189 programmer mounts to the warhead aft case at three locations as shown in Figure 1 . The three programmer tabs are 0.22 inches thick, with a width of 0.75 inches ( 2 of the tabs) and 0.50 inches (the remaining tab). I have done back-of-theenvelope calculations that indicate the baseline design is adequate. My quick analysis is based on assumptions, some of which are conservative and others which are not. I strongly recommend that the programmer component group have the feet of the programmer analyzed in more detail to verify my quick look analysis (see appendi $x$ ).

The shock which will drive the programmer the hardest is a rocket motor ignition, which is given in the SB as Figure 3.7.3 (included here as Figure 2). In applying this shock spectrum to the programmer to determine stress in the mounting tabs, I made the following assumptions:

1) Applied loads are split equally between the three feet [This is probably non-conservative since the programmer is not symmetric, the mass is not evenly distributed, the feet are not equally spaced, and the width of the feet are not all the sinie.]

2) Each of the feet acts as a cantilevered beam with the tab at tachment to the yrogrammer assumed rigidly fixed. (This is conservative 'The other extreme (not used) would be a beam fixed it both ends which will produce stresses half as big as the cantilevered assumption. The real answer lies su.newhere in between.]

3) The resonant frequency of the programmer is less than 400 hertz, so that the peak shock response will be less than - equal to $60 \mathrm{G}^{\prime} \mathrm{s}$. (As can be seen from the shock spectra (Figure 2) for uissile burn, the programmer 
will see about $40 \mathrm{G}$ 's for a 100 hertz resonance, $60 \mathrm{G}$ 's for a 200 hertz resonance, $40 \mathrm{G}$ 's for a 300 hertz resonance, $60 \mathrm{G}$ 's for a 400 hertz resonance, $130 \mathrm{G}$ 's for a 700 hertz resonance, etc. For all resonant frequencies between 10 and 400 hertz, the peak response would be 35 to $60 \mathrm{G}$ 's.]

4) There are no stress concentrations at highly stressed areas. [There will be stress concentrations, but I am ignoring them.]

5) The programmer must survive loads defined in the SB. [These loads will be adjusted as tests are performed to measure actual values. The intent of the current SB is to be conservative so that levels will come down or remain unchanged in future issues of the SB document (as opposed to finding that the levels must be increased). It is likely these levels will decrease when test data comes in, but it is possible that they will increase. In other words, the design loads are a moving target.]

My simple analyses show a peak stress in the programmer tab of $17 \mathrm{ksi}$ (A356 aluminum has a yield stress of $27 \mathrm{ksi}$ and an ultimate of $33 \mathrm{ksi}$ with $3 \%$ ductility). I am fairly confident that the conservative and non-conservative assumptions offset each other to some degree, but this needs to be verified. My general approach to these kinds of problems is to do a quick, simplified analyses and determine that the design: a) is obviously adequate, b) needs more detailed analysis, or c) is obviously no good. In my mind, the programmer feet are in the "probably okay, but needs more detailed analysis" category.

JLC: $8242: j l c$

Copy to:

1522
R. C. Reuter

P. P. Stirbus

J. J. Anastasio

E. T. Cull

D. R. Henson

C. H. Pretzel

R. G. Miller
8155

8156

8156

8156

8242

8242

8242
D. L. Gehmlich

M. E. John

C. A. Pura

R. E. White

M. R. Birnbaum

J. L. Cherry

B. L. Kistler 


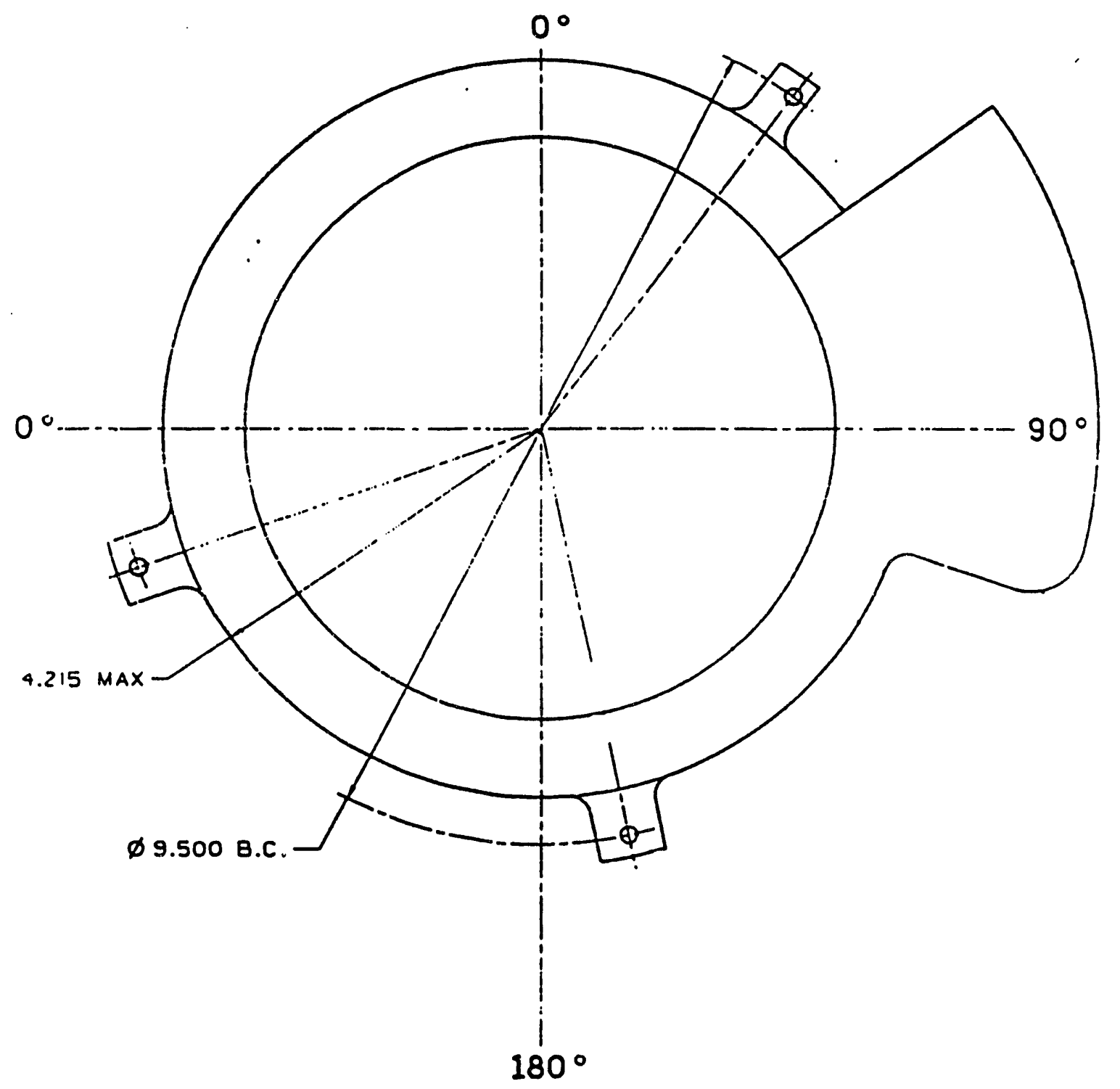

$$
\begin{aligned}
& \text { F/GURE I. } \\
& \text { PROGRAMMER }
\end{aligned}
$$


FTURE 3.7.3 SHOCK SPECTRA FOR AFT COMPONENT (All directions)

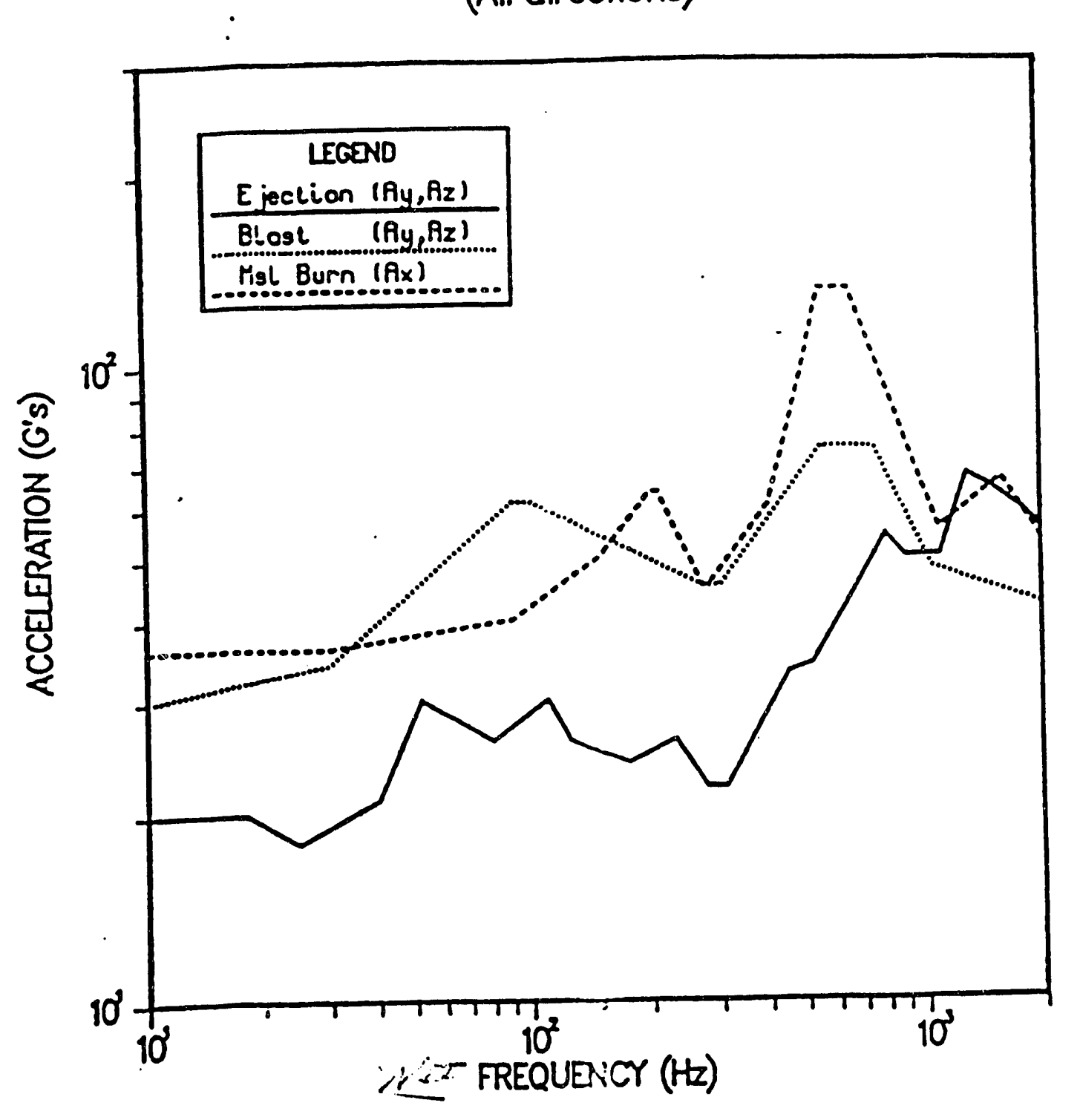

$$
\text { FIGUPE Z }
$$


Appendix

$\rightarrow-5.54 k$

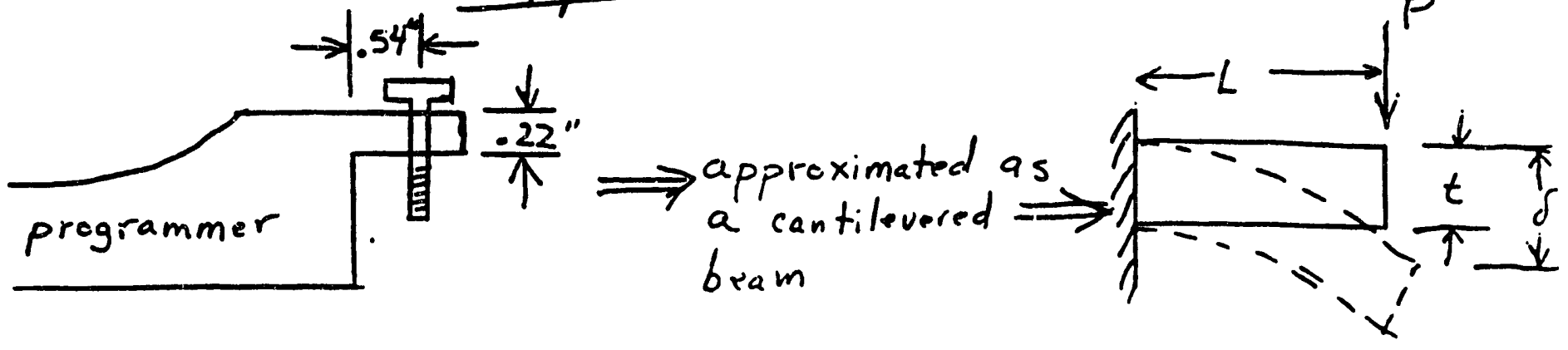

Programmer $\omega_{t}=5$ \#s

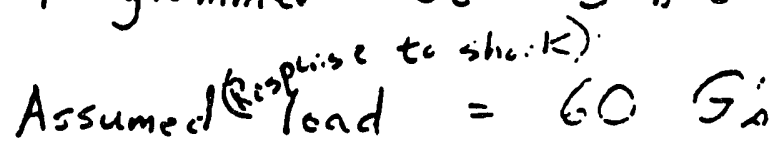

Each foot takes $1 / 3$ of total La ad $P=\frac{(5)(60)}{3}=100 \mathrm{~m}$

Cantilevered Beam formula $\delta=\frac{P L^{3}}{12 E I}$

Moment - maximum $\quad M_{\text {max }}=P L$

Shock Load from missile burn $10-400 \mathrm{~Hz}=60 \mathrm{G}$ :

$400-1000 \mathrm{~Hz}=130 \mathrm{G}:$

$1000+H_{E}=60 \mathrm{G}^{\prime}$

$$
\begin{aligned}
& \left.\sigma_{\text {max }}=\frac{M c}{I}=\frac{(P L)}{\frac{1}{12}(6)} \cdot \frac{(t)}{3}\right)=\frac{6 P L}{6 t^{2}}=\frac{(6)(100)(.54)}{(0.5)(0.22)^{2}} \\
& \sigma_{\max }=13,400 \mathrm{psi} \quad 13.4 \mathrm{ksi}
\end{aligned}
$$

STS show's static acceleration of $15.6 \mathrm{G}$ :

$$
\frac{15.6}{60} \approx 0.25
$$

$\sigma_{\max }($ static + missile bun shock $) \approx 1.25(13.4)=17$ ks

Bb 
dole: July 11, 1990 d

Albuquerque. New Mexico 87185

10: M. R. Taylor, 2314

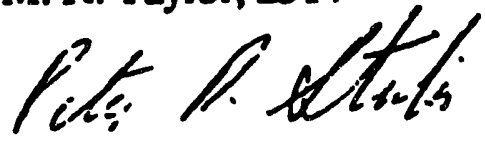

from: P. P. Stirbis, 1522

subject: SRAM II MC4073 Programmer Static Test Results

\section{REFERENCES:}

1. "Adequacy of Programmer Feet During Shock Loading," memo from J. Cherry, 8242, to C. Pretzel, 8154, April 10, 1990.

2. "W89 (SRAM II) Component Environmental Requirements," SB210447-000 Issue $\mathbf{B}$.

3. "Recommended Dynamic Test Criteria for the MC4073 Programmer and Contained Components," memo from W. J. Sieger, 1522, to J. E. Curtis, 2314 and M. M. Robertson, 2531, May 24, 1989.

\section{SUMMARY}

This memo describes the results of a static test that was conducted on the base plate of the MC4073 programmer on June 22,1990. The purpose of the test was to determine the stiffness and the ultimate strength of the base plate.

\section{INTRODUCTION}

Reference 1 presented a simple analysis of the W89 programmer feet done by Jeff Cherry, 8242. He concluded that the programmer mounting tabs are probably okay but they need more analysis. The programmer project group, 2314, provided a programmer base plate to be static tested to determine the strength of the mounting tabs.

The most severe shock environment for the MC4093 programmer is the rocket motor ignition. The shock spectra is given in Reference 2 and is shown as Figure 1. The most severe loading is in the $x$ axis which is the missile longitudinal direction.

Copy to:

1510 E. H. Barsis

1520

L. W. Davison

Attn: 1521 H. S. Morgan

1523 J. H. Biffle 1524 D. R. Martinez

1522 R. C. Reuter, Jr.

1522 W. J. Sieger

1522 Route \& File (2.155.5.70.4073)

1530 J. R. Asay

1550 C. W. Peterson

\section{J. J. Anastasio}

2314 R.F. Rieden

7542 T. L. Emest

8154 E.T. Cull

8154 J. E. Grant

8155 R. G. Miller

8242 M. R. Birnbaum

8242 J. L. Cherry

1522 P. P. Stirbis 
The recommended single shock pulse for development testing is given in Reference 3 as a $130 \mathrm{~g}, .010$ sec haversine. The shock spectrum for this pulse is also shown in Figure 1. The shock spectrum has a peak response of $200 \mathrm{~g}$ at 100 $\mathrm{Hz}$ and is a constant $130 \mathrm{~g}$ at $300 \mathrm{~Hz}$ and above.

A simplified schematic of the test configuration is shown in Figure 2. The load is applied in the axial direction. The deflection of the base plate was measured -relative to the mounting surfaces of the tabs.

\section{TEST RESULTS}

The load versus deflection for - and + axial direction are shown in Figures 3 and 4. Deflection gages 1 and 2 were installed near the 0.75 inch wide tabs and gage 3 was near the 0.50 inch tab. Note the different scales for the deflection. The maximum load was $200 \mathrm{lb}$ to preclude damage to the programmer base. The stiffness is about the same in both directions.

The ultimate load versus deflection in the + axial direction results are shown in Figure 5. For a programmer weight of $5 \mathrm{lbs}$, multiplied by $130 \mathrm{~g}$, gives a limit load of $650 \mathrm{lb}$. The average deflection at $650 \mathrm{lb}$ is .004 inches. The secant stiffness is $650 \mathrm{lb} / .004$ inches $=162,000 \mathrm{lb} / \mathrm{in}$. This results in an axial first mode of approximately $560 \mathrm{~Hz}$. Referring to Figure 1, this frequency results in a shock response of $130 \mathrm{~g}$.

The maximum load reached in the static test was $2000 \mathrm{lb}$ at which point the $4-40$ screws which attach the load plate to the prourammer base sheared out of their tapped holes.

A lateral load test was considered but the $4 \ldots i 0$ tapped holes were damaged and the load plate would have to be modific $J$ to apply a lateral load. Since development shock tests of prototype progra: :mers will start in July 1990, it was decided not to do additional static tests.

\section{CONCLUSIONS}

The ultimate static test load of $2000 \mathrm{lb}$ give an ultimate factor of safety of 3.0 based on a limit load of $650 \mathrm{lb}$ at $130 \mathrm{~g}$. It is ncluded that the programmer tabs are structurally adequate for the assumed axi. loading.

PPS:1522:Im 


\section{FGUURE 3.7.3 SHOCK SPECTRA FOR AFT COMPONENT}

(All directions)

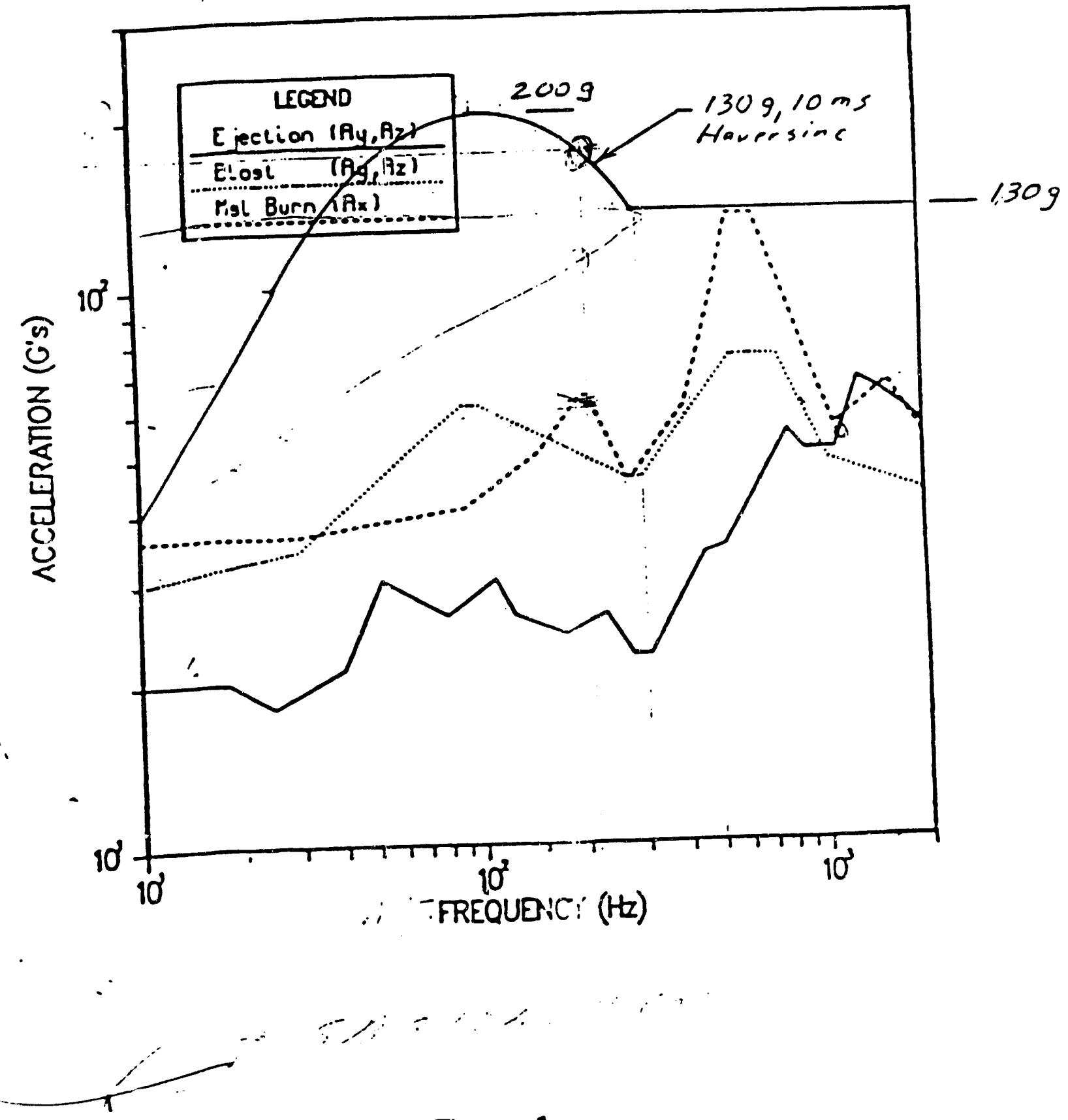

Figure 1 


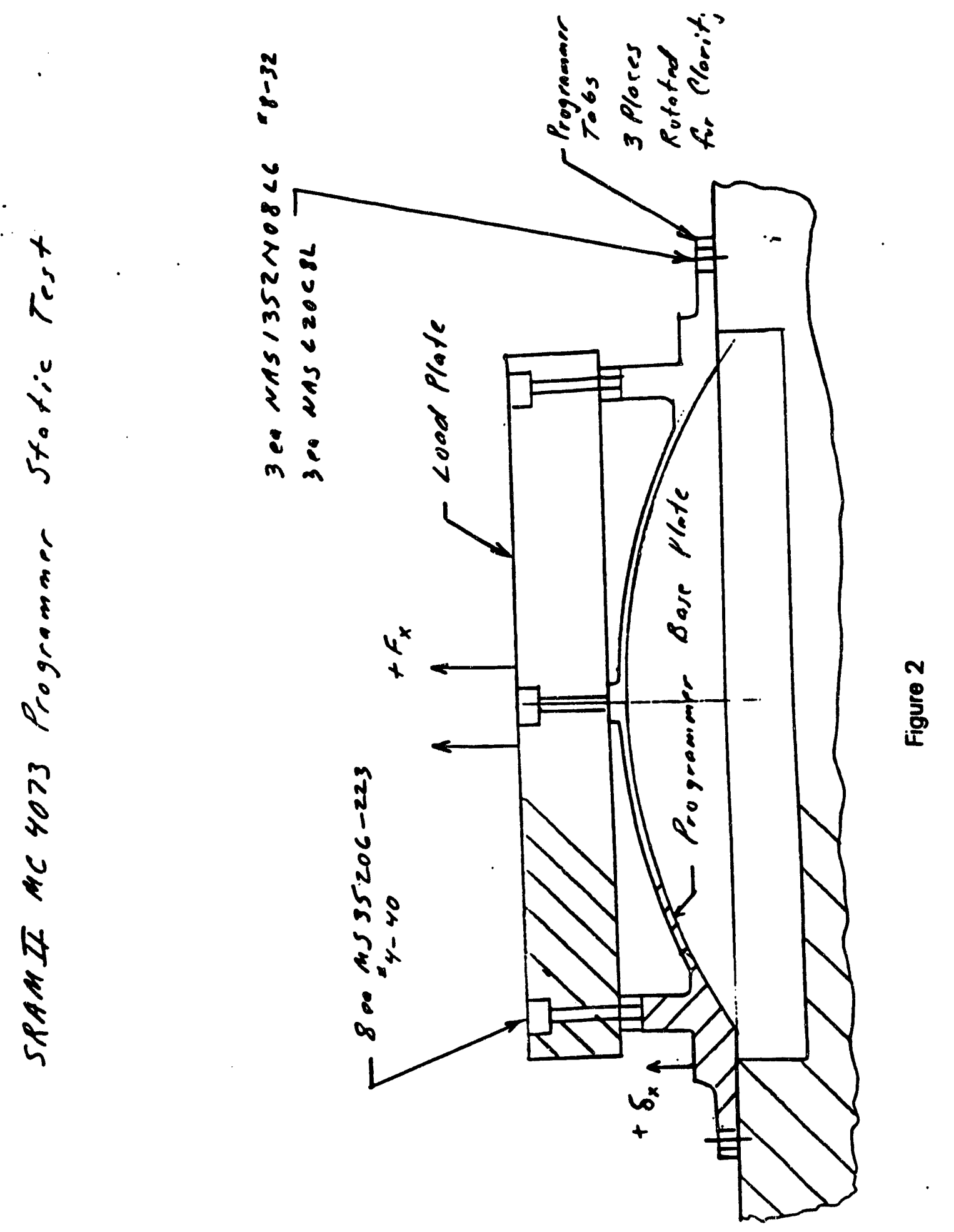




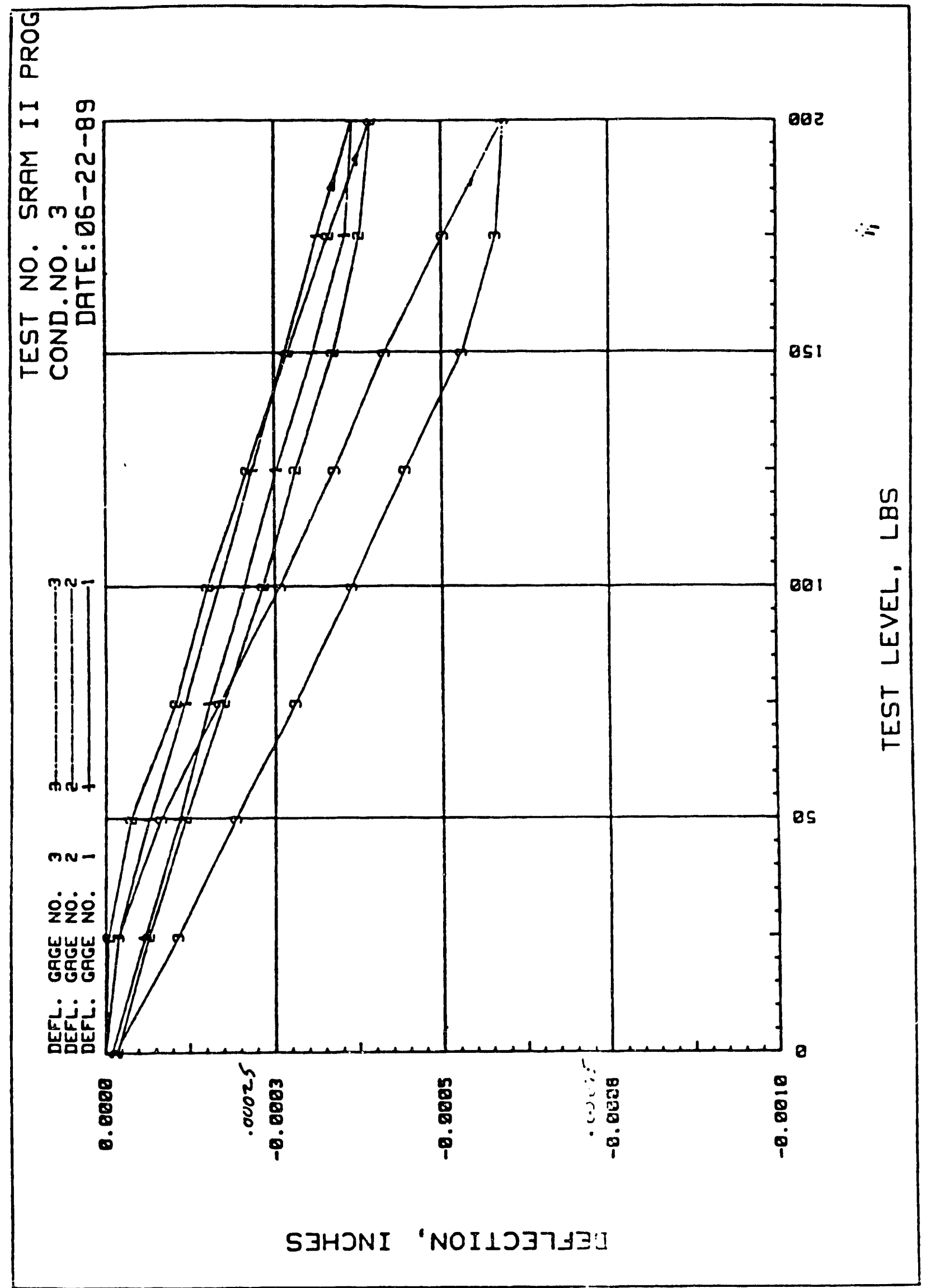

$\frac{m}{\frac{9}{3}}$ 


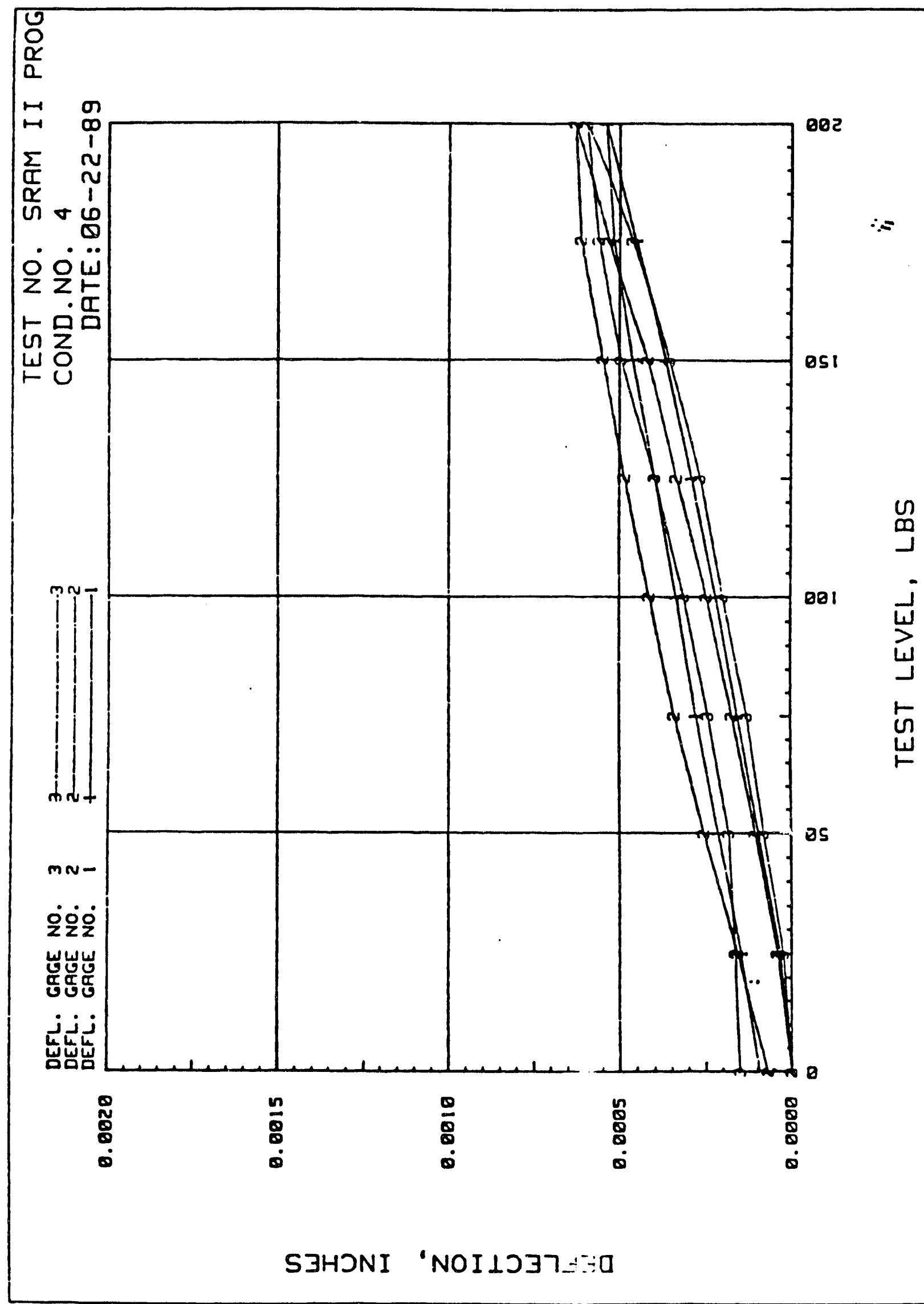




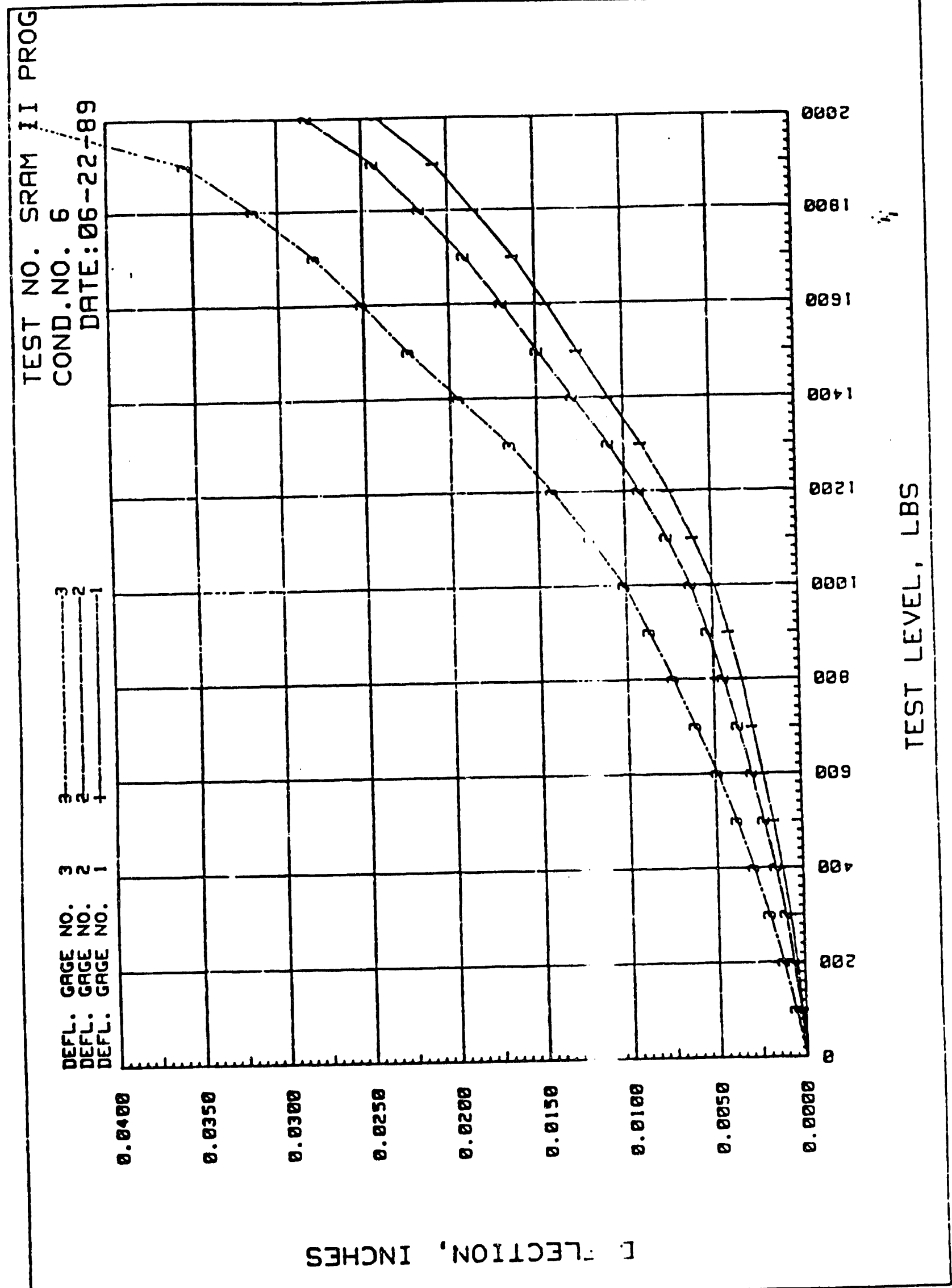

م 
APPENDIX C

Design of Static Loading Text Fixture

$\bullet$

$r$

Cl 
date: January 29, 1992

to: Brian Damkroger, 1833

\section{Muchad Morkewy}

from: Michael Markewicz, 2361

subject: Programer Base Plate Pulling Fixture

POURPOSE

To design and build a tensile test pulling fixture for the Programer Base plate.

GIVEN

The pulling fixture is to be designed to worst case parameters for the foot mounting.

The fixture must have a minimum flex during the test.

The fixture must easily bolt to the existing table.

The base plate is made from 'A356' aluminum, UTS $=40,000$ Psi. Yield strength $=30,000$ Psi.

Total Cross-sectional area of the 3 programer feet is .44

sq. In.

\section{SOLUTION}

Total load to test the plate to failure $=40,000$ Psi. *.44

Sq.In. $=17,600$ Ibs.

The fixture material is 303 stainless steel, UTS $=80,700$ Psi. Finite Element Stress Analysis Model was built using a load of 20,000 lbs. (ALGOR stress analysis program)

The model (Fig.I) Shows a Max. stress of 21,000 Psi.(Orange)

The Factor of safety for the fixture is $(80,700 / 21,000=3.8$

The model (Fig.2) shows a Max. deflection of .001 inches.

Attached are the Drawings for the fixture and the bolt hole pattern for mounting the fixture to the existing table.

NOTE

Use ONLY High Grade 1/4-20 bolts with a UTS of 6000 Lbs. or better. 12 are Required. [FS $=(6000 * 12) / 17600=4.09$ ] 8-32 tapped holes may stretch after a few tests. At this time a backing nut should be used. 


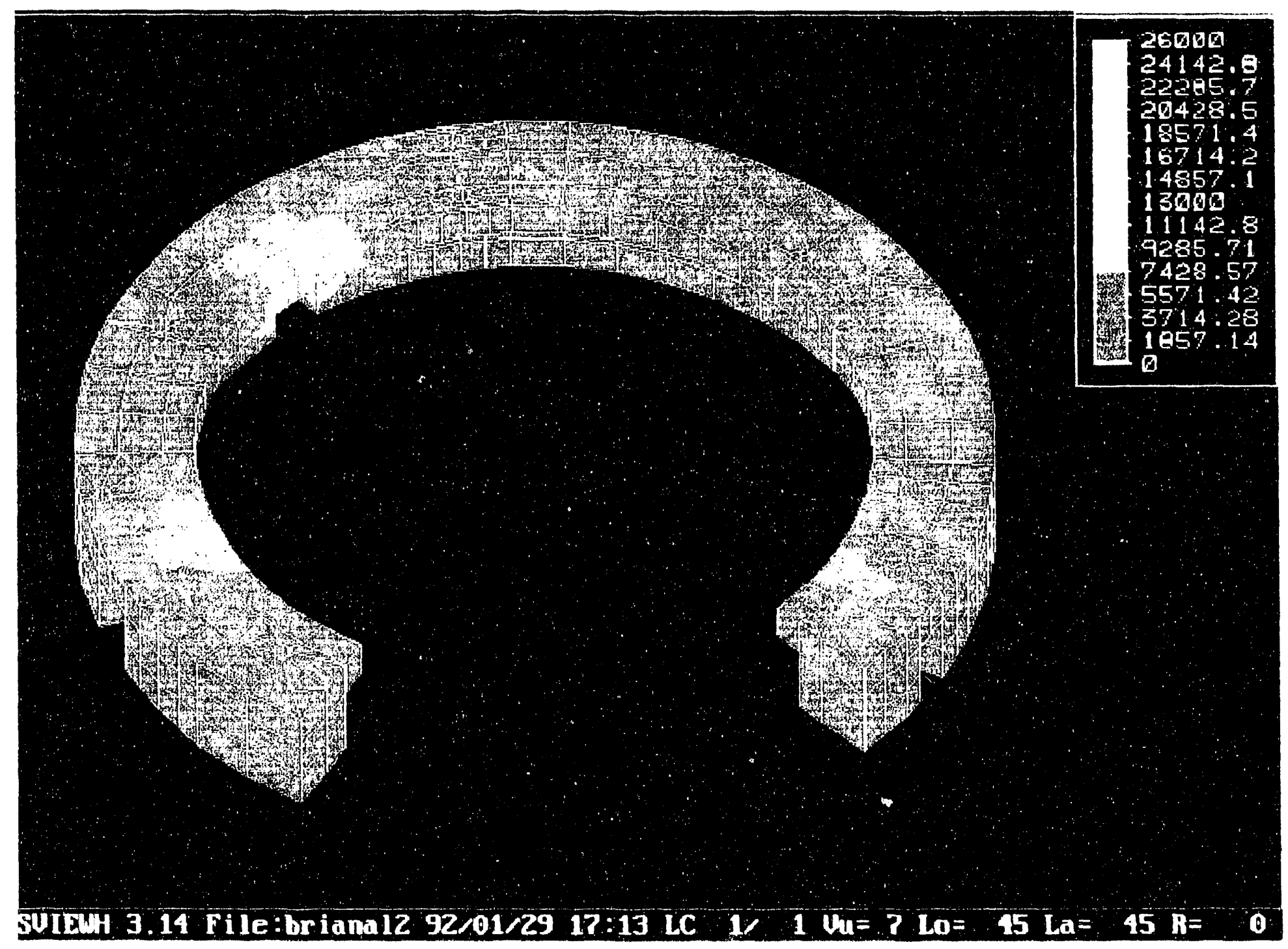

Fig.1 


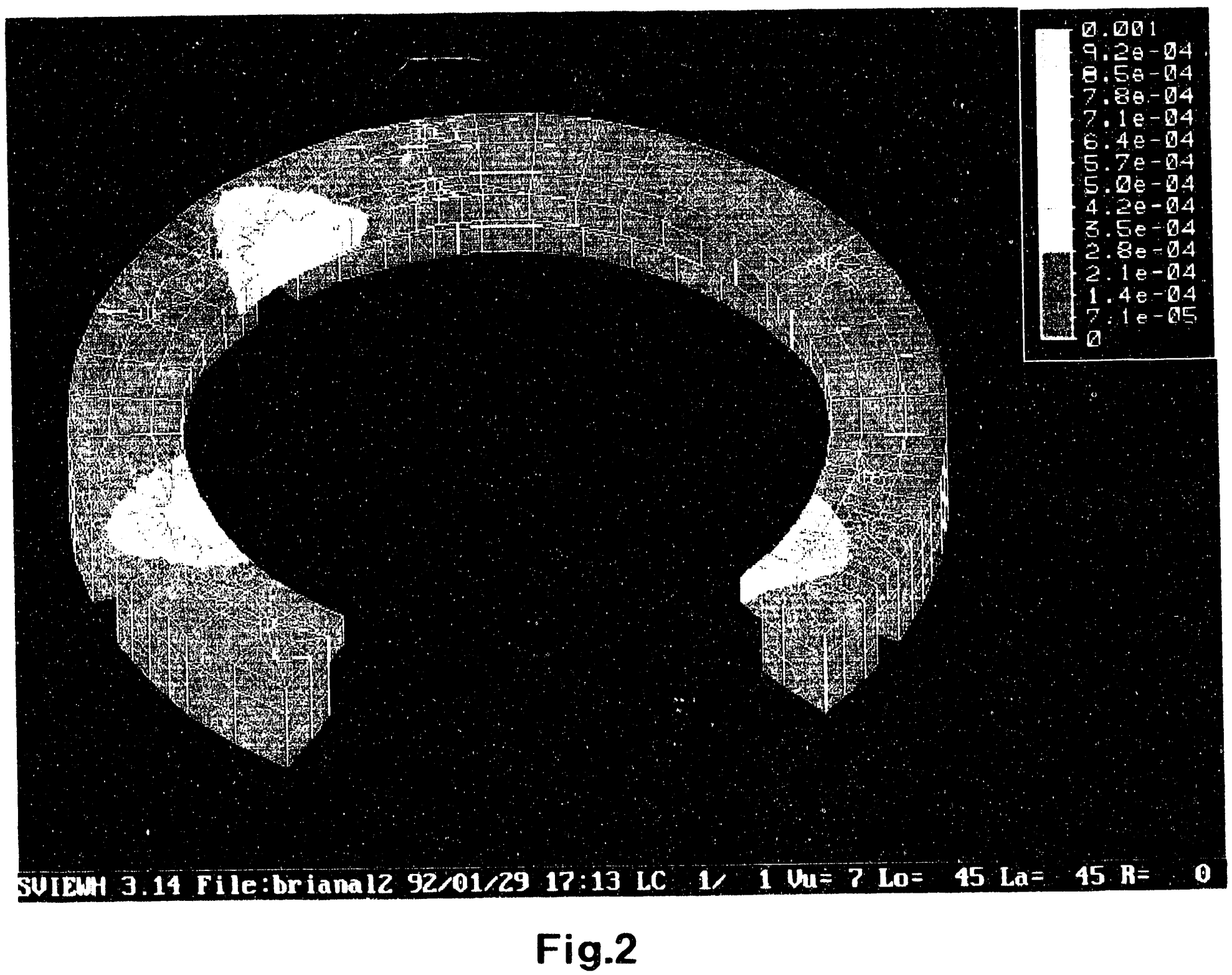




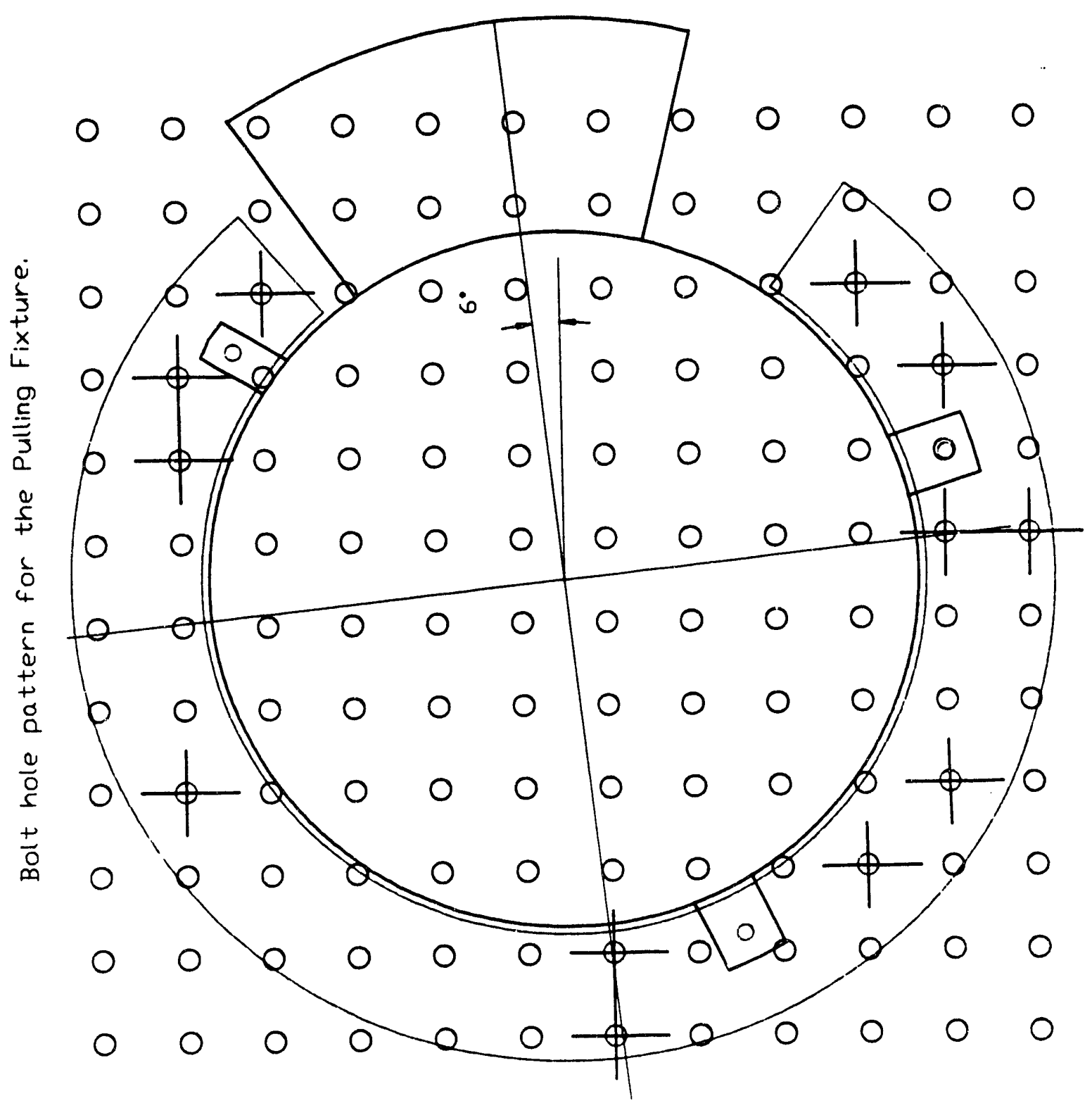

C7 


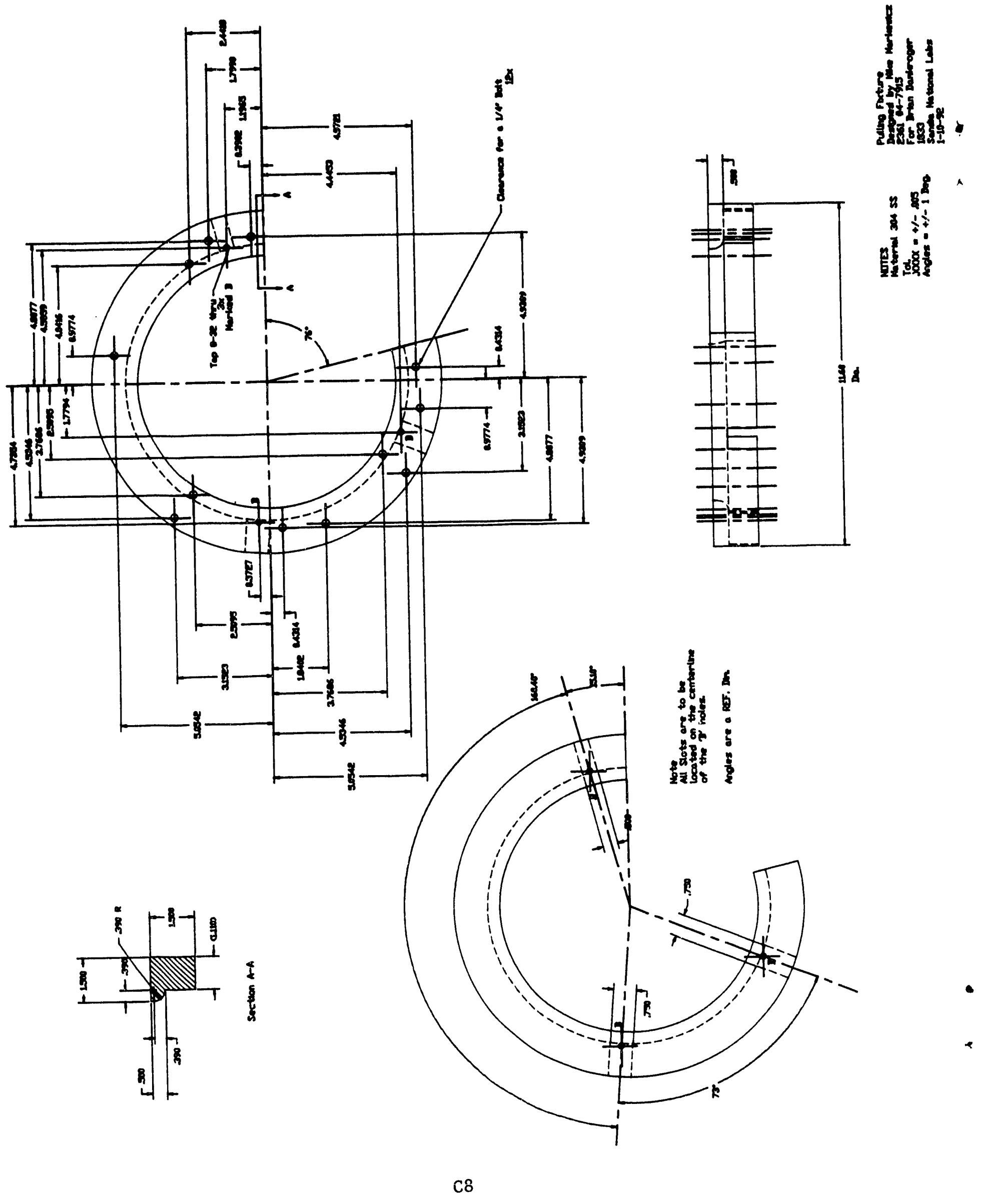


Distribution:

Unlimited Release

1

R. Owens, Allied Signal-KCD

$D / 8342 A 36$

11800

A. D. Romig, Jr.

$\begin{array}{ll}1 & 1831\end{array}$

$1 \quad 1831$

M. J. Cieslak

$1 \quad 1833$

C. V. Robino

$\begin{array}{ll}6 & 1833\end{array}$

11833

$\begin{array}{ll}6 & 1833\end{array}$

$\begin{array}{ll}1 & 2314\end{array}$

12314

$\begin{array}{ll}1 & 2741\end{array}$

12742

15354

18154

J. L. Jellison

B. K. Damkroger

M. C. Maguire

F. J. Zanner

J. J. Anastasio

L. Tafoya

W. J. Sieger

R. A. May

K. Schroeder

18316

$18523-2$

E. T. Cull

$6 \quad 7141$

J. E. Smugeresky

Central Technical Files

Technical Library

17151 Technical Publications

10 7613-2 Document Processing for DOE/OSTI 

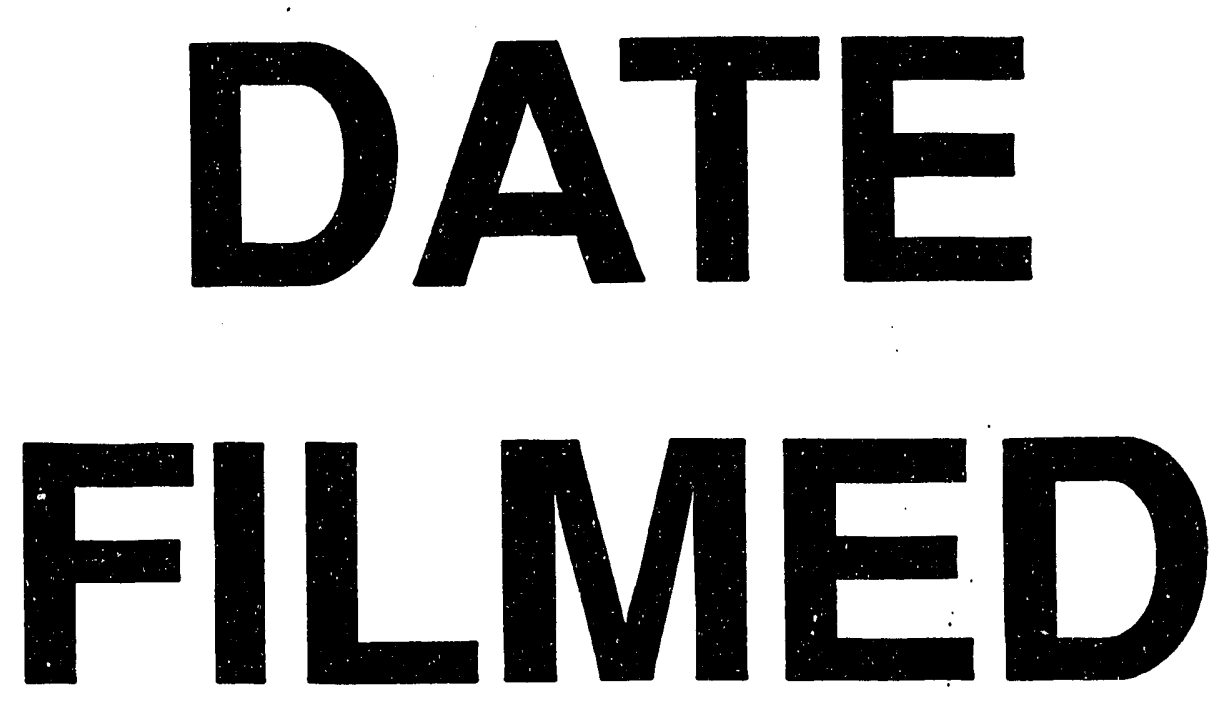

$9 / 28 / 93$
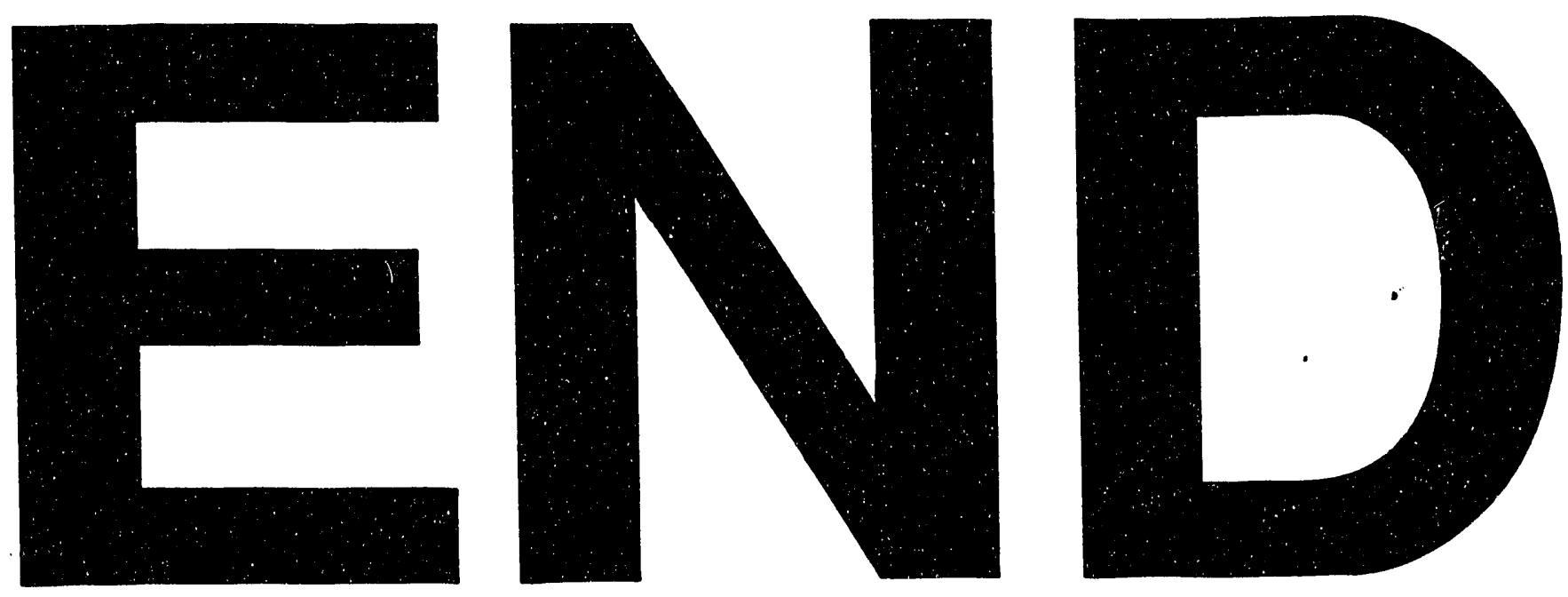
